\title{
Reification and Alternatives to Development
}

\author{
by
}

Michael D. Bueckert

A thesis submitted to the Faculty of Graduate and Postdoctoral Affairs in partial fulfillment of the requirements for the degree of

Master of Arts

in

Political Economy

Carleton University

Ottawa, Ontario

(C) 2013, Michael D. Bueckert 


\begin{abstract}
This thesis evaluates the post-development concept of "alternatives to development" from the perspectives of critical political economy and Western Marxism. Post-development theorists have long critiqued how development depoliticizes social life and suppresses alternative political imaginations. In formulating alternatives to this mode of social change, they emphasize place-based politics of cultural difference, premised on notions of coloniality, economic difference and autonomy. As I demonstrate, these theoretical positions are limiting, for they unnecessarily close off post-development theory from potential strategies and allies. Alternatively, I argue that the Marxist concept of reification provides an alternative analytical framework which transcends these limitations. By highlighting the role of capitalist class relations in shaping subjectivity and limiting political imagination, the concept of reification thereby illuminates the conditions which make thinking and acting "otherwise" materially possible, while expanding the scope for social action beyond the margins of the capitalist world system.
\end{abstract}




\section{Acknowledgements}

This project likely would not have come to fruition if it had not been for the incredible support of my thesis committee, which trusted me enough to take a chance on this rather unusual research topic. I am deeply grateful to Justin Paulson for providing me with invaluable guidance and encouragement throughout this process, and Rebecca Schein for her insightful comments and suggestions to develop my arguments further. Thanks also to Lisa Mills for agreeing to participate as internal examiner.

The Institute of Political Economy has been a truly inviting and intellectuallyenriching environment for a young radical such as myself, in no small part because of the fantastic faculty associated with it. I thank successive program directors Janet Siltanen and Laura Macdonald for their support in navigating my colleagues and I through complicated processes of research design and funding applications. I also thank Peter Andrée for helpful comments on my research proposal, and Cristina Rojas for her encouragement to explore my research questions. And of course, I can't overstate the importance of Donna Coghill in fostering a sense of community in the program, and getting my colleagues and I through the program without serious mental or bodily harm.

During seminars and over pints, I have benefitted from engaged conversations with all of my colleagues, but I want to single out in particular Christina, Darrin, Steve, Jay, Erin and Dave. It has been immensely rewarding to be around great scholars and friends who are passionately motivated for social justice.

I want to thank my family for being so supportive of my scholarly pursuits, even when it takes me so far from my prairie home. Special thanks to Joel and Kenton; our conversations have challenged me to better articulate and refine my ideas. 
Additional thanks to Arturo Escobar for graciously agreeing to meet with me. Our conversation was short, but it helped to clarify some of the positions I outline and evaluate in this work.

Finally, this project was possible thanks to funding from the Social Sciences and Humanities Research Council of Canada (SSHRC). 


\section{Table of Contents}

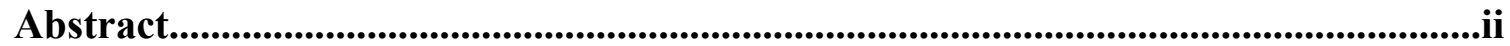

Acknowledgements....................................................................................................ii

Table of Contents...............................................................................................................................v

List of Figures................................................................................................................................vi

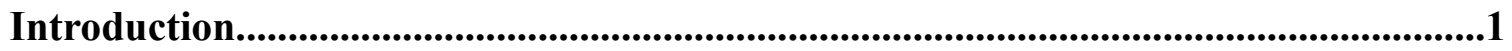

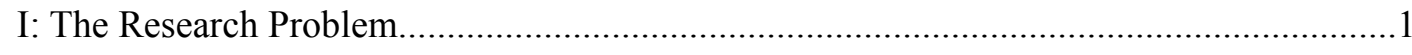

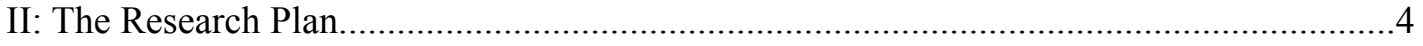

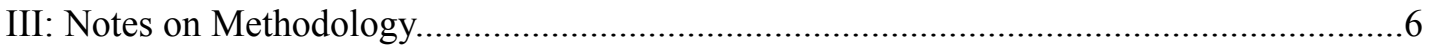

Chapter One: Development............................................................................................17

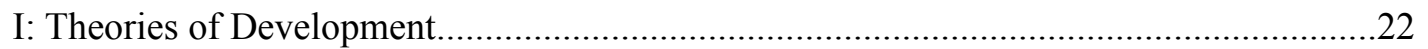

II: Beyond Development: Post-Development Theory........................................................30

III: Beyond Development: Dynamics of Global Capitalism..................................................37

IV: The Idea of Development and Its Limits.................................................................4

Chapter Two: Modernity and Emancipatory Knowledges................................................51

I: Reification and Negative Thinking........................................................................51

II: Modernity/Coloniality and Thinking Otherwise...............................................................64

III: From "Thinking” to "Acting" Otherwise.....................................................................76

Chapter Three: Economic Difference, Autonomy and the Pluriverse..........................79

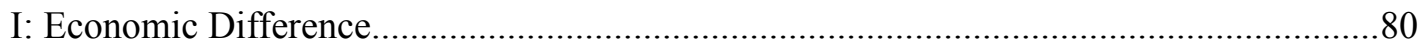

II: Locating Alternatives to Development.....................................................................90

III: Localizing Politics, Globalizing Struggles?............................................................. 99

IV: Alternatives to Development: A Summary............................................................107

Chapter Four: Uneven Reification: A Critique of Alternatives to Development.....110

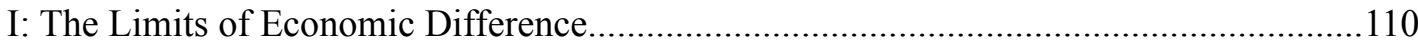

II: Class Struggle and Counter-Hegemonic Movements.................................................130

III: Resistance, Solidarity and Development Without Reification: A Research Agenda....135

Work Cited. 


\section{List of Figures}

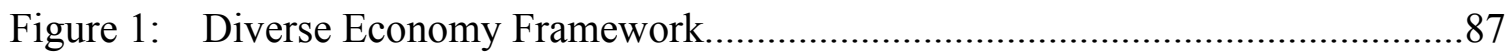


Since the established universe of discourse is that of an unfree world, dialectical thought is necessarily destructive, and whatever liberation it may bring is a liberation in thought, in theory. However, the divorce of thought from action, of theory from practice, is itself part of the unfree world. No thought and no theory can undo it; but theory may help to prepare the ground for their possible reunion, and the ability of thought to develop a logic and language of contradiction is a prerequisite for this task.

- Herbert Marcuse (1960, p. xii) 


\section{Introduction}

\section{I: The Research Problem}

Over the past 20 years, some of the most controversial and radical critiques of development have come from a school of thought known as post-development theory. This diverse group of scholars, influenced generally by post-structural and post-colonial thought, attempted to make sense of the failure of the development project to deliver on its promises; despite decades of adopting modern economic and political reforms, underdeveloped countries remained in a state of subordination to the advanced capitalist countries, with little hope for the future. Rather than calling for reform or for better policies, post-development scholars located the failure of development with the idea itself. These scholars argued that the concepts upon which the discourse of development rests - poverty, progress, science, standard of living, etc — were Eurocentric notions of social reality which did not reflect the experiences of the Third World. As an organizing principle of human life, development portrayed the Other as ignorant and impoverished, justifying intervention; in forcing underdeveloped countries to restructure their societies in the image of the First World, the development project tended to suppress or destroy other human experiences and knowledges. Central to this process is the way that development depoliticizes social life, turning the social into a technical problem to be rationally administrated by experts. For these reasons, post-development theorists called for a rejection of the very idea of development, and began to look for possible alternatives to development.

The concept of alternatives to development has undergone theoretical sophistication over the years, particularly under the direction of Arturo Escobar, 
incorporating post-colonial critiques of modernity/coloniality and post-structural critiques of capitalism yet retaining most of its original features. Against the cultural homogeneity of development and modernity, alternatives to development have been understood in terms of plurality and difference; they represent non-modern epistemologies, noncapitalist economic activities and non-hierarchical networks or radical democracy. Almost exclusively, this has meant that actors capable of participating in such alternatives have been grassroots movements engaging in place-based resistance: indigenous groups, peasants and other cultural communities. According to this framework, if the reductionistic and modernizing character of development is to be challenged, it will have to be done here, at the margins of the modern, capitalist world system.

What is rarely explored by post-development theorists is that there appear to be major parallels between their critique of the subjective effects of development and the critiques of capitalism by Western Marxism. For Marxists following Lukács, the particular material relations of capitalism have the effect of reducing knowledge and practices to instrumentalized forms, which preclude the possibility of alternative political imaginaries; this is a process known as reification. In both perspectives, social life is reduced to the technical and instrumental, and alternatives are concealed. But whereas post-development theory locates this problem with the idea of development and its modern and Eurocentric foundations, Marxism emphasizes the role of capitalism in this process, and how it conditions the way we experience the world.

Clearly these perspectives have some important elements in common, as well as some significant divergences—-but these have never been systematically explored. Instead, post-development theorists have typically ignored or refused to engage with this 
other tradition, citing it as Eurocentric. ${ }^{1}$ This is for a variety of reasons asserted by postdevelopment theorists: Marxists do not give enough attention to language and meaning; Marxists are fully within a modern, European theoretical tradition; Marxists uphold an economic analysis which is insufficient for appreciating diversity; the Marxist emphasis on class ignores how culture and ethnicity constitute the identities of people in the Global South. As I will argue, these critiques are mostly unfounded, and they prevent important engagement between two theoretical traditions which appear to be describing similar phenomena.

This thesis is therefore an evaluation of the post-development concept of alternatives to development and its theoretical framework from the perspectives of critical political economy and Western Marxism. As I will demonstrate, the concept of reification highlights the role of material processes of capitalist class relations in shaping subjectivity and limiting political imagination, clarifying the specific material and ideological barriers that capitalism imposes on the possibility of political alternatives. I will argue that by neglecting to incorporate reification into discussions about development, post-development theory limits the concept of alternatives to development in two important ways: 1) post-development theory overlooks the relationship between subjectivity and the material processes of global capitalism, thereby underestimating the barriers that capitalism imposes upon thinking and acting "otherwise"; and 2) postdevelopment theory unnecessarily limits the space for alternatives to those outside of both modernity and capitalism, thus closing off the possibility of change from within, and undermining the possibility of articulating struggles across diverse social spaces.

$\overline{1}$ For example, see Escobar 2007b, p. 181, and Mignolo 2011, p. 323. For a more comprehensive discussion see Chapter Two below. 


\section{II: The Research Plan}

This research consists of a sustained critique of post-development theory, involving a close engagement with key theorists in this field, and bringing their work into dialogue with critical political economy and Western Marxism. In particular, my object of investigation is the theoretical framework of the concept of alternatives to development, of which Arturo Escobar is the lead proponent and developer. As Escobar has reinforced this concept by adopting or collaborating with various theoretical streams outside of postdevelopment theory, I follow these detours in order to evaluate the theoretical edifice that he builds. This means that the literature I work with changes with each chapter, as I will discuss below. ${ }^{2}$ With each major theoretical intervention by Escobar et al, I respond with an alternative reading of the subject matter informed by political economy-including Marx, Harvey, Panitch \& Gindin, Brenner, Halperin, McNally and others - and Western Marxism—including Lukács, Adorno \& Horkheimer, Marcuse and Paulson. In this way, I try to re-orient the conversation towards serious engagement with the dynamics of capitalism and its effects on how we relate to and understand the world.

In Chapter One I explore the problem of development, laying out the trajectory of development theory as it has tried to make sense of the political and economic changes necessary to transform underdeveloped countries into advanced industrialized societies. I then look at two critiques of development theory which attempt to go beyond the paradigm of development: 1) I look at the early post-development critique as put forward

2 One strong theoretical influence that I do not work with is the Subaltern Studies branch of post-colonial theory, which is composed by scholars including Ranajit Guha, Partha Chatterjee and Dipesh Chakrabarty. Although clearly influential for many post-development theorists, Subaltern Studies does not contribute directly to the concept of alternatives to development, and therefore their work largely lies beyond the scope of this project. It is possible to critique Subaltern Studies from the position I take in this research - particularly their rejection of the Enlightenment and the denial of the universalization of capitalism — but this has already forcefully been done by Chibber (2013). 
by Escobar, Sachs, Shiva, Rahnema, Rist, Esteva \& Prakash, and others. I show how they interpret the failure of development in terms of its modern and Eurocentric conception of reality that reduces social life to a technocratic project; and 2) I provide a critical political economy perspective of the uneven development of global capitalism and its focus on processes of growth, dispossession and exploitation. In this way, I show that the postdevelopment critique emphasizes the subjective effects of development, whereas critical political economy correctly understands these effects in relation to the broader material processes of global capitalism.

In Chapter Two I examine the relationship between modernity and the suppression of human experience and knowledge. I show that Western Marxism provides a critique of how capitalism has corrupted the emancipatory potential of modernity, by way of the process of reification; thus reason is reduced to an instrumental character and alternatives are concealed. However, reification can be overcome and modernity can be reclaimed through dialectics and negative thinking. Then I follow Escobar in his collaboration with the modernity/coloniality/decoloniality (MCD) research project—including Mignolo, Dussel, Quijano, and to an extent Santos - in which the suppression of non-modern knowledges is a direct product of modernity. The consequence of this is that emancipation can never come from within modernity, but must be from an exteriority. I argue that this is an unnecessary limitation, for a Marxist critique of reification allows us to see "thinking otherwise" as possible not only outside of modernity, but also within. In Chapter Three, I look at the economic content of alternatives to development, and the concept of economic difference in particular, which Escobar and Rojas adapt from the work of Gudeman and Gibson-Graham. I survey those movements which are 
said to represent such difference, showing that these alternatives almost always consist of groups defending subsistence-based livelihoods. I then trace how the emphases on difference and place translate into a concern for local autonomy and radical democracy, and how this leads Escobar and Blaser to support the concept of pluriverse as a "horizontal" means of organization that respects autonomy and the ability of different ontologies to coexist. I also highlight the inherent tension between pluriversal politics and other strategies of the Left.

In Chapter Four, I take up my critique against the concepts of economic difference and autonomy as outlined in the previous chapter. I argue that by misunderstanding the way that capital relates to economic diversity, post-development theory effectively limits the relevance of its analysis to the margins, whereas a Marxist perspective which emphasizes market imperatives and uneven reification can help to explain why economic alternatives are likely to be successful in certain contexts rather than others. Further, I argue that by privileging local autonomy and radical democracy, Escobar and Blaser close off the possibility of building counter-hegemonic movements across diverse social struggles, despite the class basis they have in common. Finally, I outline a potential research agenda to further explore what the concept of uneven reification can tell us about alternatives to development, and in particular, what insights it can provide into the possibilities of resistance, solidarity, and "development without reification."

\section{III: Notes on Methodology}

There are a number of methodological issues to address here. First, this is a work of political economy. As Clement (2001) has argued, the key methodological insight of 
political economy is the need to "seek out tensions and contradictions within society as the basis for social change and struggle," with the motivation to discover "how societies are and can be transformed" (p. 406). Therefore political economy is not just about providing explanations, but is engaged as an agent of social change (Clement 2001).

More specifically, this project is grounded in historical materialism. An historical materialist approach insists that social forms originate in material conditions. This is because, as Marx \& Engels (1939/1994) write, "men must be able to live in order to be able 'to make history"' (p. 115). Social and political structures are the product of individuals "as they really are, that is, as they work, produce materially, and act under definite material limitations, presuppositions, and conditions independent of their will” (p. 111, emphasis in original). Therefore, consciousness "must be explained from the contradictions of material life" (Marx 1859/1994b, p. 211).

By taking this methodological approach, I am placing my work in epistemological conflict with the broadly post-structuralist position taken by most of the scholars I critique, and this raises some concerns which I must first address. While their own methodological positions are not always made explicit, post-development scholarship commonly utilizes Foucauldian discourse theory, ${ }^{3}$ and much of it is clearly influenced by the post-marxist anti-essentialism of Laclau \& Mouffe (1985), and more recently, Gibson-Graham (2006). As these theorists have made the critique of historical materialism and Marxist categories the centrepiece of much of their work, it is necessary to address two of their main criticisms in particular: namely, the charges that historical materialism is essentializing and deterministic.

3 The relationship to Foucault is, however, complicated and uneven. This will be discussed further in Chapter One. 
First, a common argument is that historical materialism privileges certain categories, and that by doing so it essentializes them. By focusing on categories like production and class, the argument goes, Marxists reduce the complexity and contingency of social life to "fixed" abstract concepts which are determined a priori. Laclau \& Mouffe (1987) argue that in fact Marxist theory is only partially materialist, since it remains grounded in "metaphysical 'necessit[ies]' external to it;" that is, "essential forms" and "necessary laws of history," whereas discourse theory asserts the "radical historicity of being," showing the world as "an entirely social construction of human beings" (p. 106).

It is precisely for this reason that Laclau \& Mouffe (1985) reject the ontological priority of any category or subject, insisting on the "plurality and indeterminacy of the social” (p. 152). Similarly, Gibson-Graham, Resnick \& Wolff (2000) argue that Marxists have "fixed" the category of class to specific meanings and roles (p. 6), ignoring alternative ways that a diversity of "class processes" have been experienced (p. 9). If we are to understand reality in ways which have not been pre-determined according to our essentialized categories, then we must engage in the "ontological reframing" of concepts such as class, and replace "invariant logics" with "contingent relationships" (GibsonGraham 2006, p. xxx). By discarding the assumed "necessity" of economic laws or tendencies, each capitalist site is understood instead as a set of open contingencies, with an "irreducible specificity” (Gibson-Graham 1996, cited in Gibson-Graham 2006, p. xxx). Gibson-Graham (2006) explain how this method works:

Reading for contingency rather than necessity situates essentialized and universalized forms of being like 'the market' or the 'the self-interested subject' in specific geographical and historical locations, releasing them from an ontology of 
structure or essence (xxxi).

What we have, then, is a radical deconstruction of concepts which the historical materialist approach is said to take for granted, and a reorientation away from the abstract logic of capital and towards the specificity of every site and moment. The priority and validity of categories can only be determined at this level of specificity, and not before. Clearly, this presents a challenge to the priority of class categories within the historical materialist approach. The issue of class will be dealt with in more detail below, in Chapters Three and Four. For now, it is important to address the question of abstraction and categorization.

In the introduction to the Grundrisse, Marx (1939/1973) defended the proper use of abstraction as the correct starting point for analysis. As he argued, when we start with something that appears concrete, like the population of a country, we miss that this itself is an abstraction if we do not take into account the "many determinations" of which it is composed (p. 100). This fails to move the investigation closer to reality but rather provides a "chaotic conception of the whole" (p. 100). Therefore, the correct method must consist of "rising from the abstract to the concrete," as "abstract determinations lead towards a reproduction of the concrete by way of thought" (p. 101).

This should not suggest, however, that these abstractions represent ahistorical “essences.” On the contrary, a category like "exchange value," for example, "can never exist other than as an abstract, one-sided relation within an already given, concrete, living whole" (p. 101). These abstractions had to exist in history, so to speak, and they were also historically-specific; Marx insisted that even those categories which are most abstractand therefore most universally applicable - are "themselves likewise a product of historic 
relations, and posses their full validity only for and within these relations" (p. 105). Marx therefore strongly criticized the tendency of political economists to take concepts specific to bourgeois society—such as labour-in-general — and to universalize them throughout time and space (pp. 103-5; Hall 2003, p. 120).

And so, against the claims of Laclau \& Mouffe (1987) that historical materialism is grounded in metaphysical 'essences' and therefore only partially materialist, we see that in fact the abstract categories used are necessarily historically-specific, the "sum of many, prior, determinations" (Hall 2003, p. 115). Neither does the abstract nature of the categories mean that they are no longer useful, as Laclau \& Mouffe (1985) would seem to suggest. Despite the limits of an abstraction, its remains "rational ... in so far as it really brings out and fixes the common element and thus saves us repetition" (Marx 1939/1973, p. 85). An historical materialist approach "maintains that various analytical categories or abstractions are necessary in order to make sense of the diverse nature of the concrete world" (Perrons 1999, p. 96).

Further, an historical materialist approach does indeed give priority to certain categories which are essential to the task of political economy, class being one of the most important. This is not an arbitrary choice, but a necessity due to the nature of the content we are to examine. As Marx (1939/1973) outlined, all forms of society have "one specific kind of production which predominates over the rest, whose relations thus assign rank and influence to the others" (pp. 106-7). It is this relation between categories which determines their necessary sequence, and if capital is the "all-dominating economic power of bourgeois society," the force which "determines the specific gravity of every being which has materialized within it," then capital must serve as our starting-point (p. 
$107){ }^{4}$

This leads us directly to the second objection to historical materialism as posed by post-structuralist theorists: namely, that having prioritized certain categories, this method is therefore deterministic. This alleged determinism is understood as an "essentialist notion of causality," in which "some particular aspect(s) of society, the economic, function as essential cause while the remaining aspects are approached as determined by that causal essence" (Resnick \& Wolff 1985, p. xxvi). As such, autonomous economic laws "exclude all indeterminacy resulting from political and external interventions" (Laclau \& Mouffe 1985, p. 76). For Gibson-Graham (2006), this “economism” must be replaced with the understanding that all relationships are contingent, so that while there may be forces that undermine or constrain our activity, these cannot be seen as structural but merely the "contingent outcomes" of decisions, projects and practices (p. xxxi).

This critique is especially important because it leads inevitably to the notion that, for historical materialism, subjects and identities are similarly determined by the economic base in a straightforward fashion. Much of the post-marxist critique in particular seems to be based on the idea that Marxist categories preclude the possibility of intersectional analysis. The main thrust of Hegemony and Socialist Strategy is to make such a claim, showing that socialist thought and practice has failed because of its insistence upon the "ontological centrality of the working class" (Laclau \& Mouffe 1985, p. 2). On the contrary, the authors argue, there is no reason to assume that someone considered to be "working class" will identify with working class politics. Social

$4 \quad$ As we will see below, the claims made about the nature of capitalism in this paragraph are emphatically rejected by post-structuralist theorists. This is not the place to go into this debate in detail; I will outline their objections in detail in Chapter Three, and respond with an historical materialist critique in Chapter Four. 
identities are "purely relational" (p. 86), always in a position of "unfixity" (p. 85). There is nothing inevitable nor given about the possibility of a hegemonic movement, as identification with a class position is always something that is constructed (p. 85). This is why Gibson-Graham, Resnick \& Wolff (2000) argue that "class can no longer be understood as the organizing center of individual and collective identity" (p. 9).

The post-structuralist alternative to seeing the economic as primary, then, is to depict production (practices) and signification (meaning) as "simultaneous and inextricably bound aspects of social reality," mutually constitutive of each other (Alvarez, Dagnino \& Escobar 1998, p. 4). If the material and the symbolic are on equal terms, then there is no given starting place for determining how subjectivities are formed. For Hall (1992), the importance of the "linguistic turn" in cultural studies - the discovery of discursivity and textuality—was precisely in this emphasis on language and meaning, on recognizing the symbolic as a source of identity (p. 283). Identity cannot be reduced to one's class position, but must come out of the diversity of meaning of one's lived experience. For both Laclau \& Mouffe (1985) and Gibson-Graham (2006), this conviction leads them to articulate political projects based on the multiplicity of those experiences, rather than organized around class.

The charge of determinism must be addressed in two ways. First, it is true historical materialism affirms that the economic basis of human society—simply put, the ways in which humans interact with the material world in order to reproduce themselves -is primary. However, there is no direct causal relationship between changes in the economic "base" and social or political forms. Marx (1939/1973) depicted the relationship between production, distribution and consumption (some of which appear 
more "super-structural" than others) as inter-related; although production was said to predominate, he insisted that "mutual interaction takes place between the moments" (p. 100). In terms of understanding the relationship between the economic and the ideological, Hall (1986) suggests that we must see "the former setting the limits for defining the terrain of operations, establishing the 'raw materials' of thought," though the economic cannot provide the contents of particular thoughts at a particular time, nor guarantee which ideas will be used, or by whom (p. 42). ${ }^{5}$ This understanding of the relationship between material life and social forms and consciousness is therefore far less deterministic and economistic than the post-structuralist critics allege. On the contrary, Western Marxists have long challenged "economism" in all its forms; this is particularly the case for Gramsci (1971), whose concept of hegemony was formulated explicitly as a response to economism (pp. 158-168). ${ }^{6}$

The second aspect of their critique, that there is no direct link between class and identity, is incontrovertible, but it is false to assume that an historical materialist approach requires such an erroneous belief. Indeed, the entirety of Western Marxist thought—from Lukács to Gramsci to Marcuse to Hall and beyond — has concerned itself with this as a serious political problem. It is therefore possible, and necessary, to incorporate an intersectional analysis into a historical materialist methodology. Perrons (1999) argues that class, in its specific wage-relation form, provides the 'simplest determination' of capitalist society" and therefore makes a rational point of entry for analysis, but this is no

5 As Marcuse once joked, "Not every problem someone has with his girlfriend is necessarily due to the capitalist mode of production" (The Listener [magazine], 1978). Nonetheless, the necessary material basis must first exist for it to be possible to have such a thing as a girlfriend, let alone problems with one.

6 As Gramsci (1971) has keenly noted, "It often happens that people combat historical economism in the belief that they are attacking historical materialism" (p. 163). 
way precludes an analysis into how "this structure interweaves with other forms of social differentiation," including gender or ethnicity (p. 97). Capitalism may be based on relationships of exploitation, but this is never experienced in "economic terms alone, leaving aside as less real the norms, the concepts, the cultures around which this mode of production is organized" (Hennessy 2000, p. 15). This leaves a lot of room for investigating how gendered and racialized experiences relate to the construction of identities. This is why Hall (1986) talked about "marxism without guarantees"; the social formations of ideology and common sense ensure that class politics can not be taken for granted, but must be constructed. Nonetheless, this position still differs from the poststructuralist view, in that while "the economy can't be privileged over culture in any simple way," it would be wrong to "propose a process of mutual determination" (Hennessy 2000, p. 17). ${ }^{7}$ Historical materialism maintains that despite the complex interrelationships between different social formations, class relationships still have a "determining force" (p. 15).

It is precisely this methodological assertion that I bring to my re-reading of the post-development literature: despite the complexity and intersectionality of lived experience, economic categories such as class do have a degree of "determining force" which should not be overlooked. It is, in fact, possible to show that class relationships are critical to understanding the possibilities of alternatives to development, but without subsuming or dismissing questions of cultural identity and meaning. By bringing class

7 Hall (1986) does speak of the relations between social practices as "mutually determining," but this is in the sense of there being no "one-way transmission of effects from base upwards" (p. 43). He wants to emphasize that the economic cannot "effect a final closure" upon ideology, in the "strict sense of always guaranteeing a result" (p. 43). Terminology notwithstanding, the argument in the piece seems consistent with Hennessy's (2000) dismissal of mutual determination in the sense that cultural and economic relations might be on equal terms. Hall depicts "relative openness or ... determinacy" (1986, p. 43), not absolute. 
into contact with culture, and even suggesting its (relative) predominance (at least in terms of organizing certain aspects of society), this in no way requires that the subjects identify at first, or at all, with class instead of culture. Recognizing the subsumption of cultural communities under capitalist class relations in no way determines the identity of the subjects involved (though it does create the possibility); what it does is to show the various ways that participation in these class relations obstruct and limit the ways that culture can be manifested. We can investigate and open up room for the various experiences and identities of class processes, as Gibson-Graham would say, but without the need to "dislocate" the substantive content of class categories in terms of what they reveal about the logic of capital.

One final note on methodology. Acknowledging the "politics of location" (Mignolo 1999) of myself as scholar is to recognize the limits of this work, and its necessary incompleteness. As this work is theory-based, I have considerable distance from the actual politics on the ground, and therefore I can not make context-independent claims about other peoples' experiences. In this same way, my argument has to take for granted that post-development theorists have put forward a mostly accurate account of the values and goals and identities of the communities and movements they describe. I leave open the question of whether these projects do manifest the characteristics attributed to them, for to challenge post-development theory on those grounds would require new ethnographic and empirical research, and that is far beyond the scope of this project. What I do challenge, however, is the post-development reading of the relationship of those communities and movements to development, modernity and capitalism. I therefore claim this space-limited as it is - for a constructive debate over 
the possibilities and limits of the alternatives put forward against development. 


\section{Chapter One: Development}

It is impossible to evaluate the possibility of alternatives to development without determining exactly what critics signify when they refer to the problem of development. As I will show, there are very different perspectives on what development is and how it should be transcended. In this chapter, I will survey the trajectory of development theory before looking at two critical challenges to the paradigm: 1) the post-development school, for which the problem is with the very idea of development, and its modern, Eurocentric conception of reality that reduces social life to a technocratic project; and 2) critical political economy, for which the problem is the uneven development of global capitalism, which leads to necessarily uneven experiences of economic growth, dispossession and exploitation. I will argue that while the post-development school offers an important critique of the subjective effects of development, this critique must be viewed in relation to the broader material processes of global capitalism. Prior to discussing in detail the debates within development theory, in this introductory section I will briefly outline the historical and political contexts in which the various theoretical positions were developed, in order to highlight the relationship of these ideas to broader changes in global political economy, as well as to each other.

Whereas previous attempts to make sense of social change had utilized discourses of progress and universal history, ${ }^{8}$ it was during the early post-World War Two period that

8 As Leys (1996) argues, post-Enlightenment thinkers - and especially Hegel and Marx-had responded to the rise of industrial capitalism by "understanding the evolution of human life on earth as a structured totality" (p. 5). For example, Hegel (1830/1975) understood world history as a rational process through which the "world spirit" develops the "consciousness of freedom" (pp. 129-30); as participants in this process, societies were seen by Hegel as going through "successive stages in the evolution of consciousness" (p. 129), with Western Europe manifesting "the highest principle of all," in which "the spirit's recognition of itself and its own profundity, is realized" (p. 129; 131). Marx \& Engels (1932/1994) also depicted a universal history in which humankind moved towards its full potential, but this was a materialist and revolutionary processes whereby successive modes of production were superseded by means of class struggle (pp. 123-4; Leys 1996, p. 4). History therefore involved a process 
"development" became a much narrower political project, corresponding with major transformations in the world order. The Bretton Woods conference of 1944 established several key international organizations - including the International Monetary Fund (IMF), the International Bank for Reconstruction and Development (World Bank), and the General Agreement on Tariffs and Trade (GATT)—for the purpose of facilitating international trade and monetary stability. Structurally, this incorporated the former empires of Europe and Japan into the new "US informal empire" which was starting to take responsibility for global capitalism as a whole (Panitch 2012, p. 1). ${ }^{9}$ In terms of policy, this arrangement projected the US "New Deal" onto the international stage, reflecting a "postwar Keynesian consensus": a managed capitalism with an interventionist state committed to full employment and social benefits (Rapley 2001, pp. 5-9). Early formulations of "development theory" expressed this social democratic ethos, applying its approach to economic growth to the colonial and newly independent states of the "Third World," for the purpose of making them more productive and to manage the decolonization process in a way that would prevent them from aligning with the Soviet bloc (Leys 1996, pp. 5-8; Rapley 2001, pp. 10-13).

This new project engendered two very different theoretical responses in the of moving towards human emancipation, which was understood by Marx (1844/1994a) in broad terms, as the restoration of human relationships (and thus the realization of species-being) through the abolition of private property (pp. 7-10, 20-1). The emergence of "development theory," then, marked a dramatic shift in how progress and social change were theorized; development theory made no reference to these prior debates but concerned itself solely with the technical question of how to make the national states of current and former colonies more productive (Leys 1996, p. 5), "as if [development studies] had no significant historical or philosophical roots or presuppositions" (p. 6). Critical traditions, such as dependency theory, partially avoided this "ahistorical" model of social change (Wallerstein 1979, pp. 1-3) by drawing on the traditions of Hegel and Marx, and by using notions of universal history and totality (Leys 1996, pp. 11-3; Wallerstein 1979, pp. 1-3).

9 This incorporation had several factors: the United States "underwrote the industrial reconstruction of Europe and Japan, and became the recipient of their burgeoning manufacturing exports. It also laid the grounds for US multinational corporations' expansion and the creation of the Eurodollar markets, so that by the early 1960s twice as much US FDI went to Europe as to Latin America, reversing the historical pattern" (Panitch 2012, p. 2). 
1950s-60s. Modernization theory, developed out of the behavioural sciences in the United States and reflecting the Keynesian consensus, took on the development project enthusiastically. Tied as it was to both anti-communism and American foreign policy, it was optimistic about restructuring societies to establish strong capitalist economic growth and modern political institutions (Leys 1996, pp. 10-11; Rapley 2001, pp. 15-16). In Latin America, however, theorists were more critical. The dynamic of reconstruction and investment that the United States facilitated in Europe failed to occur in the Third World, and development policy instead reproduced the unequal global division of labour (Panitch \& Gindin 2012, p. 105; Panitch 2012, p. 2). Dissatisfaction with the lack of progress led to a perspective known as structuralism, which determined that underdevelopment was actively created by export-oriented policies and that industrialization for domestic consumption was necessary in order for the periphery to develop. ${ }^{10}$

Throughout the 1970s, structuralism was the dominant perspective among Third World governments, while modernization theory remained hegemonic in the international institutions. Both theoretical perspectives affirmed a commitment to strong state involvement in economic development. With the inflationary crises of Keynesianism and Import Substitution Industrialization (ISI), however, two contemporary critiques were becoming popular among academics, if not influencing policy: structuralism was critiqued from the left by dependency theory, which incorporated elements of Marxism to

10 Of course, Import Substitution Industrialization (ISI) had already been adopted in practice in Latin America since the financial crisis of 1929, but this was a practical rather than a theoretical position (more on this below). It should also be noted that during the 1950s the United States (reluctantly) endorsed ISI in return for achieving a greater role in restructuring laws in the interests of foreign direct investment (FDI) - essentially replacing freer trade with a better investment climate - and FDI had supplied domestic rather than export markets up until the debt crisis in the 1980s (Panitch \& Gindin 2012, pp. 104-5, 213). 
argue that capitalism and Western imperialism were themselves holding back development and that states needed to direct autonomous development; meanwhile, modernization theory was attacked from the right by neoclassical economists who saw state intervention as interfering with market-led economic growth (Rapley 2001, p. 19).

The rise of neoliberalism through the 1980s radically transformed the theoretical field. As Leys (1996) argues, neoliberal ideas triumphed not because of the shortcomings of previous theories, but due to the transformation of the global capitalist economy since the 1960s. Development theory had been based on Keynesianism and capital controls which the international community was abandoning: the Bretton Woods trading regime was dismantled throughout the 1970s, and trade liberalization accelerated in the 1980s (pp. 19-21). In this changing context, neoliberalism "articulated the goals and beliefs of the dominant forces that stood to benefit from this process, and pushed it forward" ( $p$. 19). Neoliberal reforms were implemented throughout the developing world, but again this can not be understood simply as a reflection of their merit: often their implementation was a condition of the IMF's coercive Structural Adjustment Programs (SAPs) in exchange for providing deeply indebted countries with limited relief in the aftermath of the U.S.-triggered debt crisis (Harvey 2005; Rapley 2001). ${ }^{11}$

Neoliberal globalization suggested to many critics an end to development.

Because neoliberal reforms privileged the free movement of capital and economic growth

11 For uncompetitive Third World countries, the new international trading regime forced them into greater dependence upon borrowing abroad, making them vulnerable to the "Volker shock," in which the United States responded to stagflationary pressures by dramatically raising interest rates. Latin American countries were an "unintended casualty" of this domestic policy (Panitch 2012, p. 3), as their debt burden increased substantially. Africa was hit the hardest by the debt crisis, and without the same inflow of FDI during the 90s that Latin America experienced (Panitch \& Gindin 2012, p. 219). However, it must be emphasized that the introduction of neoliberal reforms was not entirely coercive: there were often domestic proponents wanting to take advantage of IMF reforms on the grounds that market discipline granted legitimacy to their countries in the eyes of foreign investors, thereby allowing them to benefit from the globalization of financial markets (pp. 240-1). 
over social goals, severely limiting the space for national economic planning, some observers argued that this represented an explicit abandonment of development itself (Leys 1996, pp. 23-4). ${ }^{12}$ Not only did neoliberals reject the goal of development as it had traditionally been understood, but globalization seemed to undermine the possibility of alternatives: disillusionment spread widely so that even dependency theorists such as Frank — whose seminal ideas will be explored in the next section-came to the conclusion that the whole idea of development was no longer tenable (Leys 1996, pp. 2931, 32; Frank 1991). This is also the context in which a growing number of poststructuralist academics began to call for a rejection of the idea of development itself, eventually to be known collectively as the post-development school (Ziai 2007a; Sachs 1992). For post-development theory, not only was development a failure, but it was a Eurocentric and dangerous project from the start. These academics worked to deconstruct the language and assumptions of development in order to open space for non-modern actors and knowledges that had previously been excluded.

This collective eulogizing for the death of development was perhaps spoken too soon: the consensus within development theory shifted away from the excesses of neoliberalism in the $1990 \mathrm{~s}$, recognizing that economic growth required an effective developmental state to facilitate markets and achieve social goals. We can place this shift

12 "The era of national economies and national economic strategies is past-for the time being, at least. With capital free to move where it wishes, no state (and least of all a small poor one) can pursue any economic policy that the owners of capital seriously dislike. Economic planning, welfare systems and fiscal and monetary policies all became subject to control, in effect, by the capital markets, signalled, in the case of Third World countries, by the conditions attached to IMF/World Bank lending-precisely the situation the Bretton Woods system was designed to prevent. ... It is hardly too much to say that by the end of the 1980s the only development policy that was officially approved was not to have one-to leave it to the market to allocate resources, not the state" (Leys 1996, pp. 23-4). Also: "Now neoliberalism, post-Keynesianism, and neo-structuralism have...become totally irrelevant and bankrupt for development policy. In the real world, the order of the day has become only economic or debt crisis management" (A.G. Frank, 1991, cited in Leys 1996, p. 24). 
in the context of a few success stories of state-led growth—especially South Korea-as well as the Asian financial crisis which exposed the necessity of regulation and institutions in managing liberalization (Leys 1996, p. 34; Panitch \& Gindin 2012, pp. 277-83). However, critiques of the entire development paradigm remain relevant, especially as inequality in the international division of labour appears to have abated little in over a half century of development:

At the end of the twentieth century the advanced capitalist countries accounted for 90 percent of all financial assets, 65 percent of world GDP, and almost 70 percent of global exports of manufacturing goods; not only did 85 percent of global FDI emanate from these countries, they were also the recipients of over two-thirds of it (Panitch \& Gindin 2012, p. 211).

The question, of course, is how to explain this failure of the development project to live up to its promises; is it a result of inappropriate modern ideas, or of capitalist processes which are inherently uneven? Before I outline those responses, in the next section I will move from contextual issues to analyze the theoretical trends in more detail, showing how as development theory has changed, it has kept in place the same basic frameworkthe policies necessary for entire societies to develop — and the same basic goal: modernized capitalist states with high standards of living.

\section{I: Theories of Development}

In general terms, development theory has sought to understand the processes necessary to bring states in the Global South to conditions of high economic growth and human welfare. Often the model of that change has been the advanced industrial countries, to which other countries aspire to emulate. Although the means and ends of development have been revised and reformulated over the years, the overall framework remains in 
place: countries are expect to modernize in order to emulate some version of a welfare state.

Modernization theory was one of the first and most well known varieties of development theory, emerging out of the United States in the 1960s. Modernization theorists argued, somewhat teleologically, that "all societies progressed in linear fashion along the same path toward development" (Rapley 2002, p. 16). However, rather than assuming that this process was "immanent and inevitable" (Pieterse 2001, p. 21), the task of development theory was to explain why and how the West was able to develop into complex and affluent societies while the rest of the world remained in an initial state of underdevelopment (Rapley 2002, p. 15; Leys 1996). To accomplish this, a distinction was often made between "traditional" and "modern" societies. As Almond \& Powell (1965) argued, modern societies are secular and rational, whereas traditional societies are personalistic and status-oriented (pp. 32-3); therefore, societies must develop by adopting "Western" political institutions based on differentiation (i.e. specialization of roles and political structures, division of labour) and cultural secularization (i.e. rational, analytical, and empirical political action) (pp. 22-4; Huntington 1971, p. 302; Leys 1996, pp. 65-6). In terms of economic development, Rostow's (1960) infamous Stages of Economic Growth argued that it was possible to categorize all societies as somewhere within five stages of economic growth, each moving from a traditional society to the "age of high mass consumption" (p. 73). Modernization in this case is understood as adopting a series of economic programs which lead to higher rates of investment, industrialization, and technical maturity. Whether the emphasis was economic or political, modernization theorists expected that there was role for the West in assisting underdeveloped countries 
in this process, by transferring modern values, through means such as education and technology, to their elites (Leys 1996, p. 10).

A very different theoretical approach, often referred to as the structuralist school of development, emerged out of Latin America in the 1950s, pioneered by Raul Prebisch, Hans Singer and the UN's Economic Commission for Latin America (ECLA).

Structuralism represented a challenge to the dominant economic prescriptions, and was to an extent a justification of already existing Import Substitution Industrialization (ISI) policies undertaken by Latin American countries after the financial collapse of 1929 destroyed their export markets (Kay 1989, pp. 35-6). Significantly, structuralists challenged the dominant diagnoses of underdevelopment as well as the assumed (exportled) solution:

The originality of the structuralist paradigm lies in the proposition that the process of development and underdevelopment is a single process; that the centre and periphery are closely related, forming part of one world economy. Furthermore, the disparities between the centre and periphery are reproduced through international trade. Thus, the periphery's development problems are located within the context of the world economy (Kay 1989, pp. 26-7, emphasis mine).

Declining terms of trade meant that the periphery could never develop if it continued to be dependent on producing primary goods for export, as this would only exasperate existing inequalities in the international market, and so Latin American countries required a strong role for the state in directing economic activity towards industrialization for domestic consumption (Kay 1989; Rapley 2001).

In the early 1960s, a radicalization of structuralist thinking alongside a convergence with various schools of Marxism led to a perspective known as dependency theory (Leys 1996, pp. 46-52), which argued that industrialization would not overcome 
underdevelopment so long as it occurred within the framework of capitalism, which was the real source of underdevelopment (Frank 1966, p. 23). Dependency theory took the structuralist critique of the world market further, arguing that unequal relationships between the metropoles and the peripheries were "an essential part of the structure and development of the capitalist system on a world scale as a whole" (p. 18); this made it possible to speak in terms of a "capitalist world-economy" which encompassed the entire modern world (Wallerstein 1979, p. 53). In this view, the function of the peripheries was to extract as much surplus to the metropoles as possible, and therefore real structural change (often sought by revolutionary movements) was actively undermined by the domestic ruling classes and imperialist powers who depended on keeping these countries in an underdeveloped state (Baran 1957, pp. 12-3; Frank 1966, pp. 20-1). ${ }^{13}$ This imperialistic arrangement therefore ensured that the process of capitalist development was "distorted and crippled" (p. 144), ${ }^{14}$ which meant that the key to economic development ${ }^{15}$ was necessarily anti-imperialist: it would have to involve independence

13 Nonetheless, it was understood by Wallerstein (1979) that while the underdevelopment of the periphery was necessary for the capitalist world-economy, this did not mean that the status of individual countries could not change: "the fact that particular states change their position in the world-economy, from semiperiphery to core say, or vice versa, does not in itself change the nature of the system ... The key factor to note is that within a capitalist world-economy, all states cannot 'develop' simultaneously by definition, since the system functions by virtue of having unequal core and periphery regions" (p. 61, emphasis in original).

14 "Thus the peoples who came into the orbit of Western capitalist expansion found themselves in the twilight of feudalism and capitalism enduring the worst features of both worlds, and the entire impact of imperialist subjugation to boot. To oppression by their feudal lords, ruthless but tempered by tradition, was added domination by foreign and domestic capitalists, callous and limited only by what the traffic could bear. The obscurantism and arbitrary violence inherited from their feudal past was combined with the rationality and sharply calculating rapacity of their capitalist present. Their exploitation was multiplied, yet its fruits were not to increase their productive wealth; these went abroad or served to support a parasitic bourgeoisie at home. They lived in abysmal poverty, yet they had no prospect of a better tomorrow. They existed under capitalism, yet there was no accumulation of capital. They lost their time-honoured means of livelihood, their arts and crafts, yet there was no modern industry to provide new ones in their place. They were thrust into extensive contact with the advanced science of the West, yet remained in a state of the darkest backwardness" (Baran 1957, p. 144).

15 It should be noted that although development is understood here in terms of economic growth, countries also require the "rational utilization" of the surplus - that is, socialist economic planning (Baran 1957, p. 18, 134). The goal of socialism clearly differentiates dependency theory from mainstream 
from the metropoles and Western imperialism, and solidarity among autonomous socialist states (Baran 1957, p. 158; Frank 1966, p. 24; Amin 1977, p. 14; Rapley 2001, pp. 16-9). However, dependency theory was never as popular as structuralism, and its implicationthe need for states to adopt autocentric national development strategies - was rarely adopted in practice (Rapley 2001, pp. 18-9).

The structuralist school of thought was dominant in Latin America until the end of the 1970s, when high inflation and perceived abuses of state interventionism prepared the way for neoliberal economic theory (Rapley 2001). If structuralism had attempted to simultaneously achieve economic growth and directly alleviate poverty, neoliberalism asserted the primacy of growth: its "central thesis is that long-run growth and development will proceed provided everything possible is done to achieve short-run allocative efficiency," which is best delivered by free markets (Colclough 1991, pp. 5-6). This rapidly became the ideological consensus within the World Bank and the International Monetary Fund during the 1980s, replacing the more Keynesian approach which had been dominant since the establishment of the Bretton Woods system in 1944 (Rapley 2001, pp. 62-5). As the policies of the international financial institutions (IFIs) were increasingly aligned with those of the U.S. Treasury, the shared commitment to neoliberalism became known as the "Washington Consensus" (Stiglitz n.d., p. 1).

The general trend in development theory since the early 1990s has been a recognition of the limits of neoliberalism and free markets, and a return for the role of the state in advancing social welfare. Income per capita in Latin America had stagnated during the neoliberal era, leading some to refer to the 1980s as a "lost decade" (Sunkel \& Zuleta 1990), and there was a consensus emerging that neoliberalism did not provide the development theory, even if the basic problematic remains the same. See Leys (2001, pp. 45-63). 
answer to poverty alleviation (Stiglitz n.d., p. 1). For the most part development theory has not abandoned its attachment to neoliberal macroeconomic policies, but scholars have complemented this approach with an emphasis on the various other factors that must be included to ensure successful and inclusive economic growth. The "New Institutional Economics" promoted by North (1995) has recognized that institutions - the "rules of the game"-are necessary to produce competitive market conditions, and to reduce the uncertainty in human exchange. Others have argued that "social capital" - in the form of relationships of trust and reciprocity, alliances and networks, and state-society partnerships - is important for the effective delivery of services (Bebbington 2008, pp. 272-3, 278). Sen (1999) has influentially re-defined development in terms of enhancing the capabilities of individuals, and Evans (2010) builds on this concept, arguing that economic growth requires the expansion of ideas (i.e. innovation), which itself requires the expansion of human capabilities through access to education and public services. In other words, states "must support a distribution of basic rights that gives individuals incentives to invest in their own capabilities" (p. 44). An approach which integrates several of these perspectives is one that diversifies and builds upon people's "livelihoods," which are conceived in terms of consisting of different types of capitalnatural, human, social, produced, and cultural—which themselves are assets that enhance capabilities (Bebbington 1999, pp. 2022, 2029-30). Looking at the list of recent World Development Reports, one can see that gender equality, reducing economic inequality, security, knowledge, and environmental sustainability have all come to been adopted by the World Bank as inputs necessary for economic growth and social welfare (World Bank n.d.). 
In the most recent Human Development Report, the United Nations Development Program (UNDP) neatly summarizes the current consensus in development theory in claiming that:

The link between growth and human development is not automatic. It needs to be forged through pro-poor policies by concurrently investing in health and education, expanding decent jobs, preventing the depletion and overexploitation of natural resources, ensuring gender balance and equitable income distribution and avoiding unnecessary displacement of communities (UNDP 2013, p. 64).

At the core of this argument is the challenge to neoclassical thought that markets are actually imperfect, and therefore state intervention is required to correct those imperfections as well as ensure that the benefits of growth are distributed widely. This position came to be referred to as neo-structuralism, or alternatively the "postWashington consensus" (Stiglitz n.d.; Fine n.d.). The state required for such a role is often referred to as a "developmental state," in that it balances market-led growth with a redistribution of wealth that directly alleviates poverty and invests in public services (Leftwich 2008; Evans 2010; UNDP 2013). Relatedly, scholars now argue that liberalizing trade and orienting to export-led growth can be impoverishing to countries which are not yet competitive, and that what is needed is a developmental state which stimulates investment and constructs the society-wide "systemic competitiveness" necessary to compete in world markets (Leiva 2008, p. 3; UNDP 2013, pp. 70-5; Sunkel \& Zuleta 1990, pp. 35-41; Rapley 2001). Such an approach is said to reflect the experiences of the East Asian success stories as well as China and Brazil—-the so-called "rise of the south" (Rapley 2001; UNDP 2013).

This only represents a small sample of the debates over development theory over the past 60 or so years, but it shows that even as the concept of development changes - in 
terms of both means and ends - the basic objective remains the same: a modernized capitalist state capable of facilitating strong economic growth and providing a better quality of life for its citizens through the provision of key public services. It should also be noted here that as the understanding of the prerequisites for development has become more sophisticated, incorporating elements such as gender, capabilities and social capital into its framework, development theory has had a related tendency to absorb external critiques of itself and turn them into essential inputs. Radcliffe, Laurie \& Andolina (2009) see this process as characteristic of "social neoliberalism" (a concept which they argue is a component of the post-Washington Consensus):

Social neoliberalism sees cultural difference, environmental protection, gender equality, and popular participation as necessary ingredients in development and accordant with capitalist markets or self-help agency ... [It represents] a rediscovery of society as a site of development needs and development potential (p. 9).

In this way, what were initially radical critiques are appropriated and lose their critical edge. This is what Hickey \& Mohan (2004) criticize about participation, and what Cornwall, Harrison \& Whitehead (2007) criticize about gender mainstreaming: for these ideas to be institutionalized, they must be "blunted and reduced to slogans and ideals" ( $\mathrm{p}$. 7). As such, "the political project of gender and development has been reduced to a technical fix" (p. 7; Hickey \& Mohan 2004, p. 4). It is likely this ability of development theory to neutralize and incorporate its critics' arguments, thereby diffusing any real radical challenge, that turns off so many of those critics from the possibility that development could be a vehicle for radical transformation. In the following sections we will look at two critical perspectives that attempt to escape the boundaries of the development paradigm. 


\section{II: Beyond Development: Post-Development Theory}

Post-development theory emerged out of a constellation of factors in the 1980s: a disillusionment with development and its apparent failure to deliver on the promise of decreasing global inequality; the rise of neoliberalism and Latin America's "lost decade"; and the growing influence of post-structuralism in academia (Rojas 2001; Leys 1996; Escobar 2007a). If dependency theory had located the apparent failures of development in the structural inequality of the world market, and if neoliberal theory argued that excessive state intervention was the problem holding back development, a growing number of academics argued that the failure was with the very idea of development. These academics ceased calling for a "better" development and instead insisted on a rejection of development itself (Ziai 2007a), and these critiques culminated in a number of collaborative publications in the 1990s, notably Sachs (ed, 1992) and Rahnema \& Bawtree (eds, 1997). Other major works that are generally identified as belonging to the “post-development” school include Escobar (1995), Shiva (1993), Ferguson (1990), Rist (1997), and Esteva \& Prakash (1998).

The post-development critique is centred on the charge that development is first and foremost an idea. While the strongest and most influential formulation of this has been Escobar's (1995) notion of development as discourse (more on this below), development has variously been treated as a belief or faith (Rist 1997, p. 21; Sachs 1992b, p. 2), a myth (Rahnema 1997a, p. ix), and "a perception which models reality, a myth which comforts societies, and a fantasy which unleashes passions" (Sachs 1992b, p. 1). ${ }^{16}$ Further, common to these critiques is the overwhelming sense that the idea of

$\overline{16}$ As Ziai (2007b) aptly points out, the common tendency among observers to associate post-development with Foucault and his concept of discourse is erroneous, as the approach in much of the literature is to depict development more in terms of crude ideology (p. 113-4). Escobar (1995) and Ferguson (1990) 
development - that is, that the adoption of modern knowledge and practices by the Third World will lead to material abundance-has failed. However, despite their conviction that the idea of development has completely lost its credibility, ${ }^{17}$ and has done severe damage to those it ostensibly was intended to help, ${ }^{18}$ its power remains unchallenged; as Sachs (1992b) argues, even though development did not work, "the idea of development [still] stands like a ruin in the intellectual landscape" (p. 1). ${ }^{19}$ The task of post-development theory, then, is to deconstruct and challenge the foundations of the development idea. According to post-development theory, the idea of development has historical roots in processes of modernity and capitalism (Escobar 2007a, p. 19), and is the successor to ideas of social evolutionism ${ }^{20}$ and civilization; both were concepts utilized to distinguish societies from each other and to justify colonial intervention (Rist 1997, pp. 39-40, 43; Rojas 2001, p. 573). As an "historical discourse" however, development emerged in the post-Second World War period (Escobar 2007a, p. 19), and its "invention" is often associated with point four of U.S. President Truman's 1949 inaugural address (Escobar 1995, pp. 3-4; Rist 1997, pp. 70-9; Sachs 1992b, p. 2; Esteva 1992, pp. 7-8):

Fourth, we must embark on a bold new program for making the benefits of our scientific advances and industrial progress available for the improvement and are the most notable exceptions.

17 This argument is most persistently made by Rist (1997): "The grand theories that promised a generalization of material well-being have lost their credibility" (p. 212); "End of sequence. End of game. The lights that made the hope glow have gone out. The huge enterprise that began in both North and South at the end of the Second World War, with the aim of accelerating 'development', has come to a complete end" (p. 220). According to Rahnema (1997a), development did not meet the aspirations of the "grassroots" but came to appear as a "nightmare" (p. x).

18 "This is how, under the banner of development and progress, a tiny minority of local profiteers, supported by their foreign 'patrons,' set out to devastate the very foundations of social life in these countries" (Rahnema 1997a, p. x). Rahnema (1997b) also uses the metaphor of AIDs to describe development as an invader which becomes internalized by "host" communities, "colonizing from within," and destroying the integrity and cohesion of those communities by turning people into selfinterested individuals without obligation to each other (pp. 118-9).

19 Or, as Esteva (1992) put it, development is an "unburied corpse" (p. 6).

20 Here social evolutionism is defined in terms of the notion that human progress is necessary and natural, and that societies pass through a series of historical "stages" (Rist 1997, pp. 39-40). 
growth of underdeveloped areas. ... More than half the people of the world are living in conditions approaching misery. Their food is inadequate. They are victims of disease. Their economic life is primitive and stagnant. Their poverty is a handicap and a threat both to them and to more prosperous areas. ... For the first time in history, humanity possesses the knowledge and skill to relieve the suffering of these people (Truman 1949, cited in Rist 1997, p. 71, emphasis mine).

Despite the arbitrariness with which this section of text was included in Truman's speech, ${ }^{21}$ it was disproportionately influential and regarded as having put forward a "new way of conceiving international relations" (Rist 1997, p. 72; Escobar 1995, p. 3). It was this speech that popularized the term "underdevelopment," therefore assigning to Third World countries a subordinate position in relation to the West (Esteva 1992, pp. 7-8); but unlike the previous colonizer/colonized opposition, it was now possible to see developed and underdeveloped countries as part of a continuum, in which underdeveloped countries were not the opposite of development but only incomplete, and therefore they could hope to "catch up" by adopting the right policies (Rist 1997, pp. 73-4). ${ }^{22,23}$ Further, it represented - alongside various other speeches and United Nations reports at the timethe "discovery" of poverty as a social problem requiring intervention (Escobar 1995, pp. 21-2), which then became the "organizing concept" for the emerging project of development (p. 24).

21 "A civil servant suggested adding that the technical assistance already granted to parts of Latin America would be extended to the poorer countries of the world. After some hesitation, the idea was taken on board as a public relations gimmick, contrasting with the rather conventional first three points. As one might have expected, the main headlines the next morning were all about 'Point Four,' although nobody - not even the President or the Secretary of State - could say more about it than what everyone read" (Rist 1997, p. 70).

22 To draw this out further, the introduction of "underdevelopment" changed the very meaning of development, which was previously understood as a natural process: "development' took on a transitive meaning (an action performed by one agent upon another) which corresponded to a principle of social organization, while 'underdevelopment' became a 'naturally' occurring (that is, seemingly causeless) state of things" (Rist 1997, p. 73, emphasis in original).

23 This framework also made it possible to see underdeveloped countries and their histories as part of the universal (linear) history of the developed world, so that "Development is a process of incorporating the story of the third world into spatial and temporal existence" (Rojas 2001, p. 578). For those cases that do not fit easily within this conception of history, their exceptionality then becomes grounds for imperialistic intervention (p. 579). 
Truman's speech was just one aspect of the historical conjuncture in which development emerged as a "discursive formation" (Escobar 1995, p. 10), resulting in "concrete practices of thinking and acting through which the Third World [was] produced" (p. 11). In addition to poverty, other "objects" that constituted this discourse included capital flows, international financial institutions (i.e. the World Bank), and cultural values such as modern education—but as Escobar argues it was not these elements themselves that initiated development as discourse (they were not all new) but rather "the system of relations established among them" (p. 40). As knowledge was increasingly organized through a set a techniques and institutions, as determined by "experts," the development discourse "created a space in which only certain things could be said and even imagined" (p. 39). It was through this system of knowledge and practices that reality was constructed; thus, "that the essential trait of the Third World was its poverty and that the solution was economic growth and development became selfevident, necessary, and universal truths" (p. 24).

Whether post-development theorists take the approach of development as discourse (Escobar 1995) or as a paradigm or "global faith" (Rist 1997) ${ }^{24}$ what they have in common is the argument that the idea of development effectively dominates the intellectual space, making critical engagement difficult. As Escobar (1995) recounts, prior to post-structuralism "it seemed impossible to conceptualize social reality in other terms"

24 This is basically the distinction between discourse and ideology. The difference of course is that ideology generally suggests a depiction of reality which is distorted, concealing the truer truth, so to speak. The concept of discourse developed by Foucault, on the other hand, is interested in power and the production of knowledge, not truth. This distinction is made by Ferguson (1990), who explicitly adopts a discursive approach as against a critique of the "ideology" of development (pp. xiv-xvi). See also Pieterse (2001, pp. 13-4), Barrett (1991) and Foucault (1972). Although concepts of discourse and ideology are deployed by different authors within the same collaborations (i.e. Sachs 1992), little thought seems to have been devoted to this apparent contradiction. Yet the question has to be asked: given the epistemological divide between these concepts, are the authors that deploy them even having the same conversation? Or are they describing essentially different phenomena? 
(p. 5). Modifications or improvements may be made, or alternative forms of development may be offered, but development itself is incontestable (Rist 1997, p. 77; Escobar 1995, p. 5). One significant contributor to this problem is the technocratic nature of development: social, political and cultural issues—such as poverty—are depoliticized and recast as problems to be solved by "neutral" scientific planning (Escobar 1995, p. 45, 143; Ferguson 1990, p. 256). As a technical matter, development is left "outside the realm of political debate" (Rist 1997, p. 78), and the very definition of underdevelopment (as lack) preconditions development as the "only possible answer" (p. 79). This is why Ferguson (1990) called development an "anti-politics machine," for it "depoliticizes everything it touches, everywhere whisking political realities out of sight, all the while performing, almost unnoticed, its own pre-eminently political operation of expanding bureaucratic state power" (p. xv).

Contrary to the view of development as an apolitical and technical process, postdevelopment theorists argue that development is an inherently political process, for it radically restructures Third World societies in Eurocentric and reductionist ways while suppressing or destroying alternative ways of thinking and acting. ${ }^{25}$ Key organizing concepts such as "poverty" and "standard of living" actually reflect modern constructions of reality that reduce the diversity of human well-being to a measurable quantity of income, while development projects destroy communal bonds and subsistence livelihoods, thereby actually creating deprivation (Rahnema 1992; Latouche 1992; Rahnema 1997a; Shiva 1992). ${ }^{26}$ The necessity of "economic growth" is revealed to be a

25 Additionally, for Ferguson (1990) the "principal effect" of development is "the expansion and entrenchment of state power" (p. 255), which occurs even when development projects "fail" (pp. 256, 257).

26 Rahnema (1992) describes the invention of poverty: "For the first time in history, entire nations and countries came to be considered (and consider themselves) as poor, on the grounds that their overall 
belief unique to Western culture (Rist 1997, pp. 214, 238), and an ideology dependent upon a "faith in progress and in techno-science" (Latouche 1997, p. 142). In the interests of that belief, nature is reduced to "natural resources" which only exist to be exploited, ${ }^{27}$ while the inevitable environmental crises that arise from industrialism are something to be technically "managed" at a planetary scale (Shiva 1992, pp. 206-7; Escobar 1995, pp. 193, 196; Sachs 1992b, p. 2). Perhaps most significantly, modern science and technology, which promoters of development consider to be "neutral and inevitably beneficial" (Escobar 1995, p. 36), are revealed to be products of Western culture which are not only unnecessary for other cultures, but also dangerous (Alvares 1992, p. 219) ${ }^{28}$ Science, at least in its dominant form, is reductionistic and universalistic, and therefore becomes "inherently violent and destructive in a world which is inherently interrelated and diverse" (Shiva 1997, pp. 161-2). ${ }^{29}$ By claiming superior explanatory power, science

income is insignificant in comparison with those now dominating the world economy" (p. 161). This notion of poverty is seen as incompatible with the perspective of the "losers" of development, who are interested not in technical indicators or income but human well-being and the social fabric (Rahnema 1997a, pp. xi-xii; Latouche 1992, p. 261). Shiva (1992) points out that this is based on a "mistaken identification of the culturally perceived poverty of earth-centred [that is, subsistence-based] economies with the real material deprivation that occurs in market-centred economies" (p. 215), a deprivation which is based on dispossession of the commons, the undermining of subsistence livelihoods, the overexploitation of the natural environment (pp. 210-11), and the war of modern individualism against "communal solidarity" (Rahnema 1997a, p. x).

27 Shiva (1997) describes this reductionistic approach to nature, arguing that it reflects a "monoculture of the mind" which makes the space for local alternatives disappear (p. 12). In one case study, she shows how "scientific forest management" reduces the diversity of life to just a few commercially valuable species while rejecting the remainder as "weeds" (pp. 19-24).

28 Alvares (1992) takes an extreme view in rejecting science outright, which many authors in the postdevelopment school do not necessarily share. For example, Shiva (1997) provides a somewhat more nuanced argument, suggesting that "the one-dimensional perspective of dominant knowledge is rooted in the intimate links of modern science with the market" (p. 27). This perspective, which clearly draws upon the language of Marcuse (1964), and suggests the possibility of science which is not harmful to diversity, opens space for dialogue with the critical theory tradition I will outline in the next chapter. In any case, all post-development authors remain skeptical about the benefits and applicability of science, not least due to the relationship between power and knowledge.

29 Further, Shiva (1997) argues that from the start modern science (in its dominant, reductionistic form) was a project of patriarchy: "In Bacon's experimental method, which was central to this masculine project, there was a dichotomizing between male and female, mind and matter, objective and subjective, rational and emotional, and a conjunction of masculine and scientific dominating over nature, women and the non-West. His was not a 'neutral, 'objective,' 'scientific' method-it was a masculine mode of aggression against nature and domination over women" (pp. 162-3). 
excludes other forms of knowledge: "everything 'non-scientific' [is] devalued as subjective and arbitrary, of marginal value, and could hardly be made the foundation of public policy" (Alvares 1992, p. 228); therefore, science remains "blind to alternatives" which do not correspond to its limited form of rationality (Shiva 1997, p. 11).

If these concepts which comprise the discourse of development are laden with assumptions which are modern and Eurocentric, "development has so pervasively spread these assumptions that people everywhere have been caught up in a Western perception of reality" (Sachs 1992b, p. 5). Thus it is impossible for critics to draw upon the language of development without subjecting themselves to its assumptions and therefore undermining their goals (Esteva 1992, pp. 7-8). It is for this reason that the early postdevelopment literature was focused on deconstructing the key concepts that support the development paradigm, so as to "disable the development professional by tearing apart the conceptual foundations of his [sic] routines" (Sachs 1992b, p. 4). This deconstruction was understood as the process through which space could be opened up for other voices, for cultural differences, and for local knowledges which had previously been excluded (Escobar 1995, pp. 216, 223; Escobar 2007a, pp. 20-1). Or to phrase this differently, it was this deconstruction which offered the possibility of a "post-development era" in which "development would no longer be the central organizing principle of social life" (Escobar 2007a, p. 20). ${ }^{30}$

The post-development school has been subject to significant critique, and it is not my intention to reproduce those debates here. ${ }^{31}$ One criticism which is relevant here is the

30 As Escobar (2012) frequently emphasizes, this is different than understanding post-development as an historical period to which we have arrived, as some critics apparently interpreted it (p. xiii).

31 For a selection of critical overviews of post-development theory see Ziai (2007a), Pieterse (2001), Veltmeyer (2001), Simon (2007), and McGregor (2009). For retrospective defences of postdevelopment theory, see Escobar (2000), Escobar (2007a) and Escobar (2012). 
charge that, regardless of the sincere political motivations behind deconstruction, postdevelopment theory is effectively apolitical: either "there is critique but no construction" (Pieterse 2001, p. 111), or it merely offers a "politics of language" which "limits action to thought" ${ }^{32}$ (Veltmeyer 2001, p. 605). Regardless of whether or not this is a fair accusation, Nustad (2007) rightfully argues that a theory's lack of direct and instrumental applicability is not in itself a substantive argument against the analysis (p. 35). And as Ziai (2007a) points out, despite the barrage of attacks that post-development has received, its two central hypotheses - "that the traditional concept of 'development' is Eurocentric and has authoritarian and technocratic implications - are hardly contested even by the sharpest critics" (p. 9). In this case, we might say that the initial task of post-development theory—-"slaying the development monster," as Escobar (2000, p. 13) has put it—has been at least partially achieved.

\section{III: Beyond Development: Dynamics of Global Capitalism}

If development refers specifically to capitalist development, with the assumption that capitalism provides human well-being, then it is important to challenge this foundation of development theory by bringing together several strands of critical political economy in order to understand and critique the dynamics of global capitalism. As we will see, development theory, including dependency theory, misunderstands these dynamics, by

32 This claim largely rests on a reading of post-development theory as post-structuralist and utilizing Foucault's concept of discourse, in which case the elements of the development discourse are "internal to the text of the discourse and do not have any empirical referents or stand in any relation of truth to the outside world" (Veltmeyer 2001, p. 603, emphasis in original). If, for example, class is merely an idea that is discursively constructed and does not correspond to objective or real conditions, then Veltmeyer argues this robs us of necessary tools for social analysis, and demobilizes political movements based on class demands (pp. 604-5). However, following Ziai (2007b) we might say that this attributes too much Foucauldian analysis to post-development authors whose use of words such as "ideology" or "belief" suggest there might indeed be a "real" which is being obscured by the false consciousness of development thinking. 
emphasizing markets rather than class and by accepting an erroneous "stages of growth" framework which assumes national societies are the appropriate unit for analyzing development. A political economy perspective is necessary because it is better capable of explaining the uneven success of the development project, and it highlights the structural changes in the global economy which development theory responds to.

Implicit in development theory is the idea that, as Adam Smith (1776/1999) argues in The Wealth of Nations, the dynamic of capitalist development derives from the "propensity in human nature" to "exchange one thing for another" (p. 117). According to Smith, this natural propensity leads people to specialize, creating a division of labour which then increases productivity, and which grows alongside the expansion of the market (pp. 117-121). As Brenner (1977) argues, this "optimistic" model "whereby the development of trade and the division of labour unfailingly bring about economic development" is held not only by modernization theorists but by dependency theorists as well (p. 27), whom he derides as "Neo-Smithian" Marxists (p. 25).

Political economy, however, puts class struggle rather than market exchange at the core of capitalist development (Brenner 1977, pp. 25-7). For Marxist geographers, such as Erik Swyngedouw (2000) and David Harvey (2006), the dynamic of capitalist development is found within the dialectical social relations of capital. The fundamental class antagonism of capital between owners and labour leads to a "series of processes, contradictions (tensions), and social struggles that render capitalism geographically and historically dynamic, but inherently unstable" (Swyngedouw 2000, p. 44). The class antagonism works out in the following way: the logical paradox of economic growth (or the accumulation of capital) in the context of equal exchange in the market can only be 
resolved when we see that labour power is the only commodity that actually produces greater value than itself (Harvey 2006, p. 24). In the production process, surplus value is appropriated (exploited) by the capitalist by paying workers for less value than they had produced. But capitalists cannot simply consume that surplus value, they must profitably reinvest it. This cycle, M-C-M' (or money exchanged for a commodity exchanged for more money than was put in), is why Marx speaks of capital as process (p. 20).

The tricky part is that to maintain this process, the capitalist must continue to find profitable avenues for that investment. And this leads the capitalist into significant barriers; these can take the form of labour and class conflict, high wages, the overproduction and therefore devaluation of goods, intense competition with other capitalists, the rise in price of inputs, natural or environmental barriers, political challenges - the list is virtually endless. The transcendence of these barriers is essential if capital is to continue to exist as capital, and individual capitals have a series of mechanisms to do so; for example, they can try to counter a rise in the price of inputs by increasing productivity through technological innovation, or through a reorganization of production. These methods assume change, but with firms staying within the same location. Alternatively, capital can opt for a "spatial fix" (Harvey 2006, p. 415), and this "temptation for capitalists to engage in interregional trade, to level profits out of unequal exchange and to place surplus capitals wherever the rate of profit is highest is in the long run irresistible" (p. 417). This is why we see the "continuous restructuring of the capital circulation process" as the geography of production, consumption and exchange undergoes constant revolution (Swyngedouw 2000, p. 49).

Capitalism is therefore an "inherently geographical process" (Swyngedouw 2000, 
p. 43), driven by the "countervailing forces" of class relations (Harvey 2006, p. 417).

Uneven development does not simply mean that some countries develop faster than others, nor that production is unevenly distributed across space, but that class relations force capital to constantly shape and reshape the geographic landscape. Despite capitalism's aspirations for universalism, uneven development is inevitable, since the process of breaking down "spatial barriers and regional distinctions" for the sake of accumulation has the contradictory effect of producing new barriers and distinctions, which then must also be overcome (p. 417). ${ }^{33}$

If the dynamic of capitalism is located with class, and not market exchange,$^{34}$ then a prerequisite for economic development is the construction of class relations. Brenner (1977), following Marx, insists that the creation of a specific class structure is necessary before capitalist development can occur, one that introduces market imperatives that compel accumulation based on relative surplus labour —or, the constant revolutionizing of production (this is explored in more detail in Chapter Four). Marx (1867/1990) located the origin of these necessary capitalist class relations in historical processes of dispossession, or what he referred to as so-called primitive accumulation (p. 873), when "great masses of men are suddenly and forcibly torn from their means of subsistence, and hurled onto the labour-market as free, unprotected and rightless proletarians" (p. 876). ${ }^{35}$

33 In this way, Marx actually inverts Smith's formula, in which the geographical expansion of markets, driven by the natural propensity to exchange, was thought to lead to development. Instead, Marx shows that the development of the productive forces, driven by class relations, leads to the geographical expansion of capitalism.

34 This is not to say, of course, that somehow markets are unimportant for capitalism. As we will see in Chapter Four, market imperatives are absolutely essential in order for labour to be treated as a commodity. The point here is that markets, in the absence of a capitalist class structure, do not in themselves drive economic growth.

35 While this process is said to take different forms in different places, in England this has been characterized by the expropriation of peasants, the usurpation of communal property (Marx 1867/1990, p. 878), enclosure of the common lands (p. 885), "clearing of the estates" (p. 889), "conquest, enslavement, robbery, [and] murder" (p. 874). 
Whereas Marx only went as far as describing this as an historical process, Luxemburg (1913/2003) demonstrated that the destruction of non-capitalist social organizations is essential for ongoing capital accumulation on a global scale. ${ }^{36}$ "Natural economies"Luxemburg grouped peasantry, feudal societies and primitive communism in this category — are of little use to capital, posing rigid barriers to accumulation; they provide little demand for consumer goods, and have no surplus population to provide labour power (pp. 348-9). It is for this reason that capitalism fights a battle of "annihilation against every historical form of natural economy that it encounters" (p. 349). But the assault of capital does not end with the destruction of natural economies. It goes much further:

Natural economy, the production for personal needs and the close connection between industry and agriculture must be ousted and a simple commodity economy substituted for them. ... But as soon as simple commodity production has superseded natural economy, capital must turn against it. No sooner has capital called it to life, than the two must compete for means of production, labour power, and markets. The first aim of capitalism is to isolate the producer, to sever the community ties which protect him, and the next task is to take the means of production away from the small manufacturer (p. 382).

We therefore see that destructive processes of ongoing dispossession and disruption are essential to capitalist development. However, it should be noted that while dispossession is a requirement for the construction of capitalist class relations upon which development rests, dispossession in itself does not in itself guarantee successful economic development if it results in extreme deprivation and impedes the reproduction of a healthy working

36 This is due to the contradictions of capital: maintaining the subordination of labour under capital acts as a brake on the possibility of re-investing surplus value, so that "the realization of the surplus value for the purposes of accumulation is an impossible task for a society which consists solely of workers and capitalists" (Luxemburg 1913/2003, p. 330). The non-capitalist social environment is therefore essential, both for absorbing the products of capitalism, and supplying the resources and labour power necessary for capitalist production (p. 347). 
class (Arrighi, Aschoff \& Scully 2010, p. 436). ${ }^{37}$

So far I have explained the core dynamics driving the uneven development of capitalism. To highlight how this political economy approach differs from development theory one can draw on the work of Halperin (2007), whose "horizontal perspective" of global development complements my own. Halperin critiques three methodological features shared by all perspectives on development, including both modernization and dependency theories: 1) analyzing "development" as a phenomenon which reflects the experience of whole countries; 2) "the use of a profoundly erroneous account of modern European history as a starting point and comparative focus for analyzing contemporary 'Third World' development;" and 3) the reproduction of superficial binary schema, such as modern/traditional and core/periphery (p. 544). For Halperin, these represent a false "ontology and history" of development which obscures actual historical processes (p. $544)$.

The first feature, to see development as "vertical" or operating on a national level, is replaced by Halperin with a view of capital accumulation driven by local and translocal classes and elites along networks of exchange (pp. 550-1):

Capitalist expansion has been, everywhere and from the start, essentially transnational in nature and global in scope, involving not whole societies but sectors, regions, and groups in Europe, the Americas, Asia, and Africa - characterized not by processes centred on empires and nation-states, but by trans-local/crossregional interactions and connections (p. 544).

Moving away from the focus on nation-states to that of horizontal networks of

37 To clarify, the authors' argument is to disprove the thesis that dispossession is a condition for development, using the case of South Africa to argue that dispossession "generally undermines the conditions for successful development" (Arrighi, Aschoff \& Scully 2010, p. 411). While their emphasis on the barriers that dispossession can present in terms of undermining human welfare and economic development is quite useful, their analysis seems to overlook its importance in creating the necessary class relations for capitalism to operate. 
capital accumulation, we can see why economic growth does not necessarily lead to higher standards of living. As Halperin argues, not all ruling groups wish to industrialize their economies, as they require the continued subordination of labour to capital—and with it lower consumption rates of workers - in order to maintain profitability (p. 552). In this way, increased standards of living actually become a barrier to capital accumulation, and capital is required to transcend such barriers. So long as there are easier ways to maintain wealth and power, the trans-local capitalist class(es) is unlikely to engage in industrialization in a way that actually benefits the local working classes (p. 551).

This leads us to the second feature of development theory which Halperin challenges: the normative, historical model of European states which countries are compelled to follow. Halperin finds, in fact, that such a model obscures how European capitalism actually developed: previous to the world wars, Europe actually resembled the pattern of industrialization as it occurs in underdeveloped countries today. The dualistic character of development — that is, the wealth of industrialized centres alongside stagnating conditions of life for the majority of the population —was characteristic to Europe then, and is characteristic to the Third World now (p. 555). It was only the European labour movement, which gained immense political strength during wartime, which eventually drove a concern for domestic markets and investment, raising standards of living at the national level (p. 554). It is therefore wrong for dependency theorists to argue that dependent states were forced into an economic trajectory unlike that taken by the West, even if their analysis of the policies which kept those states dependent was accurate, for the history of European development actually fit into the same model of 
dependency (pp. 44-6). ${ }^{38}$

Finally, a third feature of development theory is the reproduction of unhelpful binary schema; these binaries include "West/rest, core/periphery, colonizer/colonized, modern/ traditional" (p. 550). When these are adopted by critical perspectives, including dependency theory and subaltern studies, these schema obscure the nature of domination within both the Third World and Europe: on one hand, they assume that colonization victimized entire Third World societies rather than selectively supporting and enriching existing privileged classes and local patterns of exploitation; and on the other hand they "promote an account of European development as devoid of [internal] subalternity, racism, exploitation, and imperial domination," whereas these were processes were a “central part" of recent European experience (p. 550).

This horizontal perspective of global development therefore reveals that development theory, by focusing on countries and national societies as whole units, is incapable of making sense of uneven development, or the existence of "industrialization without development" (p. 544) in countries all over the world. However, although the state is clearly not the most appropriate unit for understanding the development of capitalism, neither can we dismiss the role of states within capitalism, for they play an important organizational role. By representing the interests of numerous class fractions (however unequally), the capitalist state maintains a "relative autonomy from the shortterm interests of capital," which allows it to fund social welfare and manage class tensions that otherwise might allow the capitalist system to fall under its own

38 I should emphasize that when Halperin discusses the analytical accuracy of the dependency model, she is referring to its discussion of the dualistic character of development. We have already seen that the focus of dependency theorists upon unequal market exchange overlooks the role of class structures in economic development. 
contradictions (Swyngedouw 2000, p. 50; Mahon 1977). The state also provides essential functions - like protecting property rights and investing in infrastructure - which are necessary for capital accumulation (p. 50). To adopt Harvey's terms, the state therefore helps to reduce the barriers to capital accumulation, while simultaneously creating new barriers (through taxes, regulations, etc.).

Similarly, capitalism is organized by states at a global scale. In Arrighi's (2010) analysis of capitalism as a world system, he identifies a series of successive but overlapping historical periods ("long centuries") within the last 500 years, each comprised of a world system of capital accumulation led by a hegemonic state with the political structures and organizational capabilities necessary "to control the social and political environment of capital accumulation on a world scale" (p. 14). With each transition from one period to the next, the world system was reconstituted: regimes of accumulation shifted from material to financial expansion, or vice versa, constituting a full systemic cycle, ${ }^{39}$ and the centre of the world economy shifted from one region to another, with a corresponding change in leadership (p. 332). The most recent period, with the United States at the centre of the world system, began with the decline of the British regime in the late $19^{\text {th }}$ and early $20^{\text {th }}$ centuries, and was consolidated in the post-World War Two period (p. xii). ${ }^{40}$ Panitch \& Gindin (2012) explain how the new "informal"

39 In each "century," Marx's process of capital (MCM') is expressed in two phases of accumulation: first, in the MC phase of material expansion, capital "sets in motion" a mass of commodities; second, in the CM' stage of financial expansion, capital "sets itself free" from commodity production and turns to financial dealing. Together, these two alternating phases "constitute a full systemic cycle of accumulation" (Arrighi 2010, p. 6).

40 For Arrighi (2010), the American phase was based on material expansion, with strong Fordist and Keynesian economic planning, replacing the increasingly unprofitable financialization of the British regime. In the 1970s, however, the American phase entered into a long decline with the financial expansion associated with neoliberalism (pp. 227, 301-10). Panitch \& Gindin (2012) however take exception to the thesis of American hegemony in decline, arguing that financialization has strengthened its institutional power at the centre of the global economy (pp. 12-17). 
American empire that emerged in this period "constituted a distinctly new form of political rule:"

Instead of aiming for territorial expansion along the lines of the old empires, US military interventions abroad were primarily aimed at preventing the closure of particular places or whole regions of the globe to capital accumulation. This was part of a larger remit of creating openings for or removing barriers to capital in general, not just US capital (p. 11).

It is in the context of these broader structural transformations that we can locate key moments in the development project—from the Bretton Woods agreement in 1944 to its jettisoning in the 1970s — as representing the strengthening of the capacity of American empire to organize global capitalism (pp. 9, 12-17, 74).

In sum, a critical political economy approach can provide an analysis of the uneven development of global capitalism that goes beyond the paradigm of development theory and its "stages of growth" thesis. We can see that capitalism is driven by class relations, expands "horizontally" rather than "vertically," and is organized and facilitated by domestic and imperialistic states; hence, there is no reason to believe that capital accumulation will necessarily lead to higher standards of living for entire societies. Although this may seem similar to the UNDP's (2013) argument that economic growth does not necessarily translate into human development and that "pro-poor" policies and effective institutions are necessary, a political economy perspective goes further to emphasize that processes of dispossession and exploitation are central to capitalism. This allows us to critically assess projects intended to promote human well-being, and points toward the role of organized labour in achieving material gains for workers. 


\section{IV: The Idea of Development and Its Limits}

In focusing on the idea of development and the way that it shapes reality, postdevelopment theory does something interesting: it makes a very important critique of the subjective dimension of development, and especially the depoliticization and technocratic approach to social change which suppresses other ways of thinking and acting. When post-development authors argue for an alternative to development (or modernity), they are arguing for an alternative to the very idea of social life as a technical process, and an alternative to the coercive imposition of modern ideas and practices upon non-modern communities. Resistance to development, therefore, takes the form of deconstructing the idea of development and its supporting concepts (themselves organized through techniques and institutions), breaking apart the entire conceptual apparatus in order to reveal its parochial character and rediscover what it has excluded. In the following chapters I will show how, for post-development theory, this deconstruction opens up the possibility of reclaiming emancipatory knowledges which are non-modern (see Chapter Two) and economic practices which are non-capitalist (see Chapter Three).

However, the critique of development offered by political economy allows one to challenge the post-development critique on two fronts. First, it compels one to challenge the post-development assertion that the idea of development has been an unqualified failure. That may have seemed like an reasonable conclusion during the 1980 s and early 1990s, in the midst of structural adjustment and the "lost decade" of the neoliberal period, but the recent economic growth of countries such as South Korea, Brazil and India shows a much more mixed and contradictory record that cannot simply be swept aside. If deprivation, dispossession and exploitation are real consequences of development, not 
everyone shares in this experience. And indeed, for many people development has not meant the human suffering assumed by post-development theory but it has delivered on substantial material benefits, particularly gains in education and health (UNDP 2013). In reality, the success of the development project has been remarkably uneven, and political economy is better capable of explaining why and how this is so.

Second, and related to the last point, a political economy approach reveals that the successes and failures of development are much less dependent on the idea (which obviously can be applied in some cases), but are the result of the changing and uneven nature of global capitalism which the idea of development rests on, adapts to, and justifies. I have already discussed the historical and political contexts out of which various theories of development emerged, but I should emphasize that these theories are largely trying to make meaning out of processes which they cannot control. It would be a mistake, for example, to see the neoliberal shift(s) as a case of better theory informing policy; the policies of financial deregulation that started in the 1970s were "less determined by an ideological commitment to getting the state out of markets than by state actors pragmatically trying to catch up with the globalizing markets they had earlier nurtured" (Panitch \& Gindin 2012, p. 267).

In stating this position, I am open to attack from post-development theorists for emphasizing the "primacy of the material over the discursive" (Escobar 2000, p. 12). Dependency theory and other Marxist critiques are challenged by Escobar (2000; 2007a) for being more concerned with capitalism than with development or modernity, which he argues "arises out of their unwillingness to accept the poststructuralist insight about the importance of language and meaning in the creation of reality" (2000, p. 12). While there 
is some truth to this charge in that capitalism is indeed the primary focus of political economy, it would be wrong to suggest that political economy or even historical materialism therefore needs to regard language, subjectivity or meaning as irrelevant. For example, we can agree that discourses of poverty and underdevelopment are important for organizing the work of development institutions and justifying aid programs. However, broader transformations of global capitalism fundamentally restructure and reorient how development takes place, and these discourses are largely responding to rather than driving these processes. ${ }^{41}$

It is true that how we conceptualize and relate to the world is important, and this is something that political economists have not often taken into account. However, postdevelopment theory gives too much credit to ideas as forces driving the transformation of social life. This will be evident in the following chapters when I show that alternatives to modernity and development, which are based on new knowledges, subjectivities and practices, overlook or underestimate the material constraints upon those alternatives. And so although the post-development critique of the subjective effects of development is important, specifically the depoliticization of social life and the suppression of alternative imagination, in the next chapter I will argue that this phenomenon can also be understood through the analysis of reification as developed by the Western Marxist tradition. The crucial difference, however, is that reification is not reducible to modernity but has to be

41 I write this at the risk of replicating a base-superstructure framework. See the section of methodology in the Introduction for an account of how historical materialism avoids doing so. Interestingly, Escobar (1995) suggests that it is possible to see development economics as the rationalization of class interests in the post-war period, but insists that it "should not be seen as [an] ideological or superstructural reflection," which would create a division between "the ideal" and "the real" (p. 84); rather, it is important to see how "a certain historical conjuncture transformed the mode of existence of economic discourse, thus making possible the elaboration of new objects, concepts, and methodologies" (p. 84). At first glance this appears relatively consistent with the argument I am making, but the tension between our arguments will become apparent in the chapters that follow. 
understood in relation to the material dynamics of global capitalism. 


\section{Chapter Two: Modernity and Emancipatory Knowledges}

Issues of epistemology are featured prominently in the work of both post-development theory and Western Marxism. This chapter will explore how each perspective understands the relationship between modernity and the suppression of human experience and knowledge. As I will argue, both perspectives argue that modernity has contributed to such suppression, and that alternative ways of thinking and knowing are therefore necessary for the emancipatory task. However, by conceptualizing modernity in very different ways, Western Marxists are able to see emancipation coming from within modernity, while post-development theorists argue that emancipation can only come from a position of exteriority. This has significant implications both for locating the agents of emancipation, and for determining the possibility of articulating common struggles between movements. Therefore, investigating the role of modernity and reason within these critical perspectives will be critical to evaluating the current impasse that exists between them and their political projects, and the potential for transcending it.

\section{I: Reification and Negative Thinking}

For Western Marxists, the concept of modernity tends to be used interchangeably with the concept of Enlightenment, which Horkheimer \& Adorno (1944/2002) discuss in broad terms as the "advance of thought" and the "disenchantment of the world" (p. 1). In this sense they appear to be following philosophers such as Hegel (1830/1975), who depicted world history as the "evolution of consciousness" (p. 129), and Kant (1784/1947), for whom Enlightenment was understood as the use of reason to progressively transform society, thereby leaving behind the "immaturity" of submitting to tradition and authority 
rather than using one's own intelligence (p. 132). Kant's approach is helpfully

reformulated by Foucault (1984), who argues that we should think about modernity as an attitude, or a "mode of relating to contemporary reality" (p. 39) which involves a “permanent critique of our historical era" (p. 42). ${ }^{42}$

What is of interest in the analysis of modernity, then-for Western Marxists as well as Hegel, Kant and Foucault — is the relationship between rational thought and emancipation. The critique of modernity brought forward by Western Marxists is precisely the charge that modernity is contradictory, and that through its contradictions rational thought has been degraded, eroding its emancipatory potential. And so, if modern society has developed in a way that suppresses human experience and forecloses emancipation, the culprit is not the concept of Enlightenment itself. Rather than rejecting modern reason, the Western Marxist tradition follows Marx in reasserting it. This begins in Marx with a reformulation of Hegelian philosophy, and in particular Hegelian dialectics.

In Reason and Revolution, Marcuse (1960) describes how Hegel's concept of dialectics was taken up by Marx, and became central to Western Marxist thought. As Marcuse notes, for Hegel there are no fixed and stable objects, only movement and relations. Nothing simply "exists;" everything "becomes." The appearance of reality, seemingly given and concrete, must therefore be understood as negative, or "other than its real possibilities;" it reveals its truth only in the process of "overcoming" this negativity (p. 26). The overcoming of negativity is precisely the task of the dialectical process. As every mode of existence is constituted by contradictory relations, "any Enlightenment, and instead adopts modernity as an attitude and applies it to his own research agenda (pp. 45-6). 
particular content can be unfolded only through passing into its opposite. The latter is an integral part of the former, and the whole content is the totality of all contradictory relations implied in it" (p. 66). Put another way, no existing things can be understood in themselves, apart from the greater whole in which they participate; they must be grasped as "mediated conceptual moments which are only fulfilled by revealing their social, historical, and human meaning" (Horkheimer \& Adorno 1944/2002, p. 20).

Hegel's dialectics were adopted by Marx, who turned them into tools for materialist analysis. Like Hegel, Marx emphasized the "negative" character of reality, and that every particular can only be understood in its relation to the whole, or "negative totality" (Marcuse 1960, pp. 312-3). In applying these concepts to capitalism, Marx outlined how the capitalist social order progresses "through the development of the contradictions inherent in it" (Marcuse 1960, p. 311), driven by the negativity of reality itself — epitomized by the alienating social division of labour — which is revealed as a historical condition (p. 314). Moreover, freedom is seen to be possible in the negation of this negativity—namely, the abolition of alienated labour (p. 282). Far from metaphysical abstraction, Marx's reformulation of Hegel allowed him to analyze the real contradictions of capitalism underneath its casual appearances, point out capital's historical character, and agitate for revolutionary action.

Although the negative character of Hegelian and Marxian dialectics clearly distinguishes them from the more empiricist and positivist traditions of the Enlightenment, they are still grounded in the paradigm of modern reason. Therefore, from the perspective of Western Marxism, the problems with the dominant forms of rationality in modern society do not stem from modernity itself, nor from reason as such, but 
actually reflect the very disintegration of reason as a result of its contradictory development. For Horkheimer \& Adorno (1944/2002), Enlightenment thinking is "inseparable" from freedom in society. However, it also contains a "germ," latent within itself, that contributes to its regression (p. xvi). This germ, which allows Enlightenment to relapse into mythology, and cuts off modern analysis from truth, consists of the desire to wholly dominate nature and human beings (p. 2) —a goal which refuses to allow anything to remain "outside" and unknown (p. 11), which fears any departure from "the facts" (p. xvi), and therefore has led to the discarding of meaning and of self-awareness in favour of calculability and formal logic (pp. 2-3).

What Horkheimer \& Adorno are pointing to, and which is also targeted in the writings of Lukács and Marcuse, is a tendency in rational thinking to discard a dialectical understanding of reality in favour of a "one-dimensional" reason, one which privileges the quantifiability of science and, for reasons discussed below, inevitably becomes a conservative force in society. The emancipatory potential of Enlightenment thinking is therefore undermined when this tendency to rationally organize every aspect of reality is developed. As Lukács (1923/1972) argues, this regression of reason is attributed to a process known as reification, which emerges alongside the historical development of capitalism.

In tracing the relationship between capitalism and the contradictions of rational thought, Lukács (1923/1972) takes Marx's point of departure in Capital— the commodity —as the "central, structural problem of capitalist society in all its aspects" (p. 83). According to Lukács, "there is no problem that does not ultimately lead back to that question and there is no solution that could not be found in the solution to the riddle of 
commodity-structure" (p. 83). There are two reasons why the structure of the commodity is so special, and so representative of society as a whole. First, the commodity is dialectical; its totality is composed of constitutive aspects, qualitative (as in its use-value) and quantitative (its exchange-value), which do not oppose each other as separate entities, but are in an inseparable relation (Harvey 2010, p. 24). Second, its true dialectical nature has been hidden from view, and we can only see its surface, quantitative dimensions. It is this latter aspect, described by Marx as commodity fetishism, which Lukács is particularly interested in.

In the first paragraph of Capital, Vol. 1, Marx (1867/1990) notes that the "wealth of societies in which the capitalist mode of production prevails appears as an 'immense collection of commodities'; the individual commodity appears as its elementary form" (p. 125, emphasis added). Right away, Marx hints that there is something more to this picture, and he later reveals the human, social relationships which form the basis of that wealth, and which provide the qualities that those commodities appear to hold (pp. 1645). Marx noted that although the proportions of value exchanged in the market actually derive from the qualities of human labour, the quantitative exchange of commodities appears to reflect the objective characteristics of the objects themselves, their "socionatural properties" (pp. 164-5). This is what gives commodities their "fetish" character (p. 165). The social relations that constitute the capitalist economy thus appear natural and objective, outside the scope of human agency. Reification is therefore understood as a process through which "capitalist society makes all personal relations between men take the form of objective relations between things" (Marcuse, 1960, p. 279), and has the effect of "concealing their origin, their mechanisms of perpetuation, and the possibility of 
their transformation" (p. 280).

The emergence of reification, based as it is on the generalization of commodities, must be seen to be historically specific. As Marx (1867/1990) argued, commodities take on their fetish character because of the "peculiar social character of the labour which produces them" (p. 165), in which individuals do not come into "social contact" except in the market to exchange the products of their labour, so that "the specific social characteristics of their private labour appears only within this exchange" (p. 165; Marcuse 1960, pp. 279-80). This situation where social labour is mediated solely within the market, through the exchange of commodities, is unique to capitalism; although the existence of the commodity form itself is not new, never before had it been the dominant form within society (Lukács 1923/1972, pp. 85-6). As Lukács goes on to argue, however, we must not see the shift from occasional to generalized commodity production as merely a quantitative change - that is, defined by an increase in the number of commodities. Rather, this shift had a qualitative character: unlike before, the commodity form came to dominate the "total outer and inner expression of life in society," making commodity fetishism a characteristic of modern capitalism (p. 84).

If commodity fetishism is characterized by the dialectical whole being reduced only to its quantitative parts, then the domination of the commodity form over society is likewise characterized by the suppression of all human experience which cannot be understood through the reified categories of the market, and the further concealment of the human and social basis of economic forms. It is my task below to elaborate on the effects of this process, to illustrate how this critique of the subjective effects of capitalist social relations in many ways parallels the critiques of modernity and development by 
post-development theory.

As already noted, one consequence of reification is that the social character of labour is concealed, so that economic activity appears as "material relations between persons and social relations between things" (Marx 1867/1990, p. 166). The effect of this is the apparent naturalization of economic laws, and the suppression of any sense of human agency. The individual confronts a marketplace where objects appear to operate according to their own, natural logic; economic laws confront the worker as "individual forces that generate their own power" (Lukács 1923/1972, p. 87). The alienated products of labour appear objective and independent from the workers, and therefore control them (p. 87). This objective material power over the individual increases with advances in the division and specialization of labour, as tasks are further atomized and subjected to the principle of rationalization; under Taylorism, even the psychology of individuals is reduced to minute parts that can be rationally organized (p. 88).

Lukács (1923/1972) characterizes this as a process of dehumanization; the qualitative attributes of the individual worker are eliminated and their creative agency is "reduced to the mechanical repetition of a specialized set of actions" (p. 88). Just as the objects of production are fragmented under increasingly atomized production processes (pp. 88-9), this necessarily implies the fragmentation of the subject of production as well. Compared to the abstract, rational laws of production, human qualities are merely "sources of error" to be reduced. The individual is no longer the "authentic master" of their work, but has become "a mechanical part incorporated into a mechanical system" (p. 89); the worker not only confronts a world that appears alien and independent from her will, but she must also conform to its seemingly natural laws (p. 89). Thus, "the 
personality can do no more than look on helplessly while its own existence is reduced to an isolated particle and fed into an alien system" (p. 90).

This dehumanizing alienation destroys any true concept of community. The "fate of the worker becomes the fate of the whole" (Lukács 1923/1972, p. 91), as all relations within capitalist society are subject to reification and fragmentation. The bonds between individuals within community are degraded as people "learn to satisfy all [their] needs in terms of commodity exchange" and thus confront each other as abstract and isolated parts within a rationalized system (pp. 90-1). The collective that is created is built on the "negation" of individuality, as human beings are "forced into real conformity" via a labour market that treats human labour as abstract and equivalent (Horkheimer \& Adorno 1944/2002, p. 9). This forced conformity is itself dangerous, for it contains the threat of fascism: that which does not conform must be purged, and so "everything which is different ... is exposed to the force of the collective," which is "manipulated as an agent of violence" against it (Horkheimer \& Adorno 1944/2002, p. 22).

But one of the most important effects of reification is upon epistemology. Lukács $(1923 / 1972)$ intimates that it is no coincidence that the conceptual system of the natural sciences developed simultaneously with the capitalist mode of production, and offhandedly suggests that capitalism may have been the causal factor in their parallel development (p. 131). It may be wise to take this as a logical argument, rather than as an historical one. In any case, as capitalist forms became entrenched and took on their reifying power, scientific thought, which reflects the rational and atomizing tendencies of capital, became the dominant form of knowledge. Lukács points out that together these rational forms - capitalism with its specialization of skills, and science with the 
rationalization of matter-have led to "the destruction of every image of the whole" (p. 103). It is important to emphasize that this is not a rejection of science itself, but a critique of the way in which scientific reason has been adopted as the sole methodology for discovering truth. Mathematization (as the extreme form of scientific reason) may be appropriate to understand certain phenomena, but in modern society it has been identified with truth itself (Horkheimer \& Adorno 1944/2002, p. 18).

The epistemological hegemony of scientific reason is dangerous from a dialectical point of view precisely because of the necessary incompleteness of the knowledge it produces. This rationalism claims to have found the "principle which connects all phenomena" (Lukács 1923/1972, p. 113), and the "universal method to obtain knowledge of the whole of existence" (p. 114). This comes up against a serious limit as rationalism meets irrational objects - that is, objects that cannot be reduced to their "rational elements" (p. 116). Actually more than a mere limit to knowledge, the very existence of irrationality erodes the basis for a system that claims to rationalize everything (p. 114). For this reason, anything incapable of conforming to this rational system is regarded as an illusion or is suppressed, as nothing is allowed to remain "outside" (Horkheimer \& Adorno 1944/2002, p. 11). Knowledge, organized solely by rational principles which fragment and atomize it, is itself held hostage to a "formally closed system of partial laws," blind to the qualitative material base of reality (Lukács 1923/1972, p. 104). As Lukács (1923/1972) warned, this blindness prevents bourgeois rationalism from any substantive, critical analysis of society. Just as individuals in capitalist society confront a reified world which appears objective, natural, and thus alien to any human agency, so is this experienced by the rational subject. Rather than oriented to 
transformation, thought is captive to contemplation — the study of formal laws which appear to function "without the intervention of the subject" (p. 128). Bourgeois society appears immutable, as a given (ahistorical) reality, a thing-in-itself, and this reified world is the only object of study available (pp. 109-10).

In this way, the ideal of scientific knowledge, when applied to society, becomes an "ideological weapon of the bourgeoisie" (Lukács 1923/1972, 10). Removed from any critical content, reason becomes "one-dimensional:" it suppresses any idea or objective which transcends the existing order, thus containing the possibility of qualitative change (Marcuse 1964, p. 12). Marcuse (1960) therefore noted the particularly counterrevolutionary tendencies within positivism, which assumes that society can be understood by applying the model of the natural sciences, itself supposing that society is rationally and necessarily ordered and excluding the agency of people in transforming it (Marcuse 1960, pp. 343-5). When thought is oriented to society in this way it becomes an “instrumental reason," merely affirming the existing order, and applied only to its continued preservation and expansion (Horkheimer \& Adorno 1944/2002, p. xv; p. 64). In this context technology is far from a neutral force, but actually compounds the experience of reification: social life still appears to be determined by objective laws, but these are no longer "mysterious" and "uncontrollable;" rather, they appear as "as calculable manifestations of (scientific) rationality" (Marcuse 1964, pp. 168-9). The intervention of human agency has been completely purged from social life, which is now merely a technical matter in which "domination functions as administration" of the existing order (255).

At this point, the parallels between this description of the effects of reification 
upon knowledge, and the post-development critique of development and modernity (as outlined in Chapter One), should be clear. In both cases, science comes to exclude other ways of knowing, and transforms social life into a technical project, suppressing social and political alternatives. But from the Marxist perspective, what post-development theorists seem to be describing is actually the phenomenon of reification, which is a tendency in modernity but not synonymous with it. This should not exclude the possibility of modern reason from contributing to an emancipatory project. Reason must instead be reclaimed from its reified, regressive forms, and be put to use as dialectical thinking.

In order for reason to break free from its one-dimensional form, it must reclaim the understanding of reality, and society, as dialectical. Rather than engaging in thought that simply accepts, calculates and observes that which exists, Marcuse (1960) calls for "negative thinking" which analyzes the "world of facts in terms of its internal inadequacy" (Marcuse 1960, p. viii), and therefore functions as a "determining negation" of whatever appears to be given (Horkheimer \& Adorno 1944/2002, p. 20). At the core of this method is reclaiming the contradictory nature of reality. In a positivist framework, contradiction is always a sign of un-truth, suggesting that our knowledge is faulty or incomplete. And yet, in the dialectical view, contradictions belong to the nature of reality itself, and especially to capitalism (Lukács 1923/1972, p. 10). By purging contradiction from its analysis, science has abstracted from reality (Marcuse 1960, p. vii). The task of negative thinking is to focus on the contradictions in society, in order to break through reified thought and show where the possibilities for qualitative, emancipatory change can be found. 
This is why the proletariat is so important for this emancipatory project, for the dialectical knowledge of reality is inseparable from their class standpoint (Lukács 1923/1972, p. 21). As Rees (2000) explains, the consciousness of workers is shaped by two contradictory experiences. On one hand, as described above, workers are treated as commodities, and therefore they are subjected to processes of atomization and alienation. On the other hand, unlike other commodities, labour cannot be separated from its sellers, and therefore workers experience an "impulse to resist," based on the "rightful exercise by the sellers of control over the conditions under which they will part with their labour" (p. 14). Unlike the bourgeoisie, who are "blinded to the true state of affairs" by reification (Lukács 1923/1972, p. 166), the proletariat directly experiences the brutal contradictions of social existence, and therefore the worker is forced to "surpass the immediacy of his [sic] condition" (p. 166).

As we see, then, the "necessity" of the given reality can only be challenged by those who experience it as "insufferable pain" and "unnecessary" (Marcuse 1964, 222). For Lukács (1923/1972), it was the only the proletariat who would be able to fill this role, and he hoped that the class consciousness derived from their lived experience as commodities would lead to their conscious participation in the abolition of reified thought and alienated labour (p. 205). However, the Frankfurt School identified powerful ideological tools, including mass entertainment (Horkheimer \& Adorno 1944/2002) and technology (Marcuse 1964) which prevented this consciousness from being realized. This led Marcuse (1964) to suggest the revolutionary potential of the lumpenproletariat: the "substratum of the outcasts and outsiders, the exploited and persecuted of other races and other colours, the unemployed and the unemployable," who exist "outside the democratic 
process," and whose situation is most immediate and intolerable (p. 256). Because they remain positioned formally outside of the system, their criticisms cannot be deflected, and their very existence reveals the game to the "rigged" (pp. 256-7). As I will show in Chapter Four, the concept of uneven reification developed by Paulson (2005) shifts our attention further to the political agency of those who are incompletely subsumed within capitalist class relations. This suggests the potential for anti-capitalist struggles outside of capitalist relations, by agents other than the proletariat, something which Lukács did not consider. However, what is important here is that within capitalism it is the experience of those who most directly suffer under its contradictions who are most capable of breaking from reification ${ }^{43}$ - supposing that the ideological tools noted above are not strong enough to resist this process - and recovering the dialectical emancipatory potential of modernity.

So as I have demonstrated, for Western Marxism, modernity is contradictory and regressing, but its restoration comes from within, through the renewed action of the oppressed whose experiences, capacities and individualities have been suppressed. For post-development thought, as I will show, the standpoint of the oppressed, the subaltern, is also critical to accessing and reclaiming the knowledge necessary for restoring humanity and social life. However, a dominant theme within these works is that emancipation cannot come from within modernity, but only from an "exteriority." This has major implications for both where the relevant emancipatory actors are to be located, and for the possibility of linking common struggles. In order to understand this disagreement, and to evaluate the post-development appeals for "worlds and knowledges

$\overline{43}$ For a dissenting view, see Holloway's (2002) formulation of mystification-as-process. 
otherwise" (outside of modernity), I must first look at how post-development theorists have come to conceptualize modernity.

\section{II: Modernity/Coloniality and Thinking Otherwise}

Early post-development thought was primarily concerned with deconstructing the hegemonic discourse of development, but this theoretical approach shifted in the beginning of the $21^{\text {st }}$ century as Arturo Escobar entered into a collaborative research program with a diverse group of Latin American and European/American thinkers sharing a broadly post-colonial perspective. First referred to as the modernity/coloniality (MC) research program (Escobar 2007b), it was soon modified to read as modernity/ coloniality/decoloniality (MCD) (Escobar 2008). Main contributors include Peruvian sociologist Anibal Quijano, Argentine-Mexican philosopher Enrique Dussel, and the Argentine semiotician Walter Mignolo. While not belonging to this program, the Portuguese sociologist Boaventura de Sousa Santos shares similar research interests, has collaborated with some of the MCD theorists on other projects, and is frequently cited by them, and so he can fairly be included in this section..$^{44}$ As we will see, there are many disagreements between these theorists, but what is common is their approach to questions of modernity/coloniality, their task of discovering emancipatory knowledges "otherwise," and their departure from the perspective of Latin America and of the subaltern. As Escobar (2007b) writes,

Rather than a new paradigm "from Latin America" ... the MC [modernity/

44 This is primarily because Santos' "ecology of knowledges" approach complements the MCD emphasis on epistemological change, as I will discuss below. On the other hand, Santos (2010) has criticized postcolonial authors for privileging coloniality as an explanatory factor at the expense of critiquing capitalism; he thinks it is "wrong for postcolonial criticism [referring to Quijano here] to focus more on western modernity than on capitalism" (235). 
coloniality] project does not fit into a linear history of paradigms or epistemes; to do so would mean to integrate it into the history of modern thought. On the contrary, the MC program should be seen as an other way of thinking that runs counter to the great modernist narratives...; it locates its own inquiry in the very borders of systems of thought and reaches towards the possibility of noneurocentric modes of thinking (p. 180).

Central to this program is their alternative (non-Eurocentric) approach to analyzing modernity, which they believe allows them to pose new questions about it (Escobar 2007b, p. 181). This approach "decenters" modernity from its "alleged origins and linear history" (p. 184) and departs instead from a world-systems analysis, locating the origin of modernity not with the Enlightenment in the $18^{\text {th }}$ century, but with the colonial "discovery" of the Americas in 1492 (p. 184; Mignolo 2000a; Dussel 1996). The proper unit of analysis is not modernity but modernity/coloniality, for "there is no modernity without coloniality, with the latter being constitutive of the former" (Escobar 2007b, p. 185). From this viewpoint it is impossible to analyze modernity without reference to the "dark side" of Western civilization: colonial power relations which suppress all other ways of acting and knowing (Mignolo 2011; Quijano 2007; Escobar 2008). In this way discussions of modernity are always linked to its political expansion; for their purposes, there is no modernity which is not politically acted on other subjects. Modernity is a "spatial-cultural project" that requires conquest (Escobar 2008, p. 65), one local history (the history of Europe) which imposes itself as a universal global design (Mignolo 2000a), “subalternizing” and subsuming other local designs (Escobar 2007b, p. $183)$.

MCD theorists therefore make a distinction between the image of modernityunderstood as the history of ideas, philosophy, etc.- - and the modern world system, which 
is more about the "spatial articulation of power rather than a linear succession of events" (Mignolo 2002, p. 60). The concept of Enlightenment is not forgotten, but it is not equated with modernity itself. Importantly, neither is modernity a derivative of Enlightenment, for that would place the beginning of modernity at the $18^{\text {th }}$ century and ignore the entire history of the modern/colonial world system (Mignolo 2002, p. 61). Instead, it is understood as the "second phase" of modernity (Dussel 2000, p. 470; Mignolo 2000a, pp. 18-9). By designating Enlightenment as modernity's "second phase," we can see that the "emancipatory rational nucleus" of modernity was born amidst the background of Europe's colonial expansion, which allowed it to claim the "centre" of space and time, and render all else immature, barbarous and underdeveloped (Dussel 1996, p. 52). In this way, the elements of Enlightenment—-ideas of newness, the advanced, the rational-scientific, the secular" - cannot be understood in and of themselves, for they necessarily belong to a "universe of social relations" (Quijano 2000, pp. 543-4); therefore, Quijano (2000) argues that whatever the term modernity refers to today, it involves the totality of the modern world-system over the past 500 years, as a model of global power (pp. 546-7).

It is in the light of this broader concept of modernity/coloniality that development is now to be understood. For Escobar (2008), the discussion of development is but a "subsidiary" to the discussion of modernity (p. 161), for the paradigm of development is merely one "global design" originating out of the local history of the "modern West" (p. 170). Development can also be seen as a part of the "imaginary" of modernity (Mignolo 2000a, p. 280), the imputed "aspiration" for the West which justifies the cultural Europeanization of modern global designs (Quijano 2007, p. 169). If the promises of 
development serve as ideological support for modernity, the epistemological privilege of modern science serves at least as important a role by suppressing opposition. Reason has a political character, as the complex of modernity/rationality results in the colonization of imagination (Quijano 2007, p. 169) and the suppression of non-scientific knowledges, what Santos et al. (2007) refer to as "epistemicide" (p. ix). As Santos (2006b) argues, "techno-scientific knowledge" supports the hegemony of neoliberal globalization, for together they discredit, conceal and trivialize epistemological and political alternatives (pp. 13-4).

From this perspective, investigations into the "myth of modernity" such as those by the Frankfurt school and other critical traditions cannot remain at an intra-European level, but must be expanded to the level of the world system (Dussel 2000, p. 477n14). This has major implications for where we are to locate emancipatory potential. If for Western Marxists the standpoint of suffering and oppression under capitalism was the point of departure for liberatory thinking, for MCD theorists the "politics of location" is similarly important (Mignolo 1999), for "your location in the colonial matrix of power shapes the way you look at the world" (Mignolo 2011, p. 293). However, the proletariat are no longer sufficient for providing the necessary emancipatory perspective, for they remain "internal" to Europe's modernity, and to retain this Eurocentric framework is to ignore the global character of modernity/coloniality. The colonial character of modernity therefore requires that we depart instead from the "exteriority" of the world system.

The standpoint of exteriority is thus critical to the work of the MCD theorists. But as Escobar (2007b) is quick to point out, the concept of exteriority is not meant to refer to a "pure outside untouched by modernity," but rather to an "outside that is precisely 
constituted as difference by a hegemonic discourse" (p. 186). This exteriority which is produced by modernity/coloniality is what is referred to as the "colonial difference," and it is paradoxically both the "space where coloniality of power is enacted" (Mignolo 2000a, p. xxv), and also the source for ethical challenges to the dominant discourses (Escobar 2007b, p. 186). Departing from the standpoint of the colonial difference therefore has two aspects. First, by starting with the miserable reality of those who are suffering (Dussel 1996, p. 12), the dark sides of modernity are revealed "from the perspective of the receivers of the alleged benefits of the modern world" (Escobar, 2007b, p. 189), thereby contradicting the rationality of modernity (Dussel, 2000, p. 473). Second, with the "innocence" of modernity thus denied, it is then possible to affirm the "alterity of the other" (Dussel 2000, p. 473). This project of affirmation and reclamation of the difference which has been suppressed itself takes a number of forms. In the next chapter, I will look at recent efforts to develop a "political economy otherwise" (Rojas 2007) by affirming and reclaiming economic difference. First, I will look at how the colonial difference shapes the MCD approach to alternative epistemologies.

As argued above, the epistemological privilege of modern science has rendered all other forms of knowledge as subordinate or invisible. Therefore, "it is not possible to think and even less enact alternatives for emancipatory social change without epistemological changes" (Santos et al 2007, p. xlix). This recognition has brought theorists including Mignolo, Escobar and Santos into a common research project called "Worlds and Knowledges Otherwise" (Mignolo \& Nouzeilles 2003; Escobar 2007b), which builds on the analysis of colonial difference from the MCD project to discover ways of thinking and knowing "otherwise" that break from the coloniality of modern 
power relations. From the standpoint of subalternized knowledges - themselves victims of modernity - the task common to these theorists is to reclaim these epistemologies and position them in relation to other knowledges without subsuming or subalternizing either of them. They want to move away from the current "ontological struggles" (Escobar 2012, p. xxviii) between knowledges, and instead construct an "ecology of knowledges" in which a non-hierarchical relationship exists among different knowledges based on their mutual incompleteness (Santos 2006b, p. 20). Therefore, in most cases this approach involves not a simple rejection of Western epistemology, but a recognition that salvation cannot come from it (Mignolo 2000a, p. xvi); science can contribute to emancipation but only if it loses its universalistic character and becomes one form of knowledge among many (Santos et al 2007, p. li).

There are several different theorizations about what this epistemological reorientation might look like. One of the earlier formulations of thinking "otherwise" was the concept of "border thinking" (Mignolo 2000a; 2000b). Border thinking offers the possibility of thinking from the intersection of "supposedly incommensurable forms of knowledge" (Mignolo 2000a, p. 85); namely, Western modernity and the "diversity of categories suppressed under it" (p. 93). At the intersection of epistemological traditions, border thinking engages in a double critique, thinking from "both and at the same time neither of them" (p. 67). Santos et al (2007) offer a similar method in the concept of "translation," which seeks to overcome epistemological barriers between knowledges by turning "incommensurability into difference ... [thus] enabling mutual intelligibility" (p. xl). Despite the similar approach, these authors depict these practices as leading to somewhat different political forms. Santos (2000b) sees translation as forming the basis 
for a counter-hegemonic globalization, in which the political future begins at the crossroads of these knowledge traditions (see also Santos et al 2007). This vision is also reflected somewhat in Dussel's (2002) concept of trans-modernity as a worldwide project of liberation involving a "multicultural response" by cultures which have been silenced, and which respects their heterogeneity (p. 236; Dussel 2000). For Mignolo (2011), border thinking furthers diversity as a universal project (p. 310), but this vision is less about articulating into a common movement and more about concurrent projects operating without universal truth (p. 52). This latter vision, in which "communal nodes" cooperate rather than compete, and without any one extending itself as a universal, is what Mignolo (2011) refers to as a "decolonial Cosmopolitanism" (p. 52) and parallels what Escobar (2012) refers to as a "pluriverse" (p. xx). ${ }^{45}$ In each envisioned future, respect for diversity of cultures and epistemologies is essential, but there is a subtle tension between those who see this diversity as the principle which brings movements together and those who see diversity as the principle that ensures movements are protected against each other.

This tension builds out of and exacerbates a more fundamental conflict within this group of collaborators, between those who are willing to draw from traditions of European thought, and those who take on a more rejectionist attitude towards modernity. In the former category are Dussel (1996; 2000) and Santos (2001a; 2006b; 2010), who utilize and reformulate European and American critics of modernity and capitalism, and incorporate a dialectical approach into their analyses. This is especially evident in Dussel's (1996) "liberation philosophy," which is an explicitly dialectical and "negative" approach, and which starts with the reality of those suffering under capitalism on the

$\overline{45}$ This concept as it pertains to the possibility of political coalitions is further developed in Chapters Three and Four. 
periphery of the world system (hence, the negation). However, liberation philosophy consists not merely of negation, but also of the affirmation of the "exteriority of the other" (pp. 6-7). In this way, Dussel's (2000) project to "transcend" modern reason is not antimodern or premodern, and neither is it postmodern in the sense of denying modernity and critiquing all reason (p. 474); rather, it is a denial of reason's "violent, Eurocentric, developmentalist, hegemonic" forms (p. 473), a process by which modernity and its denied alterity would "mutually fulfill each other in a creative process" (pp. 473-4). Echoing the Western Marxist critique, modernity is not to be abandoned but fulfilled, although this emancipation must involve the subaltern of the capitalist world system. Santos (2000b; 2001a; 2010) is similarly willing to engage with, and not merely oppose, modernity and Western knowledge traditions. While conceding that there are no longer modern solutions to modern problems, and that the perspective of the "utmost margins" is still important, he nonetheless suggests that a radical critique of modernity is still possible from "inside" (Santos 2010, p. 227, 232). For Santos, insisting on a standpoint which is external to modernity is problematic, as the dialectical nature of modernity makes any distinction between inside and outside untenable (p. 232n2). Rather, Santos draws upon dialectical thinking and puts it to use in his "ecology of knowledges" project. This is clear in his method of a "sociology of absences," as an "enquiry that aims to explain that what does not exist is in fact actively produced as nonexistent" by the hegemonic epistemology (Santos 2006b, p. 15), and its complementary method of a "sociology of emergences" which seeks to identify those alternatives which have been "declared non-existent" (p. 29) and which are "contained in the horizon of concrete possibilities” (p. 31). Echoing Lukács' “ought” and Marcuse's negative thinking, 
Santos (2000b) asks us to look for the "Not Yet," the possibility beneath the given reality which "exists as mere tendency" (p. 30).

Going even further, Santos (2001a) also takes up the project of restoring modernity to its emancipatory potential. As he sees it, the paradigm of Western modernity is under threat, for neoliberalism has removed from modernity the dialectical tension between emancipation and regulation. As emancipatory knowledge is subsumed underneath the regulatory knowledge of modern science, there is no dialectical movement; ${ }^{46}$ without the negation of the negation, "negation is mere destruction, without contradiction, affirmation is self-aggrandizing complacency" (pp. 292-3). The result of this is a "societal fascism" which involves the "collapse of the most trivial expectations of the people living under it," as the emancipatory promises of modernity are shown to be mere fictions for large sections of the population (Santos 2001b, p. 186). Therefore, reinventing this dialectical tension - presumably through the sociology of absences and emergences-is seen as an emancipatory task (Santos 2001a, p. 293). Far from rejecting modernity, Santos (2010) rather seeks to reconstruct modern ideas and concepts from the perspective of modernity's victims, an approach which he refers to as "oppositional postmodernism" (p. 226). The parallels between this critique of modernity and the one offered by Western Marxists should also be clear; although the loss of dialectical tension within modernity has been moved from the origins of capitalism and industrialism to the neoliberal era, ${ }^{47}$ Santos is nonetheless revealing potential points of convergence for these critical perspectives.

$\overline{46}$ Note the parallel here with Marcuse (1964).

47 The reason for this shift-moving the loss of modernity's dialectical tension from capitalism per se to its neoliberal form - is not apparent to me, and perhaps deserves further exploration, but that is beyond the scope of this work. 
Other thinkers, including Mignolo (2000a; 2000b; 2011) and Escobar (2007b; 2008), take a more rejectionist position towards European epistemological traditions. Whereas Dussel (1996) embraced the usefulness of Marx, and engaged in a rigorous "rereading" of his manuscripts, for Mignolo (2000a) the usefulness of Marx is limited as he remained firmly within Western epistemology (and "cosmology") (p. xxi), and Latin Americans have not shared with the European proletariat the same "experiences of capitalism" (2000b, p. 10). The "decolonial" perspective Mignolo (2011) offers would confront all of "western civilization," including liberal capitalism and Marxism, from the perspective of coloniality (p. xviii). From this point of view, Marxism is itself a Eurocentric global design (Mignolo 2000a, p. 310) which confronts capitalism from within Europe first, and then exports this model of confrontation elsewhere (Mignolo 2011, p. xviii). Escobar (2008) similarly partially conflates historical materialism with dialectical materialism (its "philosophic principle") to show Marxism's universalistic impulses (p. 123). Even if Marx is partially useful in some cases, belonging or contributing to the Marxist or any other Western tradition is not permissible for those who wish to think from a decolonial perspective. What European theorists "seem unwilling to consider," according to Escobar (2007b), is "that it is impossible to think about transcending or overcoming modernity without approaching it from the perspective of the colonial difference" (p. 186). All other critiques remain captive within Eurocentric categories (p. 186), ${ }^{48}$ and therefore to think from the "Western canon" is to "reproduce the

48 Although the Eurocentrism of Western thought and its analytical categories is often pointed out, it is usually assumed, rather than explained, that those forms of thought are therefore inappropriate for current analysis. However, this dismissive attitude is in danger of conflating two different types of Eurocentrism: the first emerges out of the limited nature of data, due to the historical situation in which the theory was formed, and the second involves actively distorting the available data to meet specific ends (this distinction was made by Vivek Chibber during a panel session at the Historical Materialism conference, New York University, April 26th 2013). While post-development and the MCD school seem to assume that all Eurocentrism belongs to the second category, and therefore furthers coloniality, it 
colonial difference" (Mignolo 2002, p. 66).

This fundamental skepticism of the emancipatory potential of European theoretical traditions leads Mignolo and Escobar to something of an epistemological purism. As Escobar (2007b) writes, "the goal [of the MCD project] is to craft new forms of analysis, not to contribute to already established (Eurocentric) systems of thought, no matter how critical these might be" (p. 191, emphasis added). The assumption here appears to be that modernity always implies expansion and conquest by (European) universals, and so theoretical traditions that developed within Europe have an inherent and unavoidable universalistic character. ${ }^{49}$ Efforts to synthesize critical perspectives from Europe and Latin America are therefore criticized for subsuming the specifically "local" content of each perspective, thus undermining epistemological diversity: as Mignolo (2011) asks, why "aim for a synthesis [between two perspectives] and not for a world in which many worlds (in this case, theoretical worlds) would coexist and work together in their respective milieus?” (p. 323). Once again we can see that whereas Santos depicted the diversity championed by an "ecology of knowledges" approach as providing the ground for common struggles, for Mignolo and Escobar diversity is the principle which keeps local knowledges and movements insulated from being infringed upon by any other.

This fear of local knowledges and movements being absorbed into universal projects is best captured in Escobar's (2008) description of alternative modernities. The

seems problematic to reject "Eurocentric" thought simply because it originated in Europe, as this presumes that its limitations cannot be counteracted by providing additional data.

49 There is, however, some ambiguity here, as Escobar also argues that some aspects of modernity will have to be part of the transformation to a different (non-modern) world. This point was made during a panel at the Canadian Association for Latin American and Caribbean Studies (CALACS) congress, Carleton University, May $5^{\text {th }} 2013$. The distinction that Escobar is making here, given his other comments which reject modern theoretical traditions, is not clear to me. 
term alternative modernities — and its subsidiary, alternative development (see Chapter Three) — is meant to refer to instances in which local groups contest the aims and values of modern projects - in Escobar's example, literacy campaigns-from the perspective of their cultural difference, but without rejecting outright the projects themselves (pp. 1845). These projects still represent the imposition of European concepts, yet they are modified so as to better match the needs and goals of the intended beneficiaries. There is a recognition here that modernity and development are not simply one-way transmissions, but are negotiated on the ground, and this points to the "transformative potential of local histories on the developmental global design" (p. 170). However, Escobar is quick to point out the limitations of alternative modernities, for in his view they still subsume and incorporate all projects into a single, if diverse project, therefore excluding the "potential of the subaltern perspectives" (p. 170). This is precisely what Mignolo (2011) warns against in his descriptions of "rewesternization" projects, including the efforts by the Left to "reorient" globalization, but which continue to privilege one universal political trajectory and subsume all others within it (p. 37).

It is for these reasons that Escobar (2007b; 2008), and more recently Mignolo (2011), have argued that we should strive towards the possibility of alternatives to modernity. An alternative to modernity, in Escobar's (2007b) words, would consist of "an alternative construction of the world from the perspective of colonial difference" ( $p$. 206n7), building on cultural, ecological and economic "practices of difference" (p. 198). Escobar is not pointing to a future in which modernity ceases to exist, but is describing a political desire for an era in which "development and modernity cease to be the central organizing principles of social life" (p. 206 n. 7). It is not surprising, then, that Escobar 
and Mignolo find in indigenous, ethnic communities and peasant networks - those who are seen as most fully practicing "difference" - the most promising manifestations of alternatives to modernity. For Escobar (2012) this is because they place the strongest emphasis on different "philosoph[ies] of life" (p. xxvi), and by contrasting their "lifeworlds" with the violence of development are able to reveal the irrationality of modernity (p. xi). Mignolo (2011) similarly finds hope in the communal and noncapitalist social forms put forward by indigenous movements (pp. 307-12), and seems optimistic about efforts to integrate indigenous concepts into Latin American institutions and politics, thereby "re-directing a previously Marxist/socialist/theology of liberation, and critiquing development and turning it into a radical decolonial option" (p. 306). These alternatives will be explored further in the next chapter.

\section{III: From "Thinking" to "Acting" Otherwise}

Post-development theorists and Western Marxists have both put forward emancipatory projects in which "thinking otherwise" plays a central role in destabilizing regressive and reductionist forms of thought, thereby opening up space for the possibility of alternatives. However, It is evident that by taking a different approach to modernity than that of Western Marxists, the MCD school-Escobar and Mignolo in particular-have created a lot of distance between these two projects, despite describing the problem in roughly similar terms. First, this is because the MCD school tends to locate the source of the problem in modernity/coloniality itself, whereas Marxists see reification as a regression of modernity located in the social relations of capitalism. Second, by understanding modernity in terms of coloniality and spatial processes of power, the MCD group has 
shifted the relevant emancipatory actors further into the "exterior." We are asked to look beyond the proletariat of Europe, and to see potential in the subaltern on the peripheries of the capitalist world system, precisely because of the colonial difference they embody which serves as a challenge to modern projects and imaginaries. Third, the MCD school has mostly given up the task of overcoming or re-orienting modernity itself. Thinking "otherwise," while paralleling Marxist dialectics, therefore becomes not about overcoming the regressive forms of modernity from within, but about neutralizing the power of any one claim to truth, of seeking some form of global and egalitarian configuration between equal knowledges and practices.

There are some authors, including Santos and to a lesser extent Dussel, who demonstrate the possibility of bridging these perspectives, who see the conceptual shift to modernity/coloniality as helpfully expanding our vision beyond the proletariat but still see its emancipatory potential within a dialectical and counter-hegemonic modernity. However, the overall tendency among these collaborators is to depict modernity as an inherently European and universalistic project, and therefore remain skeptical of any tradition or political movement that has origins in the lineage of the Enlightenment. For Escobar and Mignolo who seek a more radical rejection of modernity, alternatives to modernity and development are most promisingly found in indigenous and peasant communities, those who are seen as most fully embodying and practicing "difference." This represents another feature distinguishing post-development theorists from Western Marxists: whereas the Frankfurt School was incapable of developing an emancipatory project outside of the realm of thought, for post-development theory —at least in its 
current form ${ }^{50}$ - it is not enough to "think" but also to "act." As such, constructing "worlds and knowledges otherwise" requires practices of economic difference, which I turn to in the next chapter.

50 As I showed in Chapter One, early post-development theory was primarily involved in deconstructing concepts of the development discourse, and was often criticized for lacking practical applicability. 


\section{Chapter Three: Economic Difference, Autonomy and the Pluriverse}

If Escobar had earlier referred to alternatives to development (1995), more recently this concept has been absorbed within the concept of alternatives to modernity (2008) as described in the previous chapter, which emphasizes the practice of difference and the refusal to subsume local projects to privileged and universalized ones. This is what distinguishes an alternative to modernity from both alternative development and alternative modernities, which involve various levels of contestation over the values and goals of modern projects but without a fundamental rejection of modernity itself (understood as being subject to the designs of others). In this chapter I will examine these alternatives in more detail, focusing on their economic content in particular. And so although the terms "alternatives to development" and "alternatives to modernity" can more or less be used interchangeably, I will use the former more frequently to emphasize this economic — rather than epistemological—focus.

In this chapter I will explore these alternatives by examining the concept of economic difference, providing a brief survey of alternatives to development as identified by post-development theorists, and showing how this leads to a commitment to autonomous political organization. This will prepare the necessary ground for my critique in the following chapter, where I will bring in the concepts of the subsumption of labour under capital and of uneven reification, with their focus on class relationships, in order to reveal the limits of the concept of economic difference and the possibility of building counter-hegemonic movements across unevenly reified spaces. 


\section{I: Economic Difference}

As demonstrated in the previous chapter, the post-development critique of modernity/coloniality leads these scholars to locate emancipatory potential in the exteriority of the capitalist world system, that is, with those who embody a "colonial difference" which challenges modern ways of doing and thinking. This colonial difference can be seen to have an economic aspect, in the sense that economic difference exists which is not reducible to but challenges the world capitalist system; as such, postdevelopment theorists are interested in locating these non-modern and non-capitalist economic practices of difference which can be built upon to construct "worlds otherwise." This brings post-development theory to champion indigenous and peasant movements, as well as other community-based movements, as the most inspiring manifestations of alternatives to modernity. ${ }^{51}$ But before we can survey these movements we must first examine this much-emphasized concept of economic difference. While this concept has always been implied within post-development writings, and the emancipatory actors remain largely the same as they were twenty years ago, "economic difference" has recently been subject to far more rigorous formulation, inspired by recent critiques of political economy.

For Escobar (2007), finding alternatives to modern economic projects requires that we come up with "new economic imaginaries" capable of building "concrete projects of world transformation" upon practices of "economic difference" (p. 198). He suggests that most scholars of the MCD school continue to utilize Marxist and political economy analyses which are insufficient for such a task (p. 198, 205n5), arguing that it is necessary

$\overline{51}$ I will show below that this support ranges from particular movements to social movements more generally. 
for the MCD school to engage in a dialogue with theoretical perspectives that approach the economy "from the perspective of difference" (pp. 199-200). Rojas (2007) makes a very similar argument when she outlines her proposal for an "IPE [International Political Economy]/development otherwise" (p. 585). While noting that the fields of IPE and development studies have begun to incorporate a recognition of cultural difference, Rojas argues that they continue to ignore coloniality by "forgetting" the relationship of colonialism to modernity and capitalism, ${ }^{52}$ and dismissing alternative rationalities ( $\mathrm{p}$. 574). Further, IPE and development studies suppress noncapitalist alternatives by depicting capitalism as hegemonic and ignoring economic diversity (p. 574). Therefore, an IPE/development "otherwise" would require two major transformations: first, it requires a disidentification from capitalism, thereby making economic difference visible and preventing non-capitalist alternatives from being marginalized (p. 574); second, it requires decolonization, which is possible by including "proposals from marginalized cultures" and learning from the work of postcolonial and postdevelopment thinkers, and in particular the MCD school (p. 574, 582).

Escobar and Rojas are thus moving towards the same centre: Escobar wants to lead his fellow MCD theorists towards an analysis of economics that emphasizes difference, whereas Rojas wants to move political economy/development towards both economic difference and MCD. In both cases we therefore find an integration of the analysis of modernity/coloniality with post-structural political economy. Further, in both cases the authors assert the centrality of the concept of economic difference, which serves

52 The point that Rojas (2007) makes here is probably not so much that political economists ignore the historical relationship of colonialism to capitalism and development-although this could be the intent - but rather that political economists, including dependency theorists, read "the political economy of the south through the lenses of European capitalism" (p. 580), rather than incorporating "proposals from marginalized cultures" (p. 574). 
in their view as a fundamental critique of both conventional economics and Marxist

political economy. To investigate further how economic difference constitutes such a critique, it is helpful to look at the two main sources Escobar (2008) relies upon (as outlined on p. 73); namely, the economic anthropology of Stephen Gudeman (1986; 2001), and the post-structuralist political economy of J.K. Gibson-Graham (1996; 2006)..$^{53}$

According to Escobar (2008), established political economy approaches have taken "the economy" for granted, performing "an analysis of capital largely in terms of structures and devoid of culture" (p. 73). For this reason, Gudeman's (1986; 2001)

account of economics as culture is seen as a welcome alternative. The main argument put

forward by Gudeman (1986) is that universal economic models-whether neoclassical or Marxist ${ }^{54}$-are not appropriate for analyzing other (i.e. non-Western) societies, because

53 There is a third, parallel argument from the Subaltern Studies school which is relevant here, but which is not explicitly utilized by post-development theorists. Chibber (2013) summarizes the argument as follows: "if the social matrix and developmental arc of the modernizing Global South are not the same as those of early modern Europe, if their dominant political and cultural forms depart so radically from those of the modern West, then the theories imported from the West cannot be appropriate to the study of Eastern settings. As a result, the East needs its own, sui generis theoretical categories" (p. 14). This is more of an historical argument than those utilized by Gudeman and Gibson-Graham, but it nonetheless leads to the same basic conclusions. As an historical argument, however, it depends upon certain claims made about the history of India which suggest the radical specificity of colonial capitalism: for example, Subalternists claim that the Indian bourgeoisie failed to become hegemonic, that capitalism failed to universalize, that power operated in a different form, etc. (see pp. 12-20 for an overview). In each case, because India's development was fundamentally different from the West, Subalternists proclaimed the inappropriateness and Eurocentrism of classical theories, such as Marxism. However, as Chibber carefully and compellingly argues, each of these claims are inaccurate, based on misreadings of history and/or erroneous understandings of the logic of capitalism, and therefore their conclusions are groundless; rather than being constituted by fundamental differences (an idea which for Chibber promotes a renewed Orientalism), East and West are subject to "the same basic forces [of which capitalism is one] and are therefore part of the same basic history" (p. 291, emphasis in original). In that case, analyzing those forces "must, of necessity, draw on the universalizing categories of postEnlightenment theories" (p. 243).

54 This charge that Marxism presents a "universal" economic model in the same way as neoclassical theory is to conflate two very different exercises: neoclassical theory assumes that the economic behaviour it describes is universal and reflecting human nature rather than specific to capitalism, and therefore projects onto other societies (in space and time) a certain economic rationality that doesn't necessarily exist. This is known as formalism. Marxist economic theory is first and foremost a critique of capitalism, and so its "model" is only universal within capitalism, which is explicitly an historicallyspecific set of social relations. 
"economies and economic theories are social constructions" (p. vii). To the extent that universal models appear to be functional this is because they tend to prove a confirmation bias; that is, they are merely "reflexive projections" in that the "reconstructed data can only point back to the axioms at the core of the model" (p. 34). Instead of reflecting universal patterns of human behaviour, Gudeman (1986) argues that "securing a livelihood ... is culturally modelled in all societies" (p. 37, emphasis added); therefore understanding the economic practices of other societies requires attention to local models and constructions (p. 142). ${ }^{55}$

Although Gudeman (2001) has constructed his own framework for analyzing local economic models, ${ }^{56}$ this is not utilized in any detail by Escobar. Rather, Escobar (2008) draws upon the more general arguments made here, in particular the critique of universal models and the imperative to investigate local economies on their own terms (pp. 73-4). Moreover, by revealing all economic forms as cultural constructions, this analysis opens the possibility of alternative organizations of economic activity, based on alternative (cultural) motives and desires.

The second major source that both Escobar (2008) and Rojas (2007) draw upon to argue for the concept of economic difference is the work of post-marxists GibsonGraham (1996; 2006). What is of particular interest here is the critique of what Gibson-

55 For example, contrary to the assumptions of standard economic theory, Gudeman (1986) points to communities where economic activities are embedded in social relationships (pp. 141, 108), including instances where the production of crops for purposes other than exchange "defies market theory that presumes humans by instinct or natural desire produce only for exchange" (Gudeman 2001, p. 47).

56 According to this framework, economic practices and relationships are depicted as divided between two realms: the community (up-close) and the market (far-distant). These realms are in a dialectical relationship, and can both complement and be in conflict with each other (Gudeman 2001, pp. 1, 5, 1012). Within these realms of activity are several value domains: the base, social relationships, trade, and accumulation (p. 5). Interestingly, the base broadly "consists of a community's shared interests," including both produced goods and knowledge/beliefs, which "express identity in community" and are unpriced (pp. 7-8). 
Graham (1996) refer to as "capitalocentric" discourse, in which "other forms of economy ... are understood primarily with reference to capitalism" (p. 6), either as "the same as, the opposite of, a complement to, or contained within [capitalism]" (GibsonGraham 2006, p. 56). This tendency is attributed to "most economic discourse" (GibsonGraham 1996, p. 6; 2006, p. 57), but the main target of this critique is clearly Marxism (Gibson-Graham 1996, pp. 5-11, 251-265). From a capitalocentric standpoint, to the extent that non-capitalist forms of production are even recognized, they exist within the "container" of capitalism, and therefore remain subordinate to it (Gibson-Graham 1996, p. 258). As Gibson-Graham (1996) warn, by invoking capitalism "in every social dimension" we have allowed it to "colonize the entire social space" (p. 259), so that "there's no room for anything else" (p. 263). Therefore, by assuming the hegemony of capitalism (p. 2), and naturalizing capital as "the central organizing principle of social life" (Escobar 2008, p. 74, emphasis in original), even critics of capitalism end up reinforcing its strength due to the inability to imagine alternatives in their own right (Gibson-Graham 1996, p. 4).

The central purpose of Gibson-Graham's work is therefore to de-centre such capitalocentric discourse, and to challenge especially the notion that capitalism is the "hegemonic, or even the only, present form of the economy" (1996, p. 2). This deconstructive exercise opens up space for the constructive elements of their project; that is, "to discover or create a world of economic difference" (p. 3), and to build upon that basis a "politics of economic possibility" (2006, p. xxxiii). The concept of economic difference invoked here is then developed and elaborated through a number of theoretical re-conceptualizations that target Marxist analysis and are thought to allow for alternative 
economic imaginaries and projects.

First, the concept of class is reformulated ${ }^{57}$ to refer to a social process that involves both the exploitation and the distribution of surplus labour (Gibson-Graham 1996, p. 52, 17; Gibson-Graham, Resnick \& Wolff 2000, p. 5). By extending the range of class processes in this way, it is possible to see exploitation and distribution of surplus labour "potentially taking place in all sites where work is performed-households, family businesses, communal or collective enterprises, churches, schools" and so on (GibsonGraham 1996, p. 17). This inclusion of distributive flows of surplus into the analysis of class thus allows one to connect the "moment of class exploitation" to other relationships in society beyond those directly involved in production (Gibson-Graham, Resnick \& Wolff 2000, p. 5). This, in turn, legitimizes class struggles outside of the domain of production, such as conflicts over the distribution of surplus. Struggles for stakeholders' rights, aboriginal rights, and environmental rights are no longer seen as subordinate to labour rights, but important in and of themselves (Gibson-Graham 1996, p. 165, 178), allowing "people to make claims on resources and flows of wealth where previously they had none" (p. 204).

Second, the space of legitimate struggle is moved from the global and structural to the local and contingent. As Gibson-Graham (1996) argue, when capitalism is viewed as a "unified system or structure," it leads to the assumption that "local and partial efforts of transformation" are futile and illegitimate, for they will always be subverted at another

57 The Marxist concept of class is a technical relationship to the means of production, which allows us to emphasize property ownership and exploitation. For post-structuralist authors (especially Laclau \& Mouffe [1985] and Gibson-Graham [1996]) this conception is problematic: beyond the reasons listed here, there is an assumption that this technical or "objective" category immediately corresponds to a social group and identity, so that the "working class" will inevitably identify as such. I have argued in the Introduction and in this chapter below that this is a misunderstanding, and that there is no automatic link between class and identity. 
"scale or dimension" (p. 256). In other words, capitalism "must be transformed in its entirety or not at all” (p. 256). However, recognizing economic difference opens up space for a politics of possibility in the "here and now" (Gibson-Graham 2006, p. xxvi). Such a politics may not involve systemic transformation, but is nonetheless "visible and replicable" immediately (Gibson-Graham 1996, p. 264). The authors compel us to take the role of place seriously, and to think of the local not as always subordinated to the global, but rather as the "ultimate locus of transformative politics" (Gibson-Graham 2006, p. xxvi).

The third theoretical innovation I want to discuss here, and perhaps the most influential and useful for post-development theory, is Gibson-Graham's (2006) diverse economy framework (See Figure 1). As the authors intend to show with this framework, our societies, despite commonly appearing to be capitalist landscapes, can be read as "landscape[s] of economic difference, populated by various capitalist and noncapitalist institutions and practices" (p. 54). Included here are various types of transactions, enterprises and labour, which are read as being alternative capitalist or even noncapitalist. ${ }^{58}$ In addition to illustrating the existence of economic diversity, this presentation is intended to suggest that there is no predictable relationship between these economic forms and practices, calling into question the "hegemonic capitalocentric dynamics" of accumulation, etc. (p. 71). Through this framing, capitalism loses its allencompassing and over-powering character and "becomes just one particular set of economic relations situated in a vast sea of economic activity" (p. 70). This transformation in understanding the economy is what allows for a new political

58 These distinctions between what is capitalist and what is not are dependent on an implicit and problematic definition of "capitalist" which is quite narrow and lacking any reference to capital itself. This will be discussed in more detail in Chapter Four. 
TRANSACTIONS

LABOUR

ENTERPRISE

\begin{tabular}{|c|c|c|}
\hline MARKET & WAGE & CAPITALIST \\
\hline ALTERNATIVE & ALTERNATIVE & ALTERNATIVE \\
MARKET & PAID & CAPITALIST \\
Sale of public goods & Self-employed & State enterprise \\
Ethical "fair trade" markets & Cooperative & Green capitalist \\
Local trading systems & Indentured & Socially responsible firm \\
Alternative currencies & Reciprocal labour & Nonprofit \\
Underground market & In-kind & \\
Co-op exchange & Work for welfare & \\
Barter & & \\
Informal market & & NONCAPITALIST \\
\hline NONMARKET & UNPAID & Communal \\
Household flows & Housework & Feudal \\
Gift giving & Family care & Slave \\
Indigenous exchange & Neighbourhood work & \\
State allocations & Volunteer & \\
State appropriations & Self-provisioning labour & \\
Gleaning & Slave labour & \\
Hunting, fishing, gathering & & \\
Theft, poaching & & \\
\hline
\end{tabular}

Figure 1. The Diverse Economy Framework. Source: Gibson-Graham 2006, p. 71.

imagination to be fostered, which can build upon existing economic difference to experiment with alternatives at the local level (p. 1, 194-6; Gibson-Graham 1996, pp. 263-5).

Thus, Gibson-Graham $(1996 ; 2006)$ have provided new theoretical tools for analyzing and describing what post-development theorists have always been arguing; that noncapitalist practices still exist, are legitimate and are capable of being sources for 
transformation. ${ }^{59}$ The critique of capitalocentrism provides support to Rojas's (2007) challenge to political economy approaches, particularly those which depict alternative forms of economy as inferior to or "in the process of transition to" capitalism (p. 574). By framing the economy in terms of diversity, it is possible to "resist the tendency to see all forms of economic activity as becoming capitalist merely because they interact with capitalism" (Escobar 2008, p. 101), and to finally see noncapitalist economic practices "in their own right" (p. 74).

For example, in Escobar's (2008) search for concrete instances of noncapitalist practices, Gibson-Graham's (1996) reformulation of class as process is very helpful, for it allows the analysis to centre on struggles over class processes of distribution. As Escobar (2008) emphasizes, "noncapitalism is defined not in terms of the control over the means of production but in terms of the circulation and appropriation of surplus labour and surplus value" (p. 74). This shift is relevant to how he approaches his case study of AfroColombian communities in the Pacific region (p. 74), which includes descriptions of cooperative shrimp-farming enterprises with a "process of governance that favours a fair distribution of wealth" (p. 101). By focusing not on how these enterprises produce wealth but on how they distribute it, and because this distributive process appears to be informed by the "logic of nonhierachy" rather than "hierarchical principles" (p. 101), Escobar can argue that these enterprises may constitute an economic form that cannot be described, strictly speaking, as capitalist (pp. 100-2).

Beyond the usefulness of these analytical frameworks, the "postcapitalist" politics

59 For example, take Mignolo's (2002) critique of the "image of capitalism as a totality that erased all other existing economic alternatives from the face of the earth" (p. 75). As he argues, capitalism may have overpowered other economic practices, but it has not erased them, and it is important to highlight those alternative economies which exist in tension with capitalism in order to locate potential alternatives to capitalism (pp. 75-7). 
of Gibson-Graham (2006) also prove to be appealing to post-development theorists, as both perspectives privilege the local as the appropriate site of politics and transformation (I will discuss the importance of place in more detail below). This is in contrast to the "politics of empire" that assumes "localized actions" to be merely reformist or accommodating (Escobar 2008, p. 67). By seeing noncapitalist activities as not only prevalent but viable (Gibson-Graham 2006, p. xxiv), Escobar (2008) can claim that there are other ways of organizing "material and social life" (p. 74) beyond development/modernity.

There is another aspect to Gibson-Graham's (2006) argument which is highlighted by Rojas (2007) and touched on but not emphasized by Escobar (2008), and which will become very important to my discussion in the next Chapter; namely, the assertion that the main obstacles to non- or post-capitalist practices are not structural constraints but "reluctant" subjectivities. Gibson-Graham's (2006) anti-essentialist approach leads them to argue that forces do exist which constrain activity, but that these have no structural reality, they are merely the "contingent outcomes" of decisions and practices (p. xxxi). What appear to be structural constraints are actually the "sedimentation[s] of practice[s]" (p. xxxiii) of individuals who have a "libidinal investment" in capitalism (p. xxxxv), or whose subjectivities have been "capitalized" (Escobar 2008, p. 100). This claim is related to the shift in emphasis from production to distribution. As Rojas (2007) argues, "the understanding of capitalism as a form of production limits the role that culture and subjectivity can play in the dislocation of capitalism" (p. 578), whereas by emphasizing distribution, we can see that the hegemony of capitalism is due to "the type of subject that makes capitalism function" (p. 579). In order to break from the hegemony of capitalism, 
then, it requires the "self-cultivation of subjects ... who can desire and enact other economies" (Gibson-Graham 2006, p. xxiii). This idea is central to Rojas's (2007) proposal for an IPE/development otherwise, which is described as "an ethic-political project asking for subjectivities able to disidentify from capitalism and to desire and create diverse economies" (p. 585).

Given the complementarity between the perspectives and goals of GibsonGraham and post-development theory, there should be no surprise that the former have come to refer to some of their own work as post-development. ${ }^{60}$ By providing postdevelopment theorists with a more theoretically rigorous language for making their arguments for economic difference, the diverse economies framework allows them to more accurately investigate and envision "the material and cultural reality of most people on the planet" (Escobar 2008, p. 75). ${ }^{61}$

\section{II: Locating Alternatives to Development}

We have seen that alternatives to development are to be built upon an "economic difference" which cannot be reduced to the terms of the models or languages of capitalism. While Gibson-Graham (2006) are interested in seeking out economic difference in both developing and (de)industrialized contexts, ${ }^{62}$ post-development

60 See Gibson-Graham (2005). Here they define "postdevelopment" as "a set of thinking and doing practices that are guided by a distinctive ethical stance" (p. 4); also, "to imagine and practice development differently" (p. 6). It is also interesting to note that they refer to Escobar and Gudeman as influences on their work, as well as involved in complementary projects (Gibson-Graham 2006, p. xiv).

61 However, as Rojas (2007) points out, Gibson-Graham do not "aim to decolonize political economy" (p. 580), which is why it is important to bring political economy perspectives such as theirs into engagement with the MCD school.

62 The application of the framework of economic difference to (de)industrialized communities has some significant pitfalls when used to justify postcapitalist politics, as argued below. I should also note that Gibson-Graham's analysis is not looking for alternatives to modernity, and so there is no reason to assume that theorists such as Escobar or Mignolo would find those examples sufficiently radical. 
theorists focus their attention almost exclusively on the subaltern peripheries of the capitalist world system. ${ }^{63}$ Although post-development theorists clearly favour the latter, this focus should not be seen as foreclosing the possibility of transformative change coming from within Western societies. At some level, these authors hold onto the possibility that alternatives based on economic difference could appear anywhere. For example, Escobar (2012) draws attention to what he refers to as "transition discourses" or TDs, which include a broad sample of cultural and ecological critiques of civilization and industrialization, and which have in common their proposals for a "transition to an altogether different world" (p. xx). Proposals for post-fossil fuel societies ordered according to new principles of sustainability, for example, are considered inspiring, if modest, steps in the right direction (pp. xxiii-xxiv). But in order to be an alternative to development, rather than simply an alternative development, Escobar suggests that transition is necessary at the level of the "entire model of society," ${ }^{64}$ and this emphasis is strongest among indigenous movements, and to a lesser extent peasant networks and food sovereignty movements (pp. xxvi-xxv) ${ }^{65}$ Therefore, while in principle alternatives to development could emerge anywhere, in practice these only seem to be found among groups on the margins, and especially those that are able to maintain some level of subsistence.

63 Early post-development literature did suggest the necessity of change to occur within the "developed" countries, but this primarily took the form of proposals for seeking sustainability through reducing consumption and living frugally. See especially Sachs (1997) and Rahnema (1992).

64 It is difficult to make sense of this emphasis of society-wide transformation for Western societies while simultaneously resisting the transformation of non-Western societies. I have to assume that this inconsistency is related to the critique of modernity/coloniality: Western societies must transcend their modern and colonial character while non-Western societies must reject the imposition of those forces.

65 Presumably, this is because their movements already represent the non-modern and non-capitalist social relations which Western societies are meant to emulate - in this case, they do not actually want transition at the entire level of their own society, as Escobar's wording may suggest. This raises a provocative question: if Western societies are meant to transform and restructure themselves in order to emulate the principles of non-modern societies, how is this not modernization in reverse? 
Post-development theorists have often categorized together indigenous peoples, peasants, and other cultural or "traditional" societies as a single, if diverse, group ${ }^{66}$ First and foremost, this is because what they have in common are their subsistence livelihoods. ${ }^{67}$ There are a number of different ways of conceptualizing this. Shiva (2005) writes about sustenance (or living) economies, where "people work to directly provide the conditions necessary to maintain their lives" (p. 17), whereas Parajuli (2004) uses the term "ecological ethnicities" to refer to "any group of people who derive their livelihood through day-to-day negotiation with their immediate environment” (p. 236). Together, these categories encompass indigenous peoples, peasant agriculturalists, nomadic shepherds, and people who depend on craft production or artisanal fishing for their livelihoods (Shiva 2005, p. 17; Parajuli 2004, p. 236). This categorization roughly correlates with Esteva \& Prakash's (1998) concept of "social majorities," which refers to people who are not fully immersed in the formal sector or the Western way of life, and whose idea of the "good life" is "shaped by their local traditions" (p. 16n2). ${ }^{68}$

66 This appears to be a mostly non-reflexive move; while post-development theorists would be the first to say that these communities and societies possess an irreducible diversity and cannot be generalized, they nonetheless do not seem to have thought through whether their framework is an appropriate way to connect them as a unified group.

67 I suspect that the use of the concept of subsistence - or "sustenance" in Shiva's (2005) formulationdoes not necessarily suppose that these communities are producing the bare minimum necessary to survive, but rather this term is likely used to signify autonomy from the market. Subsistence and autonomy, however, are not the same thing; not only is it possible to imagine the socialization of production as both autonomous from the market and productive of a surplus, but one could also imagine subsistence economies with labour subsumed under capital and therefore captive to the market (see Chapter Four for a further discussion of subsumption). On the other hand, environmental sustainability and simplicity are often put forward as virtues against consumerism and industrialization (see Chapter One), and so it is possible that some of these authors actually do mean subsistence in the sense of not producing a surplus beyond what is necessary for reproduction.

68 The concept of "social majorities" is accompanied by its opposite, the "social minorities." In this general framework, "social minorities" are those people who adopt modernity and the Western way of life, are usually among the upper classes, and are immersed in the formal economic sector (Esteva \& Prakash 1998, pp. 16-17n2). What exactly "the Western way of life" refers to is not immediately obvious, but it seems to correspond to what the authors describe as the "goods" and "services" promised by development and globalization: "ballot boxes, health care, schools, paved roads, telephones, superhighways, flush toilets, toilet paper, among others" (p. 10). This is an imprecise definition, to say the least. 
In every formulation, this diverse group is depicted as under threat from Western society and/or capitalism, which has values and practices which are fundamentally opposed and damaging to subsistence livelihoods. According to Shiva (2005), economic practices in these societies are organized around principles of cooperation, mutuality, and the production for consumption rather than exchange (pp. 54-5). Therefore, when markets are dis-embedded from social relations, they threaten the internal cohesion and even the existence of these "non-economic cultures" by replacing the needs of people and society with the abstract economic logic of greed and profit (Esteva \& Prakash 1998, p. 10; Shiva 2005, pp. 18-9). Moreover, these societies are seen as dependent upon ecological processes which they maintain, regenerate, and rejuvenate (Paraguli 2004, p. 238; Shiva 2005, p. 63), which are directly threatened by processes of capital accumulation, especially when involved in the extraction and commodification of natural resources (Parajuli 2004, p. 236; Shiva 2005).

For these reasons, social majorities are seen as having in common (at least latently) a "radical post-modernity" (Esteva \& Prakash 1998, p. 192), ${ }^{69}$ or elements of what Shiva (2005) refers to as "Earth Democracy," which is "both an ancient worldview and an emergent political movement" (p. 1). On one hand, this involves an element of opposition, directed towards modern ideologies and the "Global Project" of modernization (Esteva \& Prakash 1998, p. 1), and against the displacement, commodification and privatization of the commons (Shiva 2005, pp. 2-3). On the other

69 When Esteva \& Prakash (1998) discuss modernity, it is clear that they consider it to be the same as modernization, which they understand as the adoption of beliefs and ways of life that destroy cultures and traditions. They show no subtlety in their disapproval for what they call a "modern holocaust": "Modernization has been for [the non-modern grassroots communities], and will continue to be, a gulag that means certain destruction for their cultures" (p. 2). Post-modernity then means a rejection of modernization (and of human rights and other "sacred cows" of modernity that are used to oppress the grassroots), and reclaiming cultures, traditions and non-modern livelihoods (p. 5, 9). 
hand there is a constructive element, in that these groups seek to protect and strengthen their economic difference. For post-development theorists, these groups are advancing "proposals about initiating alternative modes of production, consumption and distribution" (Parajuli 2004, p. 241), supported by political demands for self-sufficiency and autonomy (Esteva \& Prakash 1998, p. 26), and for the right to sustenance (Shiva 2005, pp. 9-10). Esteva \& Prakash (1998) explain the radical potential of these projects:

Post-modernity already exists where people refuse to be seduced and controlled by economic laws. It exists for peoples rediscovering and reinventing their traditional commons by re-embedding the economy (to use Polanyi's expression) into society and culture; subordinating it again to politics and ethics; and marginalizing it - putting it at their margins: which is precisely what it means to be a 'marginal' in modern times (p. 194).

Most, if not all, alternatives to development located by post-development theorists are understood to share these general features, holding onto subsistence-based practices of economic difference that are oriented towards the needs of the community, and protecting those practices against the threat of external market forces which would dissolve community ties. One clear example of this in practice is the food sovereignty movement — and in particular the peasant network La Via Campesina which popularized the concept — which promotes an agrarian model based on small-scale farms and peasant agriculture, and mobilizes against threats to farmer control over production such as the liberalization of agricultural markets and the commodification of seeds (Desmarais 2007, pp. 34-9; Escobar 2012, p. xxv; Shiva 2005, pp. 145-152). In doing so, La Via Campesina is seen to be putting forward a "decolonial option," in that it "opts for and chooses the freedom of their own sense of economy and their own destiny by working for 
themselves" (Mignolo 2011, p. 299). Or put another way, food sovereignty is decolonial because its "rationality decolonizes and decentres the capitalist logic of food production and exchange" (Rojas 2007, p. 584).

Other movements have gone even further in promoting their visions of economic difference in ways that have influenced broader societal frameworks. While indigenous struggles have always been an emphasis for post-development, ongoing indigenous-led movements in Latin America have generated a lot of recent attention and excitement for the way they are transforming politics in places such as Bolivia, Ecuador and Chiapas (Escobar 2010, pp. 26-32; Mignolo 2011, p. 229). The recent introduction of indigenous concepts into the constitutions of Ecuador (under Correa) and Bolivia (under Morales) in 2008 are of particular interest, as these inclusions appear to be turning the existing institutions in a new, decolonial direction (Mignolo 2011, p. 312), moving towards epistemological change (Rojas 2007, p. 584). The central indigenous concept in question, sumak kawsay (in Quechua), suma kumana (in Aymara), or Buen Vivir (in Spanish), is taken from Andean philosophy and can be translated as "to live in fullness, to live in plenitude" (Mignolo 2011, p. 306), or as "collective wellbeing" (Escobar 2010, p. 21). It involves living in harmony, not only among humans but including "all living organisms" (Mignolo 2011, p. 308). This is seen as a profound advancement, for it introduces a "different philosophy of life" into visions of society, and an ethic of development that "subordinates economic objectives to ecological criteria, human dignity, and social justice" (Escobar 2012 xxvi). Relatedly, the inclusion of Rights of Nature in the Ecuadorian constitution represents a (potential) "civilizational transformation" by 
challenging the modern ontology which separates humans from nature, emphasizing interconnectedness and opposing exploitation and destruction (p. xxvii).

However inspiring, these transformations are also recognized as contradictory. For even as the Ecuadorian constitution of 2008 included the rights of nature and a vision of development consistent with sumak kawsay, it nevertheless stood in tension with the country's modernizing and resource-driven developmentalist Plan for 2007-2010 (Escobar 2010, p. 20-26). Similarly, the reflection of indigenous worldviews in the Bolivian constitution is clearly contradicted not least by the country's neo-extractivist economic model (Escobar 2012, p. xxx). ${ }^{70}$ The dependence of these New Left governments upon the exploitation of natural resources is the most visible source of tension between themselves and indigenous philosophies, but the conflict goes deeper than that. As Mignolo (2011) argues, "Development" promotes competition for success, rather than harmony and cooperation (p. 311), and therefore living according to sumak kawsay (when the concept is not co-opted) is completely incompatible with development and capitalist society (p. 309).

Following the Aymara sociologist Félix Patzi Paco, both Mignolo (2011) and Escobar (2010) see these indigenous concepts, and the social movements proposing them, as "advancing in a noncapitalist direction, toward the 'communal"' (Mignolo 2011, p. 310; Escobar 2010, pp. 34-8). The "communal," or the "communal system"-distinct from Marxist versions of the commons (Mignolo 2011, p. 319) —11 —refers to a "type of

70 More recently Escobar has drawn on the work of Eduardo Gudynas to argue that a model of "indispensible extractivism" may be appropriate. Such a model would supposedly allow for extractive operations under a different development model, such as Buen Vivir, by being directed only towards meeting essential goals (such as the reduction of poverty). This point was made during a panel at the Canadian Association for Latin American and Caribbean Studies (CALACS) congress, Carleton University, May $4^{\text {th }} 2013$.

71 This is Mignolo's argument, but it would be worth exploring further whether "the communal" is really that different from Marxist versions of the commons, or if there is compatibility between these 
social organization that was disrupted by European invasion, but that nonetheless subsisted for five hundred years" (p. 320). It consists of the "collective management of resources," as well as rights to "use and benefit from what is collectively produced and shared" (p. 324). As Mignolo argues, even though these communal systems are emerging from localized "memories and lived experiences" (p. 328), it is possible to consider the communal as an alternative to development with a global scope, as similar arrangements elsewhere have also been dismantled by capitalism. These local struggles can therefore connect to something larger by putting out "an invitation to organize and re-inscribe communal systems, all over the world" (p. 328). ${ }^{72}$

Finally, one recent and prominent framework for understanding alternatives to development, and which could probably be applied to many of the alternatives described above, centres on the concept of "life projects." Escobar (2008) uses this term when describing the goals and desires of the Afro-Colombian communities he works with, but the term itself appears to originate with the work of Mario Blaser (2004a; 2004b; 2010), an Argentinian-Canadian anthropologist working with indigenous peoples in the Paraguayan Chaco. Life projects are place-based alternatives to development which are "embedded in local histories," advancing different goals and visions of the world (Blaser 2004a, p. 26). As such, they are often seen as being "in the way of development," and vice versa (p. 26), although their opposition to development is always contingent upon

\section{perspectives.}

72 See also Raul Zibechi (2010) for a discussion of "the communal" as practiced by Aymara communities in El Alto, Bolivia. Beyond the collective management of resources, Zibechi emphasizes the "non-state" political character of the communal: the logic of the communal system is one of "community-based power," in which political representation is not elective but rotated among the community; this is said to prevent the concentration of power, and keeps power located within society, rather than separated by means of specialized and hierarchical political bodies (pp. 12-16). Zibechi goes further to explain how migrant communities brought the communal system from the rural into urban areas, translating it into neighbourhood organizations with regulatory power "from below" over economic and political decision-making (pp. 17-31). 
whether it furthers or hinders their own goals (p. 35). Although life projects are clearly most compatible with the subsistence-based economic practices discussed above, the concept itself implies no specific economic content. Instead, life projects are fundamentally about governance (Blaser, Feit \& McRae 2004, p. 2) ${ }^{73}$ As Bruno Barras (2004), a leader of the Yshiro-Ebitsos people of the Paraguayan Chaco describes it:

We are proposing what I call a life project. I call it that because our plans and projects are oriented to achieving autonomy in deciding our own future. We do not want somebody else taking us by the hand to lead us wherever they want to go. We want to advance our own projects so that what is done in the communities has continuity and so that the knowledge and skill brought by the technicians we hire will be transmitted to our youth. We are searching for ways to unite all our communities under one organization. We are trying to recover the way of our ancestors in organizing our communities. Who better than ourselves to do this and to fight for and defend our territories? (p. 51).

What is important here is the ability of these groups to affirm their own “ontological project[s]" (Escobar 2008, p. 305), which itself requires that they maintain "a meaningful degree of control over (or, what is the same, having some degree of control over the meaning of life as being-placed-in-the-world" (Blaser 2004a, p. 34-5). This emphasis on the need for autonomy is what provides commonality among life projects ( $\mathrm{p}$. 34), rather than any specific content, since life projects are all uniquely situated and reject "visions that claim to be universal" (Blaser 2010, p. 2).

Based on this brief survey of the alternatives to development located by postdevelopment theorists, it is clear that whether they are put forward by peasant networks or indigenous communities, these alternatives involve both the protection and promotion of visions for life that are based on subsistence livelihoods of economic difference.

73 As Blaser, Feit \& McRae (2004) argue, debates over the conditions faced by indigenous peoples have seen a shift in focus over the years from "socio-economic deprivation to legal rights and governance claims" (p. 8). This is largely because the previous attention to poverty had often led to integrationist or assimilationist policies (p. 7), whereas indigenous struggles are largely aimed at achieving greater levels of autonomy. 
Rather than allowing their social and economic practices to be subordinated to Western ideals or to the market, these communities insist on maintaining control over their livelihoods, and directing them towards common social goals. In some cases, these efforts can be seen as largely defensive, such as in campaigns to resist displacement or the introduction of commodified seeds, while in other cases communities make more deliberate attempts to transform external institutional structures in ways that are in accordance with their own life projects. Regardless of the scope of action, a common requirement for all of these alternatives is the ability to maintain some measure of autonomy over their conditions of life, against the modernizing forces of development.

\section{III: Localizing Politics, Globalizing Struggles?}

In the last section, I outlined how — according to post-development theory-alternatives to development embody economic differences that point to noncapitalist ways of living in the world, and that maintaining some degree of control over subsistence livelihoods is necessary for being able to practice that economic difference. A major issue that emerges out of this discussion is therefore the problem of political organization, as the importance of autonomy calls into question how these alternatives to development, or life projects, are to relate to one another. As I will argue, the privilege that post-development theory bestows upon the autonomy of the local leads, almost inevitably, to the concept of pluriverse as the only possible means of organizing these struggles, at the expense of other strategies common to the Left.

Most post-development theorists are not content simply to defend noncapitalist places, but are looking for ways to "imagine and construct actual different worlds" in 
ways that differ from modernity (Escobar 2004, p. 220). As Escobar (2004) notes, the task of imagining and constructing such worlds requires two important considerations: "what are the sites where ideas for these alternative and dissenting imaginations will come from?" and "how are the dissenting imaginations to be set into motion?" (p. 220). For Escobar, the movements I surveyed above are already answering these questions by mobilizing around place-based politics of difference, and producing "self-organizing, nonhierarchical networks" (2004, p. 221). I have already noted above that the local is a privileged site of struggle for post-development theory, but it is worth examining in more detail why place-based struggles are so important for these authors, as this will in turn illuminate the reasons for their emphasis on autonomous organization.

For post-development theorists, the concept of place is of critical importance because it is understood to be constitutive of identity and meaning, and it is therefore the source of alternative imaginaries. Contrary to analyses of globalization and modernity which depict place as losing its relevance, Escobar (2008) argues that place continues to be crucial for the making of "worlds" (2008 p. 30). Escobar is making a phenomenological argument here, about the way that consciousness and meaning are derived from situated experiences; identity is constructed as people encounter their immediate existence (p. 234), and places are similarly "self-consciously constructed by people through active processes of work ... narratives ... and movement" (Escobar 2001, p. 148). Local knowledge and ontologies, emerging out of these interactions, can therefore be understood as a "mode[s] of place-based consciousness" (p. 153). Of particular interest here are place-based "relational" ontologies, which challenge the modern dualisms of nature/culture and individual/community (Escobar 2010, p. 39; 
Escobar 2012, p. xxviii; see also Blaser 2010, pp. 144-5). These pose a challenge to development projects in that they foster "relational moral logics": instead of proper action being determined through reference to a self-contained object (i.e. Poverty, which would necessitate the initiation of poverty-reduction schemes), moral conduct is determined by a web of relations, meaning that all moral decisions are contextual and situated (Blaser 2010, pp. 112-4). Because relational ontologies are uniquely situated in place(s), conflict arises where "effective power [is] associated with particular cultural meanings and practices," and not others (Escobar 2008, p. 14; Blaser 2010, p. xii). These struggles over meaning, or "ontological" conflicts (Escobar 2012, p. xxviii; Blaser 2010, p. 1), are at work in the Constitutional negotiations in Ecuador and Bolivia, as well as in other indigenous, Afro and peasant struggles throughout Latin America (Escobar 2012, p. xxviii), and are most visible where life projects meet modern projects (Blaser 2010).

Because meaning and identities arise uniquely out of situated experiences, defending the ability to be different has come to be seen as the same as defending life itself (Escobar 2008, p. 25), at least according to the "movement intellectuals" advancing life projects in Colombia. For them, "difference defines being" (p. 18). However, Escobar (2008) is quick to note that this emphasis on difference should not refer to some unchanging essence, but rather something that is constantly transformed (p. 18). Similarly, Blaser (2004a) eschews ideas of "essential differences" or purity in favour of hybridity and complexity, a move that has its own political risks (p. 33). ${ }^{74}$ Nonetheless,

74 The main risk involved with this move, in the context of the politics of indigeneity, is that the political success of life projects often depends on proving their purity and essential difference, which becomes a dilemma for activists and academic allies (Blaser 2004a, p. 33). As Blaser (2004b) notes, when "authentic indigenousness is conflated with objective and observable traits (from clothing to behaviours) that conform to the dominant definitions of what it is to be Indigenous," then the indigenous movement has to conform to the same images which are used by their political enemies (such as landowners) to delegitimize their agenda (p. 53). Because of this dynamic, the debate in Paraguay about Indigenous peoples has "centred on whether or not they are hunter-gatherers" (p. 66), 
control over identity and meaning is seen as irreducibly dependent upon maintaining difference, and because difference is grounded in place, the defence of territory is absolutely critical. More than just land, territory is a place-based framework which encompasses "history, culture, environment, and social life" (Escobar 2008, p. 62); in sum, it "embodies the life project" of communities (p. 59). As such, "the struggle for territory is thus a cultural struggle for autonomy and self determination" (p. 68).

If places themselves are the sources of ontological differences (and hence, identities), and if the emphasis on difference is "not about exclusion or segregation" (Escobar 2008, p. 17), as it is claimed, then the question of organizing in ways that maintain and strengthen "autonomous forms of existence" (Escobar 2012, p. xxix) must be taken seriously. For Escobar (2008), one example of ongoing attempts to "construct autonomous ways of thinking, being, and doing" (pp. 262-3) is found in the organization Process of Black Communities (PCN) in Colombia, which emphasizes discussion and consensus-building within its movement (p. 263). In particular, Escobar is interested in a new logic of networks that he calls "flat alternatives," which prioritizes self-organization, complexity, decentralization, autonomy, and "interoperability among heterogenous networks" (p. 276). In principle, these are opposed to the hierarchical forms of organization associated with modernity (p. 290), if in practice most networks embody elements of both hierarchical and "flat" or horizontal forms (p. 276). Flat alternatives provide a way of translating difference into political strategies, and therefore allowing

which doesn't allow Indigenous peoples to "form their own conceptions of themselves" (p. 67). Blaser (2010) argues that this "reification of difference" — which includes depicting the morality of indigenous peoples as "essences out of history" - continues due to the political demand for clear categories (p. 132). 
"multiple modes of knowing" to coexist rather than subsuming or reducing any of them (p. 297).

Flat alternatives can therefore be considered one way of building the pluriverse, which is usually defined in reference to the Zapatista slogan, a "world composed of multiple worlds" (Mignolo 2011, p. 234) or "a world where many worlds fit" (Escobar 2012, p. xxxviii), which itself can be understood as an argument for the universal "right to be different" (Mignolo 2011, p. 234; see also Esteva \& Prakash 1998, p. 36, for a discussion of Zapatistas and pluriverse). As Blaser (2010) argues, the key to enacting the pluriverse is organizing in a way that provides for equality and mutuality between ontologies, and "making room for indigenous peoples' relational knowledge practices to flourish" (p. 231). This itself requires that the "point of contact" between ontologies allows for two-way communication, rather than a translation or articulation that subsumes difference into mutual equivalences (p. 231, 234). To clarify:

Translation/articulation cannot be conceived of as the establishment of equivalences on the basis of an already existing common ground such as 'reality out there'; here translation/articulation is about engaging others to construct partial common grounds (Blaser 2010, p. 234, emphasis added).

According to Blaser (2010), by endeavouring to create only partial connections, we can constitute the pluriverse as "mutually related worlds yet lacking an overarching principle" (p. 237). This process of building (or recognizing the existence of) the pluriverse is the enactment of a "cosmopolitics," or a form of politics that recognizes diversity and doesn't assume the existence of a common ground or universe (pp. 19-20). In sum, cosmopolitics "works through the specificities of particular connections, seeking to enhance those that allow coexistence in the pluriverse and disrupting those that 
impoverish it" (p. 237).

Escobar's $(2004 ; 2008 ; 2010)$ focus on horizontal, autonomous forms of organization, and Blaser's (2010) focus on partial connections and cosmopolitics, leads these authors into potential tension with the strategic and organizational preferences of other actors on the Left, particularly in terms of relating to the State and building counterhegemonic struggles. As these tensions will almost certainly affect the ability of alternatives to development to articulate to broader struggles, it will be important to look at each of these in turn.

First, the principles of autonomy and self-organization lead to a skepticism of representative democracy and the State, a skepticism which Escobar shares with most post-development authors. Both Shiva (2005) and Esteva \& Prakash (1998) outline visions of a "radical" or "living" democracy that is explicitly against representative forms of democracy, achieving instead a greater degree of autonomy for communities by moving power "downward" to the grassroots (Shiva 2005 pp. 74, 75), or returning "the government of their lives into their own hands" (Esteva \& Prakash 1998, pp. 165, 158161). Rather than arguing for a greater degree of participation within the state, Esteva \& Prakash (1998) see a need for constructing structures that can serve as an alternative to nation-states (p. 41), and Escobar points out that "non-state forms of power" are already being constructed by movements throughout Latin America (Escobar 2010, p. 32;

Escobar 2012, pp. xxviii-xxix) ${ }^{75}$ According to these authors, non-state forms of power

75 In asserting this, Escobar heavily drawing on Raul Zibechi (2010; 2012), who interprets contemporary social struggles across Argentina, Bolivia, Brazil and elsewhere as the rise of a wider horizontalist (or autonomist) movement which desires autonomy from both the state and political parties. The different participants in this movement express new emancipatory practices which take "non-state form[s]" (2012, p. 80) - the piqueteros of Argentina serve as one example - existing "always outside the institutional framework" (p. 52). 
can be found taking place in the Zapatista movement in Chiapas (Esteva \& Prakash 1998, p. 185; Escobar 2012, p. xxix), and in Bolivia and Ecuador where indigenous struggles go "beyond the state" (Escobar 2010, p. 31; Escobar 2012, pp. xxviii-xxix). As Escobar (2010) seems to suggest, the State itself cannot be reconciled with the autonomy necessary for social movements to adequately express difference. In his analysis of New Left governments in Latin America, it is made clear that these governments can only be seen as moving in a decolonial, post-liberal direction in so far as they are capable of divesting the concentration of power and releasing the "autonomy of the popular sector" (p. 20), ${ }^{76}$ and he expresses doubt in the capacity of the "the State and the Left to open up to the languages and demands of autonomous movements in just this [decolonial] way" (p. 38; see also Esteva \& Prakesh 1998, p. 166)..$^{77}$

The second potential source of tension that emerges here is the difference between “cosmopolitical struggles" (Blaser 2010, p. 19) and counter-hegemonic struggles. The attitude of post-development theorists to counter-hegemony is varied and often ambivalent, and it is clear that it means different things to different people. Escobar (2004) has previously written favourably of counter-hegemonic movements, characterizing them as advancing the "goals of equality ... and difference at the same time" (p. 224). However, more recent comments elsewhere suggest that he sees an incompatibility of autonomous movements with the State and the Left (see Escobar 2010,

76 For this reason, Bolivia and (to a lesser extent) Ecuador are seen as the most optimistic examples of governments moving in a post-capitalist and post-liberal direction, due to their partial ability to accommodate the demands of indigenous society (Escobar 2010, p. 46). On the other hand, the Venezuelan case is less promising because the concentration of state power contradicts the autonomy of social movements (p. 19).

77 Despite Escobar's critique of state forms of power as being in contradiction with social movements, he has argued that we must critically support progressive governments in the region, in the hope that these New Left projects are part of a transition towards an alternative to development. This point was made during a panel at the Canadian Association for Latin American and Caribbean Studies (CALACS) congress, Carleton University, May $4^{\text {th }} 2013$. 
p. 38), and he also argues that it is important that movements "embrace transnational concerns from a position of operational autonomy" (Escobar 2008, p. 269). Given that the concept of counter-hegemony still involves hegemony - involving a combination of both coercion and consent - it is not immediately clear how far autonomy can be extended within a counter-hegemonic arrangement. Blaser (2010) takes a more oppositional view, arguing that in discourses about a counter-hegemonic globalization, other histories such as those of life projects are either absent or subsumed within that larger story (pp. 14-5). Further, the assumption within this kind of discourse is that of a common opposition to capitalist globalization, whereas such an assumption groups together an array of actors who "understand the 'reality' of capitalism and its relation to their visions in quite different and often mutually exclusive ways" (p. 236). Rather than recognizing diversity, counter-hegemonic discourse engages in an "exclusionary politics" (p. 236), silencing dissent and homogenizing the "field of social mobilization" (pp. 236-7). Far from the cosmopolitics necessary to bring forth the pluriverse, counter-hegemonic politics can be seen as actually reinforcing the "modern regime of truth" (p. 15). ${ }^{78}$

In an extreme version of the latter argument, Esteva \& Prakash (1998) reject the "fantasy of global thinking" (p. 20), which they deem to be arrogant, far-fetched and dangerous (p. 21), given that "we can only think wisely about what we actually know well"- namely, the local (p. 22). They reject "alternative" globalists for being uprooted

78 Santos, on the other hand, understands counter-hegemonic struggles as compatible with and even necessary for an "ecology of knowledges" (2006), arguing that "transnational political mobilization" is necessary to advance an agenda that could replace neoliberal institutions with ones that would allow for the alternatives as outlined in this chapter to exist and flourish (Santos \& Rodriquez-Garavito 2006, pp. xvii, xxv-xxvi). Santos (2006) also tries to carefully balance a respect for diversity with a rejection of relativism: "The point is not to ascribe equal validity to all kinds of knowledge, but rather to allow for a pragmatic discussion of alternative criteria of validity, which does not immediately disqualify whatever does not fit the epistemological canon of modern science" (p. 21). This allows for a degree of negotiation and an ability to make "political and ethical judgements" (p. 21) which is seemingly absent in Blaser's (2010) formulation of pluriverse. 
and parochial (p. 24), arguing that shared opposition can exist only insofar as it also reflects an "affirmation of a wide variety of autonomous ways to cope" with those common threats (p. 28). And so while they insist that they do advocate for "initiatives for interconnecting local struggles" (p. 32), these initiatives must above all stay restricted to the "appropriate scale;" that is, the "human" scale, "in proportion to the human capacity for knowledge and comprehension” (p. 34).

While there are clear differences between these perspectives, what they have in common is their support for horizontal networks of autonomous, place-based communities, defending relational ontologies and life projects which involve practices of economic difference. What is not clear is the extent that these political and organizational forms are capable of articulating to other struggles (especially struggles such as labour which take a more structural, and less place-based, approach) within a counter-hegemonic formation.

\section{IV: Alternatives to Development: A Summary}

As Escobar (2012) sums up ${ }^{79}$ the proposal for alternatives to development has three central aspects:

... The steady decentering and displacement of the capitalist economy with the concomitant expansion of diverse forms of economy, including communal and noncapitalist forms; the decentering of representative democracy and the setting into place of direct, autonomous, and communal forms of democracy; and the establishment of mechanisms of epistemic and cultural pluralism (interculturality) among various ontologies and cultural worlds (p. xxix).

In this chapter I have outlined these aspects in detail, breaking them down further to illustrate the theoretical foundations of the post-development concept of alternatives to

79 The following quote is itself adapted from a summary of a proposal for the 'communal,' put forward by Félix Patzi Paco. See Escobar 2010, p. 35. 
development. First, alternatives to development engage in noncapitalist practices of economic difference that must be understood on their own terms, rather than through standard economic models or through the categories of capitalism. Therefore, any analysis of these alternatives must involve a shift away from class analysis and structural power, and towards culture and subjectivity. Second, these alternatives are located almost exclusively with rural, place-based communities that are capable of maintaining some control over their livelihoods. Third, these alternatives are politically oriented towards both defending their economic difference, and promoting visions of life based on practices of economic difference (i.e. orienting economic activity not to the market but to social or cultural goals). Fourth, a fundamental principle in protecting economic difference emerges as autonomy. This involves radical democratic forms which allow decision-making at the local level, and it also implies control over territory or means of production (in the case of peasants). Fifth, in order to respect this autonomy, relations among these communities and other actors must reflect non-modern or pluriversal principles: in particular, horizontal networks between equal ontological bodies whose difference is protected from each other. This is at least potentially at odds with counterhegemonic struggles, where the emphasis is on what unites, not what divides.

In the following chapter, I will turn to critique this post-development model of social change, challenging in particular the concept of economic difference and the emphasis on autonomy. As I will argue, post-development theory not only misrepresents the relationship between capitalism and diversity, but in doing so it limits the applicability of its politics to the margins, while overlooking the potential ground for struggles in common with other social actors. Alternatively, I will show that the Marxian 
concept of uneven reification can transcend these limitations by revealing the constraints that capitalism imposes upon thinking and acting otherwise. 


\section{Chapter Four: Uneven Reification: A Critique of Alternatives to Development}

In the previous chapter, I outlined the economic and political content of alternatives to development as discussed by post-development theorists. In what follows, I will draw upon political economy, and in particular the concept of uneven reification, in order to critique the concept of economic difference and challenge the emphasis on autonomy. In doing so, I will provide an alternative reading of these alternatives to development, expanding the scope for social struggles beyond the limits established by postdevelopment theory.

\section{I: The Limits of Economic Difference}

Having explored the concept of alternatives to development and its underlying framework of economic difference, it is important to intervene and evaluate these concepts from a historical materialist perspective. This is because the concept of economic difference is based on a misunderstanding of economic diversity within capitalism, thereby leading post-development theorists to underestimate the material constraints that capitalism imposes on alternatives.

As I have shown, post-development theorists portray alternatives to development as having the capacity to re-direct economic activity away from capitalist exploitation and towards local, social and ecological aims. This is possible because there is a wealth of diverse economic forms already available, and these practices of economic difference can be captured and mobilized if we could only build the subjectivities necessary to comprehend them. To do so would require disidentifying from capitalism, rejecting its 
(illusory) hegemonic power, and re-affirming the possibility to experiment with alternatives in the here and now. In sum, the economy is a landscape consisting of a multitude of different processes and activities, and we merely need to choose to re-direct our energy away from capitalist activities and towards noncapitalist ones.

Against this version of economic difference, I will put forward a view of economic diversity as structured by the subsumption of labour under capital. ${ }^{80} \mathrm{Critical}$ to this view is the emphasis on the continued relevance of class relations in ordering social life. Although this change in approach will not stop one from affirming many of the projects and subjects promoted by post-development theory, it will also allow one to see the existence of material and subjective constraints on imagining and doing otherwise. But before I can do this, I must first address some of the criticisms of Marxist approaches to economic diversity.

First, I should take on the criticism that Marxists devalue and delegitimize noncapitalist economic practices, or view them as obsolete. Rojas (2007) argues that the depiction of noncapitalist economies as "pre-capitalist or not yet modern" (p. 581) is equivalent to labelling them as "inferior" and "in the transition to capitalism" (p. 574), thereby maintaining a hierarchical and colonial analytical framework. Similarly, GibsonGraham (1996) allege that the relation of capitalism to noncapitalism is treated as a "binary structure in which the first term is constituted as a positivity and fullness and the second term as a negativity or lack" (p. 8). While not denying that such conclusions may have been made by Marxists in the past, this attitude is in no way inherent to Marxist analysis itself. ${ }^{81}$ While I agree that the use of the term "pre-capitalist" can be

80 This argument builds upon the work of Paulson (2005).

81 Through a close reading of Marx's lesser known writings, Anderson (2010) argues that over time, the more teleological view of economic development as a unilateral process following the example of 
problematic $^{82}$ - which is why I refrain from using it myself - the fact is that the term is merely used to distinguish capitalist forms from those that they displace, which in itself does not imply a value judgement. ${ }^{83}$

This leads to the next critique, which is that Marxists do not provide an adequate analysis of economic diversity, but depict capitalism as "integrated, homogenous, [and] coextensive with the space of the social" (Gibson-Graham 1996, p. 8). However, this is to ignore (or dismiss) the various Marxist theorizations of diversity which already exist.

One important example is the concept of uneven geographical development, particularly as it is elaborated by David Harvey. In this view, “capitalism does not develop upon a flat plain surface" but is "inserted, grows and spreads within a richly variegated geographical environment which encompasses great diversity" (Harvey 2006, pp. 415-6). Although capitalism is highly destructive of existing arrangements, as it tears down barriers to capital accumulation, its own contradictions "force it to produce new forms of geographical differentiation," and it actively reconstitutes previously existing featuresincluding institutions and prejudices — which are given "new functions and meanings" ( $\mathrm{p}$. 416). Far from a depiction of homogeneity, this approach views processes of capital as

England - especially evident in the Communist Manifesto - eventually evolved into the perspective that development can take multiple forms, and that noncapitalist societies were potential sources of alternatives to capitalism (pp. 237-8, 244). Therefore, there is an underutilized trove of writings by Marx that not only challenge the typical representation of his analysis, but also provide insight into the dialectical relationship between class, gender and race (p. 245). However, it needs to be stressed that Marxists are in no way confined to the biases that Marx may or may not have had, and that regardless of his opinions on the matter, there is absolutely no reason that a Marxist analysis has to make such assumptions about the inferiority of non-capitalist societies.

82 As an historical term, "pre-capitalist" is legitimate. The problem is applying this term to describe the present, which would suggest a certain teleology.

83 I will agree with Gudeman (1986), Escobar (2008) and Gibson-Graham (1996; 2006) that because these categories always have capitalism as their referent they are not capable of analyzing noncapitalist economic practices on their own terms, but this recognition of their limits should not lead us to abandon what they can tell us about the relationship between the capitalist and non-capitalist. These categories were never intended to fully describe all aspects of social life, only the logic of capital; as such, they do have something to say about the way that capital relates to the non-capitalist, how it orders and arranges social life. 
actively and necessarily (re)creating differences. But for Gibson-Graham (2006), attempts such as Harvey's to theorize economic diversity are denied "credibility" (p. 59) and "rendered ineffectual by the hegemony of capitalocentrism" (p. 57).

Central to this critique is the post-structuralist conviction that capitalism has no structural power (Gibson-Graham 2006, pp. xxxi-xxxiii), and that the Marxist emphasis on capital needs to be replaced with an understanding of contingent relationships between a multitude of economic practices and forms.$^{84}$ This is best illustrated by returning to Gibson-Graham's (2006) diverse economy framework (see Figure 1 on p. 87). The layout chosen therein is intended to reveal a variety of economic practices which have no predictable or structural relationship, reducing capitalism to "just one particular set of economic relations situated in a vast sea of economic activity" (p. 70). This contributes to what Gibson-Graham refer to as a "weak theory of the economy:"

We approach economic relationships as something to be contingently rather than deterministically configured, economic value as liberally distributed rather than sequestered in certain activities and denied to others, and economic dynamics as proliferating rather than reducible to a set of governing laws and mechanical logics (p. 60).

By refusing to "presume that relationships between distinct sites of the diverse economy are structured in predictable ways" (p. 71), the implication would appear to be that these economic activities—whether volunteering, housework, or wage-labour —are potentially structurally equivalent, in that we cannot know in advance how they would relate to each other.

There are some significant problems with this approach to diverse economies.

84 As Glassman (2003) argues, Gibson-Graham interpret the existence of uneven development as proof that capitalism has no core or structure, and therefore no structural power, whereas what unevenness really shows is that domination is crystallized in different formations depending on the context (p. 690$1)$. 
First there is the ambiguous definition of "capitalism," which is never defined (and devoid of any reference to capital itself!), but appears to be reduced to formal market exchange, wage-labour (with compensation set at subsistence levels) and enterprises characterized by hierarchy and private appropriation of surplus (see Gibson-Graham 2006, pp. 60-8; Escobar 2008, p. 101). By narrowly reducing capitalism to these forms and activities, the diverse economies framework presents an economic landscape where capitalist activities are clearly marginal. This allows Escobar (2008) to ask "how is one to gauge the completeness or incompleteness of capitalist development?" (p. 83), and when combined with the insistence that capitalism has no structural logic, finding the answer to this question would appear to consist of merely counting economic activities.

Against this free-floating and ambiguous model of economic difference, it is important to assert a Marxist argument for an ordered or structured diversity. Far from denying the existence of economic diversity, Marxists insist that diversity is nonetheless structured, for capitalism and its class relations have a determining (but not deterministic) force which obstructs and conditions the actions that are available to us. ${ }^{85}$ Whereas proponents of the diverse economies framework argue that the notion of capitalism subsuming other economic and social content is capitalocentric, and denies the validity and independence of the noncapitalist forms supposedly being subsumed (see Escobar 2008, p. 84; Gibson-Graham 1996, p. 6), I will reclaim and advance the concept of subsumption as critical for understanding the material and subjective constraints that capitalism imposes upon imagining and doing otherwise.

The distinction between formal and real subsumption of labour under capital is

85 For a more detailed elaboration regarding this historical materialist approach as it relates to the poststructuralist methodology I am critiquing, see the Introduction. 
developed by Marx (1867/1990) in the appendix to the first volume of Capital, and it is helpful for analyzing how capitalism orders a diversity of economic and social practices without erasing them or depriving them of relevance. This distinction allows us to see varying degrees of subsumption, and a corresponding variance in openings for political alternatives. It is perhaps most clear if we first look at instances where labour is not yet formally subsumed, and where capital has a subordinate function; Marx provides the examples of usury and merchant's capital. ${ }^{86}$ In these instances, capital has not become a dominant force, for it does not intervene in production. Instead, "the immediate producer still performs the functions of selling his wares and making use of his own labour" (Marx 1867/1990, p. 1023). These articulations of capital can represent a transition to capitalism, or they can continue to survive within a capitalist framework (p. 1023).

In contrast, the formal subsumption of labour under capital occurs when "capital subsumes the labour process as it finds it, that is to say, it takes over an existing labour process, developed by different and more archaic modes of production" (p. 1021) ${ }^{87}$ For example:

When a peasant who has always produced enough for his needs becomes a day labourer working for a farmer ... what is happening is that production processes of varying social provenance have been transformed into capitalist production ( $\mathrm{p}$. 1020).

At this degree of subsumption, the previously noncapitalist labour process comes under increasing control by the capitalist, who ensures that it conforms to "normal standards of quality and intensity," and "extends its duration as far as possible" (p. 1020). Despite this,

86 Usury involves profiting from the interest on loans, while merchant's capital involves selling goods with a profit on alienation (at a higher price than you paid for them). Capital accumulates by appropriating the surplus of existing processes at a distance, without directing or controlling the production process itself.

87 Due to the frequent use of italics by Marx, emphasis is always in the original, unless otherwise noted. 
the labour process itself is not subject to substantial change, and surplus-values can only be extracted in the form of absolute surplus-values, by extending the length of the working day through compulsion (p. 1021). Formal subsumption is always the prerequisite for next level of subsumption, but again Marx makes it clear that it can continue to exist alongside more developed capitalist forms (p. 1019).

With real subsumption, on the other hand, we finally have what Marx considers a specifically capitalist mode of production, which is expressed by the systemic production of relative surplus-values (p. 1025):

That is, under capitalism, surplus is systematically achieved for the first time through increases of labour productivity, leading to the cheapening of goods and a greater total output from a given labour force (with a given working day, intensity of labour and real wage) (Brenner 1977, p. 30).

And so whereas formal subsumption simply captured existing labour processes, and implied no change in the mode of production, "technologically speaking" (Marx 1867/1990, p. 1026), a specifically capitalist mode of production "revolutionizes their actual mode of labour and the real nature of the labour process as a whole" (p. 1021).

Crucial to the process of the increasing subsumption of labour under capital is the dispossession or alienation of what Marx refers to as the conditions of labour, which is broken down into objective conditions of labour (the means of production) and the subjective conditions of labour (the means of subsistence). As he writes:

The more completely these conditions of labour are mobilized against [the worker] as alien property, the more effectively the formal relationship between capital and wage-labour is established, i.e. the more effectively the formal subsumption of labour under capital is accomplished, and this in turn is the premiss and precondition of its real subsumption (p. 1026).

Real subsumption can then be understood as the result of a specific set of class relations 
$(\text { Brenner } 1977)^{88}$ - it is only possible when previously self-sustaining producers lose their independence to the subordination under capital (Marx 1867/1990, pp. 1028-9), and when workers are forced into the labour market "in order to procure their means of subsistence" (McNally 1993, p. 31). This is because only when direct producers are removed from their conditions of production, and labour-power becomes a commodity, do capitalist market imperatives govern the labour process, which compels the constant revolution of production methods (McNally 1993, p. 31). Therefore, capitalism should be defined not in terms of its opportunities, but its imperatives (Wood 2002, p. 6; Brenner 1977; McNally 1993): ${ }^{89}$

The distinctive and dominant characteristic of the capitalist market is not opportunity or choice but, on the contrary, compulsion. Material life and social reproduction in capitalism are universally mediated by the market, so that all individuals must in one way or another enter into market relations in order to gain access to the means of life (Wood 2002, p. 7).

Moreover, it should be emphasized that capitalists are similarly subjected to market imperatives, and in particular the requirement to produce relative surplus value; this is

88 And here I must again emphasize that class is understood as a property relationship vis-a-vis the means of production. The post-structuralist formulation of class as process is interesting, and quite useful for speaking about distributive struggles over surplus. However, it obscures the role that class relationships play in ordering and constraining economic activity, as I show here.

89 For some, this is not just a logical question but an historical one. As Wood (2002) argues, elaborating arguments put forward by Brenner, the origin of capitalism as a unique mode of production only came into being with the development of a class structure that enforced these imperatives. Market dependence is not a natural outgrowth of feudalism - as constraints on exchange were removed - but is the result of social and property relations which must be created, based on dispossession of direct producers who must enter the market even to maintain subsistence (pp. 74-5, 96-7). For Brenner (1977), this explains the failure of economic growth in the Third World: "In contrast, pre-capitalist economies, even those in which trade is widespread, can develop only within definite limits, because the class structure of the economy as a whole determines that their component units - specifically those producing the means of subsistence and means of production, i.e. means of survival and reproduction, rather than luxuriesneither can nor must systematically increase the forces of production, the productivity of labour, in order to reproduce themselves" (pp. 32-3). Some have critiqued this thesis on the basis that it takes an economistic rather than dialectical approach to understanding social change, that it is anglocentric (by arguing that capitalism first fully developed in England), and that it ignores the role of the state in establishing capitalism (Heller 2011, p. 87ff, 99-101); nonetheless, regardless of its methodological flaws and contested historical accuracy, it remains a compelling explanation of the logic of capital as dependent on relative surplus-values. 
what spurs them on "to seize the initiative" (Marx 1867/1990, p. 1023), and constitutes their "drive to accumulate by means of exploitation" (McNally 1993, p. 180).

The corollary of this point is that for producers who are not completely dispossessed of the conditions of labour, there is greater ability to resist market imperatives. For peasant households that maintain "non-market" access to the means of production and/or subsistence, there is no compulsion to conform to the standards of the market; they could "continue to subsist on their own direct production and enter into market exchanges which do not conform to market rationality." In essence, they have the choice of exchange (McNally 1993, p. 176).

This elaboration of formal and real subsumption therefore provides an alternative to the post-structural conception of economic difference. To return to Escobar's question, we now have a way of answering how to determine the completeness or incompleteness of capitalist development (although posing the question that way is itself misleading). We do not tally the activities that we judge to represent the values of capital (i.e. individual profit or hierarchal relations), and then compare them to the range of activities which we deem noncapitalist; rather, we determine the degree that labour processes have been subsumed under capital, and therefore the degree to which producers are subject to market imperatives that restrict their actions. Again, this is not to overlook or to denigrate alternative economic forms, but to locate the extent to which capital is capable of ordering or limiting that diversity. If alternatives to development involve the "decentering and displacement of the capitalist economy with the concomitant expansion of diverse forms of economy, including communal and noncapitalist forms" (Escobar 2012 p. xxix), then such alternatives would appear to be dependent on maintaining access to the 
conditions of production, or require projects to re-establish that independence from market imperatives.

It is not enough to look at the material constraints that capitalist class relations impose, for they also engender a profound impact on subjectivity and the ability to imagine otherwise. As I showed in Chapter 2, reification is derived from the alienation and commodification of labour under capitalism, and it is this process which makes capitalism appear to us as a natural and necessary state of affairs, rather than as a set of historically-specific social relationships, and which eventually reduces knowledge to instrumental reason in the service of capital. In his discussion of the subsumption of labour under capital, Marx (1867/1990) makes it clear that this mystification emerges as capital increases its control over the labour process (p. 1020), and is greatly intensified by the social relations involved in the large-scale industrial process - in particular, with machinery, cooperation and the division of labour (p. 1025). ${ }^{90}$ But if capitalist reification truly emerges as a hegemonic force under conditions of real subsumption, then the corollary of this point is the recognition that reification is "necessarily much less complete in labor environments dominated by formal subsumption" (Paulson 2005, p. 51). As Paulson (2005) argues, we must see reification as necessarily uneven across space and time (pp. 13, 44):

Reification must thus be understood in terms of struggles for hegemony that take place over uneven geographies (meant to encompass unevenness within local spaces as well as hemispheric distinctions) and uneven temporalities - the latter a function of both the length of time societies have been capitalist (i.e. in which the capitalist mode of production has been dominant) and the unevenness produced by structural changes within capitalism (e.g. variations in capitalism with each successive regime of accumulation) (pp. 45-6).

90 This is in part because machinery, science, and invention appear as the direct attributes of capital, rather than as the result of social progress itself (Marx 1867/1990, pp. 1055, 1058). 
Just as capitalism develops in an uneven fashion - creating spaces of both real and formal subsumption—so does reification (p. 53). And just as capitalism is unlikely to enforce the conditions of real subsumption upon every social space, the process of reification will never be complete either (p. 56). This unevenness is potentially the source of capitalism's vulnerability, for where subsumption is incomplete, or recently established, or weak, we can expect to find conditions of "weak" reification (p. 191), and with it greater economic diversity and openings for alternative political imaginaries.

Contributing to the weak character of reification under conditions of formal subsumption are the pre-existing traditions, ${ }^{91}$ motives and cultural practices that continue to affect the ways that capitalism is locally negotiated; "reification exists everywhere capitalism is dominant, but its ability to shape our experiences is conditioned by the social and cultural constellations with which it may or may not have to compete" (Paulson 2005, p. 100). One particular challenge for reification is that it must compete with "autonomous culture;" that is, "those traditions that require a different kind of time and different sets of values than those required for efficient commodity production (this includes, for example some religious practices as well as diverse economic practices)" (p. 117). By pointing to the existence of alternative rationalities beyond those associated with capital, these "residual" or "emergent" cultural forms can provide resources for resisting the dictates of capital and its common sense (pp. 117, 136).

For this reason capitalism - and its more recent neoliberal form in particularappears to be "most insecure" where subsistence was recently the dominant mode of production, and where "residual" traditions have not yet been stamped out or

91 The use of the term "traditions" could be controversial if it was to suggest static and ahistorical practices. Rather, for Paulson (2005), traditions are "roots through which history is understood and on top of which a future is shaped" (p. 196). 
appropriated (pp. 151-2); in Latin America, resistance under conditions of weak reification frequently take the form of indigenous struggle (p. 192). It is important to note, however, that even under conditions of weak reification there is no guarantee that people will resist the encroachment of capital, even in cases where the experience of largely subsistence-based communities in voluntarily accepting seasonal wage-labour clearly belies the notion that "there is no alternative" (pp. 134-5). Moreover, even when struggles do arise, there is nothing "inherently radical" about them, as they can just as well take a reactionary character (pp. 192). Nonetheless, these spaces prove to be at least potential sources for challenging capitalist reification and implementing noncapitalist alternatives.

At first glance, the concept of reification appears to be somewhat consistent with Escobar's (2008) phenomenological approach. For Paulson (2010), imagination begins in and with our experiences, and since our experiences are different, our imagination(s) will reflect that difference (p. 33). If reification influences imagination, leading us to think in capitalist ways, this is not "because we've been duped or because we suffer from false consciousness, but because our daily routines, everything we encounter that sparks thought, is steeped in capitalist social relations" (p. 34). Similarly, Escobar (2008) emphasizes the importance of being situated in place, for it allows for the construction of place-based modes of consciousness and ontological worlds "otherwise." In other words, imagination emerges from direct experiences with the world—and it seems likely that Escobar would agree that if those experiences are increasingly shaped and conditioned by capitalism, we would expect our imagination to reflect that. Indeed, Escobar (2001) almost concedes this point, arguing that place-based modes of consciousness are still 
relevant in "contemporary societies, perhaps with the exception of those most exposed to the de-localizing, disembedding and universalizing influence of modern economy, culture and thought" (p. 141, emphasis added). It might be possible to read this as a partial depiction of uneven reification, as consciousness in "modern" societies appears to be affected and modified to a greater extent than elsewhere. However, by considering these potentially reified forms of thought as de-localized and dis-embedded, this change in consciousness is not rooted in direct, local experiences with capitalist class relations, but is instead influenced by a more general modernity. If we use the concept of uneven reification, on the other hand, we do not make this distinction between place-based and non-place-based forms of consciousness - even reified consciousness emerges from local experience, and is necessarily shaped and challenged by it.

Where the concept of reification really challenges Escobar and others is therefore in locating the main barrier to imagining and acting otherwise in capitalist class relations, rather than in subjectivity itself. As we have seen, Escobar, Rojas and Gibson-Graham insist that the economy has no structural power, and is made up of diverse economic practices which are primarily cultural in nature - and hence, subject to cultural rather than structural logics and motivations. This leads to the conclusion that we can choose to redirect those practices, that the only thing holding back our agency is the reluctance of our subjectivities. I have argued to the contrary, that as labour processes are increasingly subsumed under capital, the ability to resist market imperatives and to imagine outside of the terms of capital decreases.

How then is one to understand alternatives to development? If one accepts the post-development focus on the subjectivities necessary to utilize economic difference, 
then one might expect that the reason that indigenous, peasants and other cultural communities are capable of putting forward the most promising alternatives to development is because their subjectivities continue to resist the imposition of modernity, having experienced its dark underside and fully aware of the threat it poses to their placebased, relational ontologies. And indeed, in contexts such as these, the application of Gibson-Graham's (2006) diverse economies framework appears to work. Take, for example, Gibson-Graham's (2005) own foray into post-development work in the community of Jahna, Philippines. As they correctly point out, this community is rich with economic diversity: "there is a thin veneer of capitalist economic activity underlain by a thick mesh of traditional practices and relationships of gifting, sharing, borrowing, volunteering, and reciprocated individual and collective work" (p. 16). These relationships form the basis of what Gibson-Graham refer to as the community economy; that is, the economic practices that allow the community to "maintain [its] well-being directly," outside of the circuits of capital (p. 16), which is particularly important given the lack of wage-labour, with most enterprises consisting of the self-employed who "produce and appropriate their own surplus" (p. 13). Whereas mainstream development work would try to shift economic activity into formal, capitalist activities, GibsonGraham argue for recognizing how the community economy is already sustaining livelihoods; by doing so, a "new decision space is opened up," which allows for the community to expand upon this noncapitalist base (p. 17). ${ }^{92}$

92 It should be noted that while Gibson-Graham (2006) present their post-development approach as something new, it strongly resembles existing approaches. For example, they emphasize the need to appreciate economic diversity: they do not represent the community in terms of "lack," but start with "an appreciation of the diverse ways in which the Jagna community already produces a culturally rich and largely sustaining lifestyle" (p. 178, emphasis in original). On the face of it, this is exactly the participatory development approach referred to as Appreciative Inquiry (AI), which focuses on existing assets rather than needs. Similarly, their desire to understand and build upon that diversity, by initiating "a full audit of livelihood practices, including the contribution of nonmarket transactions and unpaid 
What Gibson-Graham (2005) themselves acknowledge in the above case study is that this community is capable of meeting its needs without depending on wage-labour. It is my contention that this is precisely why their model appears to work; in Marx's (1867/1990) terms, the community's labour processes are not fully subsumed by capital, with most of its people still retaining control over their conditions of production. In these conditions of formal subsumption or less, the independence from market imperatives and conditions of weak reification allow the community more agency to re-direct their economic activities as they see fit. This would appear to be the case with the other alternatives to development located above - in each case the material and subjective barriers that capitalist class relations impose are absent, allowing for projects of economic difference and imagining otherwise.

If this post-structuralist analytical framework is somewhat functional in circumstances of limited subsumption, it is inevitably restricted to them. It refuses to see how economic diversity is structured under conditions of real subsumption, assuming that participation in capitalism is as voluntary to those who are dispossessed from their conditions of production as those who still maintain control over them. By dismissing the structural power of capital, this approach loses much of its relevance in urban and (de)industrialized settings of proletarianization, which is evident in Gibson-Graham's (2006) unconvincing case studies of communities in Australia (pp. 131-163). While Gibson-Graham might be able to "cultivate subjects for a community economy" (p. 162) capable of discovering new ways to organize businesses and community social programs, they continue to treat material limits to constructing new economies-like unemployment

labor" in order to determine "which of these practices could be strengthened or extended" (178), could serve as a precise summary of the Sustainable Livelihoods Framework (SLF), which is itself hardly new or radical among international development practitioners. 
—as merely psychological flaws that can be overcome through linguistic reframing (pp.

131, 138-44, 152). Without attention to the material and subjective barriers that capitalism imposes, it is unlikely that post-development theory will be able to move their analysis convincingly into urban spaces.

There is still a question about co-operatives, which are discussed by Escobar and Gibson-Graham as noncapitalist enterprises (see Escobar 2008, pp. 100-2; GibsonGraham 2006, pp. 106-126). Because co-operatives can exist anywhere, in conditions of both formal and real subsumption, it might be possible to argue that these indeed overcome the limitations I have suggested about alternatives to development—perhaps subjectivity is more important than structural power? According to this formulation, these enterprises are not capitalist because, as we have already seen, capitalist enterprises are characterized primarily by their motives (for what and for whom is surplus extracted?), and their organizational structure (who makes the decisions?); therefore, capitalist firms are those which involve the private appropriation of surplus and operate on hierarchical relations. According to this logic, if enterprises involve consensus or collaborative decision-making processes, and if surplus is distributed in an egalitarian manner, they are not capitalist. ${ }^{93}$

This view is somewhat similar to that of Santos \& Rodriguez-Garavito (2006) and

93 Strikingly, the actual production and exploitation of surplus value is missing from their discussions of co-operatives vis-a-vis capitalist enterprises; in its place, all we have is the appropriation and distribution of surplus. If surplus is distributed "fairly," presumably no exploitation has occurred? Yet exploitation should not be thought of as something that occurs only when surplus is not consumed equally by all; surplus is never fully consumed, even by exceptionally greedy capitalists, for a part of it must be advanced as capital. Exploitation should instead be viewed in terms of the production of surplus value, regardless of how it is distributed, as it is the production process which is most subject to the coercive laws of competition and hence least open to negotiation. This means not understanding exploitation in moral (and therefore voluntaristic) terms, but as something that necessarily happens in the process of producing for the (capitalist) market. More on this below. 
Singer (2006), who identify worker co-operatives and so-called "solidarity economies" as alternatives to capitalist production. Solidarity economies can be understood as federations of co-operative enterprises, which themselves reject "any separation between work and ownership of the means of production, the recognized basis of capitalism" (Singer 2006, p. 3, emphasis mine). These are not systemic alternatives to capitalist production, but are intended to "carve out niches" within it (Santos \& RodriguezGaravito 2006, p. xx), embodying "organizational values and forms that are opposed to those of global capitalism" (p. xxiii) such as participatory democracy and equity (p. xxiv). The authors note that such alternatives must be based on a "realistic assessment" of the constraints of capital (p. xx), and that their feasibility depends on their "ability to survive in a capitalist context," at least for short and medium terms (p. xxi). Nonetheless, the authors regard solidarity economies as having emancipatory effects, insofar as they improve the living standards of those involved, and successful experiments are disseminated and adopted elsewhere (p. xxiii).

While these are certainly projects to be celebrated, it is necessary to look also at the limitations that subsumption of labour under capital imposes upon them. The uneven conditions of subsumption suggest that there are also uneven conditions of possibility for co-operatives to be successful. This is because co-operatives, for all the very real benefits that they provide for their members and communities, are subject to exactly the same market imperatives that "capitalist" firms are. Rosa Luxemburg (1898/2008) explained the contradictory nature of co-operatives by describing them as "hybrid" units of "socialized production within capitalist exchange" (p. 80). Although their ownership

94 In both Santos \& Rodriguez-Garavito (2006) and Singer (2006) the term "solidary economies" is used. While this is technically an appropriate usage, the term "solidarity economies" is much more commonly used and therefore I take the liberty of using it here. 
structure may differ from other "capitalist" firms, their activities are nonetheless governed by competitive pressures - thus the worker-owners are "obliged to take toward themselves the role of capitalist entrepreneur" (p. 81), driven to self-exploitation in order to ensure the survival of the firm (pp. 80-1; McNally 1993, p. 181). And even with selfexploitation, Luxemburg (1898/2008) saw that producers' co-operatives still had to find some way of circumventing the worst of capitalist competition if they were to survive, often by means of a "constant circle of customers" upon which they were dependent (p. $81)$.

This is why, for some Marxists, it is a mistake to determine "capitalist" in terms of motives or as a specific form of ownership. As McNally (1993) asserts, it is not just the capitalist that dominates the worker, but the capital relation: "capitalism refers to that specific set of social relations in which workers are subjected to the pressures of exploitative accumulation in order that the producing unit can survive in the world of commodity exchange" (p. 180). This form of domination—of the means of production over the worker - does not cease when the workers own the business, for when subject to capitalist market imperatives these firms will function as capitalist firms, regardless of their intentions. The corollary of this, of course, is that conditions of weaker subsumption would likely provide a greater possibility of co-operatives being a viable, sustainable and non-exploitative option.

This is what Santos \& Rodriguez-Garavito (2006) miss in their otherwise helpful explanation of solidarity economies, as they continue to conflate the capitalist mode of production with a firm's ownership structure, thereby overlooking the way that cooperatives are compelled to become their own capitalists. But if these authors have 
mistaken novel forms of organization and distribution for a new mode of production, post-development theorists will suggest that it is a mistake to look for new modes of production at all. Rojas (2007) directly criticizes Santos \& Rodriquez-Garavito, arguing that capitalism is not, in fact, a mode of production, and that focusing on production (rather than surplus) is itself a failure to disidentify from capitalism. On the contrary, such a focus "limits the role that culture and subjectivity can play in the dislocation of capitalism" (p. 578). ${ }^{95}$ We can see this same approach in Gibson-Graham's (2006) appraisal of the Mondragon co-operative complex, where they dismiss those criticisms of co-operatives which focus on structural limitations, and focus instead on what they deem to be most important: ethical decision-making and subject formation (pp. 103, 111). As they argue, "Mondragon's greatest achievement could be seen as the construction of communal subjects" (p. 125).

From this perspective, a focus on the restraints that market imperatives impose upon co-operatives would simply be defeatist, whereas breaking from capitalism appears to be a question of imagination. But even when Gibson-Graham outline Mondragon's practices of ethical decision-making, which are meant to prove that the critics of cooperatives were wrong, they describe a high level of co-ordination among co-operative firms that serves precisely to circumvent market imperatives, or to minimize their disruptive impact. To take just one example, the decision to set pay at the level of the community, rather than as individual firms, works to build solidarity and prevent the division that could occur through competitive wages (p. 114). Although this is not the

95 Given that Santos \& Rodriquez-Garavito (2006) had effectively defined alternative production in terms of distribution and organization (or, in other words, culture and subjectivity), it is not exactly clear why Rojas's (2007) critique is necessary, unless the real problem is the mere evoking of the term "production" itself. 
place to evaluate the conditions of Mondragon's success in any adequate manner, it would appear to be related to this ability to successfully co-ordinate the circumvention of capitalist market imperatives. ${ }^{96}$ In a way, this both confirms and denies their argument; in their favour, it speaks to the power of imagination and collective decision-making, and shows that the limitations of cooperatives as perceived by critics are "objects of struggle, rather than necessary points of weakness or failure" (p. 123). However, this misses the point: it is one thing to assert that radical imagination is critical for organizing to overcome market imperatives, and quite another to suggest that the ability to harness such an imagination proves that market imperatives do not effectively exist.

This further suggests that the framework of economic difference applied by postdevelopment theory inevitably limits the scope of its applicability to spaces where capitalist imperatives are weak or non-existent, or where organizational capacity exists to overcome them. An historical materialist approach, on the other hand, is capable of transcending this limitation. By emphasizing the role that class plays in establishing both market imperatives and reification, it is possible to see why alternatives to development might thrive in conditions of limited subsumption, but also why they might fail in conditions where capitalism is more established. This allows us to see the real obstacles that alternative economic projects face, but is also gives us insight into where we might find opportunities to exploit, and begins to lay the foundation for building alliances across unevenly reified spaces.

96 It should also be noted that Gibson-Graham (2006) themselves concede the increasing adoption of capitalist practices and exploitation within Mondragon's cooperative firms, but minimize the implications of this (p. 123). 


\section{II: Class Struggle and Counter-Hegemonic Movements}

The concept of reification reveals the class basis of alternatives to development, in the sense that they are more likely to thrive the less subsumed they are within capitalist class relations. That is by no means to suggest that they are reducible to class, only that we have to understand them in light of their property relationship(s) to the means of production, rather than focusing exclusively on how they distribute their surplus.

This argument might still be contested on the grounds that I am fitting indigenous and peasants' struggles into a class framework where they do not belong, or that their identity is not one of class, but related instead to culture or ethnicity (for example, see Alvarez, Dagnino, \& Escobar 1998; Laclau \& Mouffe 1985). However, it is possible to assert that these social movements have a class character-insofar as their struggles involve resisting dispossession and/or exploitation from capital—without reducing them only or even primarily to class. I have already argued in the Introduction that there is no direct link between class and identity - class consciousness can never be taken as a given, but is always something that must be constructed. However, class struggle does not depend upon class identity, but emerges from the fact that "the concrete conditions under which the valorization of capital is consummated are always contested" (Heinrich 2012, pp. 193-4). It is therefore possible to argue that "class struggle always exists alongside the capital relation, whether or not it is referred to as such" (p. 194, emphasis in original). This is precisely what Spronk (2013) argues when she applies E.P. Thompson's concept of "class struggle without class" to a Latin American context; resistance to class exploitation does not require class consciousness, but the latter only emerges when people "act upon their politicized notions of their class differences" (p. 78). Peasant, 
indigenous or other cultural forms of resistance to capital may not be experienced as class struggle, but that in itself does not mean that they are not, in fact, class struggles.

It is therefore possible to assert that capitalist class relations are problematic for human emancipation, both within and outside of what we might deem to be "modernity;" or alternatively, under different degrees of subsumption under capital. For some it is a question of resisting imposition and dispossession, while for others it is a question of breaking out of existing capitalist relations which control and exploit their labour-power. This raises the question of whether class constitutes common ground for articulating struggles across these uneven spaces. As I have shown, however, post-development theory puts up many barriers to this prospect, not least by minimizing the importance of class. Even though it is clear that Escobar (2008) is interested in fostering networks of struggles in common and applying the political program of post-development more broadly, he continues to define the problem primarily in terms of subjectivity, asking if “'collective disidentification with capitalism' (and with development and the strong versions of Euro-modernity) ... is an act of decoloniality in which all humans can participate?" (p. 311, emphasis mine). By posing the question this way, suggesting that we all need to find ways of disidentifying from capitalism, it is clear that he is unable to see the way that independence from capitalist class relationships is what makes "disidentification" materially possible — and therefore not immediately transferable as a political project to conditions of real subsumption.

This barrier to articulating a common project is compounded by a somewhat rigid protection of "difference" for its own sake. As demonstrated above, post-development theorists resist anything that appears to be related to modernity, on the grounds that local 
projects might be subsumed within universalistic ones, including projects of the Left.

Therefore, place-specific, localized actions are privileged, and the form of solidarity

preferred - the pluriverse - is understood as providing a space in which different

"worlds" can co-exist, with strict autonomy from each other. And so while there might be

a possibility of negotiating across "worlds," this is only insofar as such negotiations do

not in any way overrule decision-making made at the local level. The pluriverse, as a

political formation which protects the autonomous self-organizing of communities, is

seen as an end in itself rather than a means of organizing for goals that might be

privileged on the Left. $^{97}$

But what are alternatives to this conception of pluriverse? After all, one should

not be interested in abandoning the local, and neither should one understand capitalism as

erasing all difference and joining us together as a totalizing multitude (s ee Hardt \& Negri

2000). ${ }^{98}$ If one indeed recognizes and respects the desires of cultural and territorial

97 There is also, of course, the question of right-wing autonomy and reactionary politics at the local level, and whether post-development is actually supporting such activities by privileging autonomy for its own sake. While this is a problem which is sometimes acknowledged (see even Esteva \& Prakash 1998, p. 3, who argue that the KKK and neo-Nazis are grassroots movements which are not part of their project - indeed, they are "fully immersed in modernity or pre-modernity"), it is usually quickly brushed aside. Ziai (2007b) helpfully discusses the varying degrees to which this problem is present in post-development theory: he locates "two conflicting discourses" in post-development literature, both between and within the texts: 1) a "neo-populist" variant which "romanticiz[es] traditional culture, portray[s] cultures as static and rigid, is based on a complete rejection of modernity and promotes the return to subsistence agriculture;" and 2) a "skeptical" variant, which is "more skeptical in evaluating local communities and cultural tradition, more cautious in criticizing modernity, employs a constructivist perspective on culture and avoids sketching models of future transformations of society" (p. 119-20). As Ziai argues, while the neo-populist variant leads to "conservative or reactionary antimodern position," the skeptical variant leads to a position of radical democracy (p. 121). And so although critics have mostly focused on the neo-populist variant (which we see in Esteva \& Prakash), others such as Escobar have a more nuanced and less problematic position on this matter (p. 120). Still, even with a more skeptical approach, the inability or unwillingness of post-development theorists to systematically distinguish between radical and reactionary political movements raises serious concerns with their position of privileging autonomy in principle.

98 Hardt \& Negri's (2000) account of Empire, in which there no longer is any "outside," making the defence of the local counter-productive and difference irrelevant, appears to be a major source of much post-development and post-colonial distrust of the Left. 
political bodies - i.e. life projects - to retain their autonomy over their livelihoods and goals, then is it still possible for the Left to relate to them?

If the subjective effects of development are understood in terms of reification, then those in the Global South must address the issue of capitalism as much as those in the Global North, for reification only ceases when our relationships cease to be mediated by commodities (Paulson 2005, p. 19). How exactly to accomplish this, however, has never been met with a particularly satisfactory answer. For Lukács, reification would only be overcome when it was fully complete, as the negative effects of complete reification upon working bodies would unite the proletariat into a revolutionary movement, which would then "forge through it and out the other side" (Paulson 2005, p. 38). I explored some of the problems with this in Chapter Two. Apart from the question of whether reification could actually ever be complete, this position hardly seems realistic nor progressive, especially considering the potential for reification to lead instead to reactionary violence and fascism (see Horkheimer \& Adorno 1944/2002). Moreover, when Lukács (1923/1972) privileges the emancipatory and dialectical role of the proletariat, one cannot help but feel that he is taking the same methodological position as Marx (1867/1990), who in Capital assumed capitalist society to be (logically) "pure," split between the bourgeoisie and proletariat. If this was the case, the proletariat would indeed be the potential subjects capable of understanding this totality and therefore breaking from it. But if the totality of capitalist society is composed of diverse class positions, and is expanded to a global scope, then this position seems less tenable. Even when Marcuse (1964) proclaimed that revolutionary potential was now more accurately located in the "substratum of the outcasts and outsiders, the exploited and persecuted of 
other races and other colours, the unemployed and the unemployable" (p. 256), he was unable to provide a compelling reason for why that was so, and how their marginalized position could be translated from merely illustrating the contradictions of society into actually overturning it.

This is why recognizing reification as uneven is so important, because it allows us to give up on seeing liberation as only possible when reification is complete (Paulson 2005, pp. 52-3). On the contrary, those who are "best positioned to confront the behemoth of global capitalism" are those social movements that are capable of exploiting the "cracks" in reification (p. 155). This provides the potential for creating networks of solidarity where those in conditions of weak reification can actually play the stronger role. Paulson (2005) describes what solidarity across unevenly reified spaces would require:

materially linking disparate struggles together, stretching these links across different regions and social spaces such that weak links of reification can be exploited to their fullest and help pull apart those that remain stronger, increasing the realm of possibility all the way along the chain (p. 230).

Similar to the pluriversal approach, this form of solidarity would have to recognize difference, rather than universality (p. 187). However, unlike the pluriverse, the recognition of difference is less a goal than a strategic requirement; struggles against neoliberal globalization are diverse, and so a diversity of tactics, organizations and activities are required to bridge movements and put forward an agenda that meets the needs of both the Global North and South (pp. 163, 187). This also implies a similar approach to autonomy, which must not be an end in its own right, but has to mean "autonomy from capital" if it is to be progressive (p. 230n108). Indeed, building counter- 
hegemony implies persuasion — it refuses to assume that the values and goals that people currently hold are somehow perfect and sacrosanct, but are subject to change. The act of persuasion does not imply domination, but negotiation and co-operation. Convincing others to take another path is not in itself morally negative - it depends on the means and content of that negotiation.

While this would surely be anathema to Blaser (2010) or Mignolo (2011), reinforcing ties of solidarity into the construction of a counter-hegemonic movement requires that progressive forces "forge a coherent ideology without being dogmatic" (Paulson 2005, p. 189). Although a daunting task, Paulson suggests that a place to start would be "concrete action toward decommodification (and thus reification)" (p. 189). A strategy of decommodification has the potential of bringing "modern" struggles together with those promoting alternatives to development, addressing the challenges we do indeed have in common. But this will not occur if we continue to put barriers between us in the name of protecting our own differences. The question must not be one of separation, but of balance and respect; we must discover "how residual and emergent culture can be invigorated to operate against reification—moving dialectically toward a desired future, while respecting the dignity of tradition and without asserting a vanguard role" (p. 136).

\section{III: Resistance, Solidarity and Development Without Reification: A Research}

\section{Agenda}

In this thesis, I have argued that post-development theory does not see the constraints that capitalism imposes upon imagining and acting otherwise, and is therefore unable to 
explain why alternatives to development are more likely to be a possibility in certain social spaces rather than others. To achieve alternatives to development in conditions of real subsumption — where capitalism most fully regulates social life —it would require challenging the material basis of reification: alienated labour. Further, post-development theory does not see that resisting the commodification of labour is therefore a material interest that unevenly reified spaces have in common, and instead puts up unnecessary barriers to counter-hegemonic struggles. Alternatively, the Marxian concept of uneven reification, by revealing the relationship between radical imagination and the commodification of labour, can potentially provide new insight into several levels of struggle, as I will suggest below. In this section I will outline a tentative research agenda to explore these ideas further.

First, as argued above, the concept of uneven reification allows one to understand the class aspect of those movements that are identified as alternatives to development, especially indigenous and peasant struggles. The implication of this emphasis is substantial: whereas post-development theory locates alternatives to development on the basis that they manifest some epistemological or economic difference, the concept of uneven reification suggests that these differences are made materially possible because of their class character. Therefore it should not be surprising that the ability to maintain subsistence is common to the diverse movements promoted by post-development theory, including Blaser's Life Projects, Shiva's earth democracies, and to many of the peasants represented by La Via Campesina, for their alternative imaginaries and social projects are closely related to an independence from capitalist imperatives, and the non-alienation of labour. This also clearly highlights why autonomy — territorial autonomy for Life 
Projects, autonomy over livelihoods for peasants — is so important for these groups, as it protects them from the commodification of labour. To put this another way, the class basis of these groups is precisely what allows their economic activity to be "embedded" in local society, reflecting alternative cultural rationalities and goals.

Once the class basis of alternatives to development is recognized, it is then possible to evaluate the conditions necessary for the maintenance or construction of these projects, as well as to assess and resist the threats that would undermine them. Unlike what is argued by post-development theory, the decisive factor allowing such alternatives is not the absence of Western epistemologies, but rather some degree of independence from capitalist market imperatives, which is more directly threatened by mining development, the dispossession of land or the commodification of seeds. Therefore, in this perspective it does not matter whether or not these struggles are modern or nonmodern, for if the problem is reification then these struggles can take any form so long as they are anti-capitalist, challenging the commodification of labour. ${ }^{99}$

Second, the concept of uneven reification can assist in understanding the transformations taking place in Ecuador and Bolivia at the level of the state (as discussed in Chapter Three). On one hand, the ability of social movements in these countries to put forward alternative philosophical concepts, such as sumak kawsay or Buen Vivir, and to have them be at least formally recognized at the level of the state constitution, is likely related to the limited degree of subsumption of labour under capital in those countries: capitalist social relations are limited in scope, and strong traditions remain which can

99 I want to stress that the perspective that I am presenting has little to say about the specific content of these alternatives to development, which is more likely to be revealed through ethnographic work, such as that by Escobar (2008). All that uneven reification reveals is the relationship of these groups to modernity, development and capitalism, and is in no way able to predict the specific cultural forms that these movements will take. 
attest to the possibility of alternative ways of ordering social life. This reading differs from the one offered by post-development theory by locating the material base that supports the continued strength of alternative philosophies, and therefore presents a hypothesis for why this kind of transformation is occurring in the Andes, but not in Venezuela, for example. On the other hand, the capitalist imperatives which do exist, mainly at the level of the state, are certain to throw up major barriers to the actual implementation of alternative political projects. It is not just a question of disidentifying from capitalism, of breaking from modern epistemology, but of consciously overcoming the barriers to alternatives that capitalism presents.

This latter point breaks with post-development theory more decisively. Escobar (2010) explains the tension between the incorporation of indigenous concepts into these countries' constitutions and their ongoing neo-extractivist ${ }^{100}$ development programs $(\mathrm{p}$. 20) in a very different way:

[As in all cases of progressive South American governments] there is a significant gap and lack of coherence between pronouncements and the actual practice. The results, in short, leave much to be desired. This gap is not accidental; on the contrary, it reflects the fact that all of the progressive regimes continue to be trapped in developmentalist conceptions (p. 25, emphasis mine).

For Escobar, the updated constitutions fail to bring about radical change for they do not go far enough, and therefore do not adequately represent the "conceptual rupture" that would make such change possible (p. 23). ${ }^{101}$

${ }_{100}$ Neo-extractivism is discussed in detail by Gudynas (2010); the basic idea is that although the extractive sectors remain essential to a country's development strategy, this is complemented with progressive tax and royalty rates, a more active role for the state, and progressive social programs, among other features.

101 This kind of argument is repeated throughout the essay in question (Escobar 2010). To give one more example, Escobar (2010) argues that the Bolivian transformation, as articulated by Vice-president Linera, remains "within the confines of established Eurocentric and modernizing Left perspectives" (p. $30)$. 
This approach, however, overlooks other important constraints that face political actors in the context of global capitalism. To make this point, it might help to look briefly at an analogous argument in Chibber's (2013) critique of Partha Chatterjee: Chatterjee had made the claim that postcolonial India adopted a program of modernization because the Indian political elite had internalized the Western discourse of nationalism, thereby remaining captive to colonial forms of thought and subordinate to the West. Alternatively, Chibber argues that modernization was not the result of the passive acceptance of ideology, but can be explained as a rational response to the pressures originating in capitalism: the demands made upon the state by the world economy, as well as the domestic capitalist and working classes, could only be met through a modernizing agenda. Chibber's point is that Chatterjee had given too much credit to the role of ideas, while overlooking the real structural constraints of capitalism (pp. 249-50, 262-270, 2801).

In examining the cases of Bolivia and Ecuador, it seems appropriate to take an approach similar to that of Chibber. Although conceptions of the world are certainly important in influencing state policies, these may not be even the primary factors: many observers have pointed out the structural contradictions and path dependencies underlying the neo-extractivist development model of these Andean countries (see Bebbington \& Bebbington 2011; Kohl \& Farthing 2012), which significantly constrain what can be politically achieved. Rather than depicting the failures of Morales in Bolivia or Correa in Ecuador to break from extractivism in terms of their acceptance of modern ontology, it is important to see the contradictions of current policies as the result of politicians negotiating the "gap between the imagined transformation natural resource 
rents will bring and the structural limitations of extractive economies" (Kohl \& Farthing 2012, p. 226). This kind of negotiation points to the difficulty of articulating struggles across unevenly reified spaces.

Third, the concept of uneven reification allows for the recognition of social change beyond the margins of the capitalist world system, in the cities and slums, and elsewhere. I have argued above that post-development theory mostly confines alternatives to development to those movements which are rural and subsistence-based, and its analysis is likely to remain relevant for only those spaces. As such, post-development theory does not address the reality of urbanization, ${ }^{102}$ and offers little for the people who in cities. This is a serious limitation considering that half of the world's population now lives in urban areas, and "residents of slums ... constitute a staggering 78.2 percent of urbanites in the least-developed countries; this equals fully a third of the global urban population" (Davis 2006, p. 23). ${ }^{103}$

The post-development theorists' de facto abandonment of the city is likely a result of their apparent tendency to equate urbanization with industrialization and

102 The partial exception would be Esteva \& Prakesh (1998), who frequently reference urban "marginals," or those who live in slums. They celebrate the autonomous organizing of neighbourhoods, as a way of communities re-creating their cultural fabric, which is also understood in terms of "re-embedding" the economy into their culture. These activities are depicted as anti-modern, rejecting state services and other "modern intrusions" such as latrines, as well as rejecting the formalization of the economy (i.e. paying for housing construction rather than building houses themselves) (pp. 80-6, 94-106). Regardless of how widespread these sorts of sentiments are (I am skeptical that this represents a common attitude among "marginals"), these passages are entirely without reference to the market imperatives that capitalism imposes upon these communities, and therefore ignores the real obstacles that would be faced by people attempting to "embed" their livelihoods in alternative cultural practices and goals.

103 There are many factors driving these processes of "urbanization without industrialization" (Davis 2006, p. 14), including conflict, the 1980s debt crisis, and the implementation of SAPs which imposed agricultural policies resulting in the dispossession of small producers from agriculture and into cities where employment did not exist (pp. 14-6). "As a result, rapid urban growth in the context of structural adjustment, currency devaluation, and state retrenchment has been an inevitable recipe for the mass production of slums" (p. 17). These processes are not likely to reverse, making cities and slums increasingly important spaces for social change. 
modernization. ${ }^{104}$ Cities would appear to be understood as inseparable from modernityor at least they have never been dealt with in any other way_-and it would be consistent with the post-development critique of modernity (see Chapter Two) to therefore see cities as irredeemable, and to retreat instead into spaces which are non-modern. ${ }^{105}$ But what about those people in urban spaces, under conditions of real subsumption of labour under capital or otherwise,${ }^{106}$ who are dissatisfied with their situation and desire change?

I argued in Chapters One and Two that one of the central aspects of development/modernity critiqued by post-development theory can be understood in terms of reification, and that by challenging reification it is possible to reclaim, rather than reject, modernity. In a similar way, it might also be possible to re-claim "development" if it lost its technical, depoliticized character. If this was the case, then it might be possible to think in terms of "development without reification," or a re-politicized social change. ${ }^{107}$ If development meant full, human development (in a socialist sense) ${ }^{108}$ then it

$\overline{104}$ For example, see Escobar 1995, pp. 39, 126. However, references to urbanization are so uncommon throughout post-development literature that any systematic analysis of the concept in their work is impossible.

105 On the other hand, Escobar occasionally qualifies his critiques by arguing that certain aspects of modernity can be included as part of pluriversal or non-modern projects (see for example Escobar 2010, p. 36; see also note 49 above), which could potentially include urbanization or a re-orientation of the city. However, this is only speculation, as to my knowledge Escobar has not made such a claim.

106 It should not be assumed that urban spaces are conducive to real subsumption, or even formal subsumption. For that to be the case, relative or absolute surplus labour would have to be exploited by capitalists. But Davis (2006) outlines numerous situations in slums where the labour market is either informal and subject to the extreme absolute exploitation of labour (hence limited subsumption), or essentially non-existent: labour has been commodified, but there is no buyer for labour-power (pp. 174190). This should not suggest that the market imperatives associated with formal or real subsumption are not present: on the contrary, the unemployed are still dispossessed from the conditions of production, but the difference is that there may not be a means for attaining subsistence through the market, either.

107 The necessity of politicizing development is certainly not an original insight, but is a common theme in critical development studies. What is unique about my concept of "development without reification" is that it identifies and targets the material basis that facilitates depoliticization.

108 See for example Panitch (2008), who understands socialism as allowing the full development of human capacities, which includes the individual, institutional and collective capacities to democratically govern everyday life (pp. 203-6). This kind of human development is not possible within capitalism: "capitalism is unjust and undemocratic not because of this or that imperfection in relation to equality or freedom, but because at its core it involves the control by some of the use and development of the 
could utilize the desires of people for the promise of development but direct that desire towards noncapitalist ends. Again, it would make no difference whether such a project would be "modern" or not, so long as it worked against reification — and therefore, such a project could be carried out in potentially any social space.

The possibility of "development without reification," however, depends on the ability to develop strategies of de-reification. As argued above, because reification is rooted not in a mere illusion or false consciousness, but emerges out of the alienation of labour, it can never be abolished until alienated labour is abolished; this is why the recognition that reification is uneven across space and time is so promising, as it presents the possibility for challenging reification from a position of externality. But it must also be possible to challenge reification from an internal position, even if abolition is unlikely; this is the argument made by both Heinrich (2012) and Holloway (2002). Although constituting a "structural background," reification "affects different individuals with varying strength and can be penetrated on the basis of experience and reflection" (Heinrich 2012, p. 185). For Holloway (2002), the very fact that we can criticize fetishism is proof of its opposite, anti-fetishism (p. 89). If most efforts against reification have been at a highly theoretical level (see Chapter Two), the work of Paulo Freire (1970/2007) may serve as a prototype for a more engaged de-reificatory practice, as it addresses the central expression of reification: the uncritical, instrumental character of knowledge. Freire's approach to adult literacy education, by involving the critical transformation of students, and their activation as political subjects, appears to resemble what I have suggested as “development without reification,” although a closer 
examination of Freire's work in relation to the Western Marxist tradition is necessary to determine whether these are in fact compatible projects. ${ }^{109}$

A critical, politicized social change could go a long way in challenging technocratic development programs, and constructing more participatory democratic processes of governance; we can see movement towards this in the participatory municipal budgeting of Porto Alegre (Santos 1998), and other social efforts inspired by the notion of the "right to the city" (see Harvey 2008). Nonetheless, however radical and participatory these processes may be, people can never be fully emancipated within a context where class relations and market imperatives continue to separate people from each other and their work, denying them their full capacities and potential, and obscuring the social (and transformable) basis of economic processes. This is why such struggles cannot be confined to the individual or community level, but must aim towards decommodification — of labour, but also of goods and services — through the building of a counter-hegemonic movement capable of doing so. A broad-based "development" strategy that aims towards "re-possession" of all that people have had dispossessed, both

109 Freire (1970/2007) approaches education in a manner which is similar to the negative dialectics of the Frankfurt School. Freire criticizes the one-dimensionality of what he calls the "banking" concept of education, in which students are alienated as they accept a passive role and adapt to the world as it is (pp. 72-3). Against this, he offers "problem-posing" education as a way of raising critical consciousness and breaking from oppression (pp. 79-86). The reality of oppression is eventually perceived by students, through a dialogical process, "not as a closed world from which there is no exit, but as a limiting situation which they can transform" (p. 49). However, there are some theoretical positions in Freire's work which distinguish his approach from that of Western Marxists, and may prevent utilization of his theory as a means of "development without reification." First, while his approach is strongly dialectical, Freire focuses not on class (or the alienation of labour) but on "oppression," drawing more from Hegel's master-slave dialectic than from Lukács. This does not necessarily mean that Freire's approach cannot be re-directed towards alienated labour, but the appropriateness of such a move cannot be assumed; it must be justified. Second, there seems to be a tension between the mutual dialogical approach of Freire's education program, and the apparent assumption that that dialogue will necessarily lead to support for struggles for liberation, as if this is an objective interest that can be discovered as already existing (see especially pp. 94-5). Asserting the existence of objective interests is what Hall (1986) warns us against, for it "guarantees" a political outcome, whereas what is required is the hard political work of organization, persuasion, and the forging of interests in common. 
materially and in terms of capacities, could see a simultaneous improvement of living standards (which in the context of slums cannot be understood as merely a "Western" constructed need) alongside improving the conditions that make thinking and acting "otherwise" possible.

Fourth, and finally, resisting reification is also relevant for those of us fully immersed within "Western modernity." As David McNally has argued, ${ }^{110}$ any socialist project needs to overcome the alienation of labour, and de-commodify the reproduction and regulation of social life. This suggests that socialist projects at home have a baseline in common with alternatives to development elsewhere. If so, it may be possible to organize relationships of international solidarity around that baseline, drawing upon the experiences and alternative philosophies and values of alternatives to development (hence "exploiting the cracks" of reification), as critical information to transform ourselves as part of a de-reificatory process. Solidarity therefore has the potential for mutual change. A solidarity approach to development would not refuse social change, or modernity per se —but it would help communities resist the creation of capitalist class relations and increasing market dependence. Such a project would also respect autonomy, but not as an end in itself. Local communities are not morally neutral—one must enter partnerships to further social justice, not to protect privilege, discrimination and exploitation.

How exactly solidarity across unevenly reified spaces can contribute to a process of mutual social change and de-reification, however, needs to be further explored. It could be worthwhile to assess the limits and potentialities of such a strategy by investigating contemporary struggles, such as the campaigns against the development of

110 This point was made during the opening plenary session of the Historical Materialism conference, New York University, April 26th 2013. 
the "tar sands" in Northern Alberta. These campaigns are composed of loose coalitions of indigenous and non-indigenous groups with potentially conflicting interests, including environmentalists, unions and churches. As indigenous groups resist the encroachment upon and pollution of their territory, non-indigenous activists often draw upon the former's "other" ways of envisioning and relating to the earth, and mobilize these to suggest the possibility of alternatives to energy consumption and consumerism. ${ }^{111}$ If the focus of these campaigns was to be put upon the relationship of tar sands development to capitalism - how capitalism structures our behaviour in environmentally harmful ways, how it threatens the existence of alternative livelihoods on its periphery, and thus how it is a threat in common to all parties - then there would be a possibility of leveraging the "thinking otherwise" of indigenous communities to inspire the transformation of wider Canadian society, while defending indigenous territory. However, if these efforts take a more post-development approach, framing the problem in moral and epistemological terms, then there is a danger of bypassing an understanding of the structural logics of resource extraction in Canada's political economy, and therefore missing the constraints on thinking and acting otherwise that must be consciously negotiated.

A critique of development which emphasizes uneven reification is therefore capable of illuminating the conditions which make thinking and acting "otherwise" materially possible, while expanding the scope for social action beyond the margins, to several levels of struggle. If this critique therefore transcends some of the limitations set

111 This theme, of looking to an indigenous "balance with nature" in order to critique aspects of modern society such as consumerism or industrialization, is common within environmental circles, and has been articulated by popular authors including David Suzuki, Wade Davis and Jared Diamond. Unfortunately, the distinctions between indigenous and modern societies are usually depicted in terms of values and epistemology, which does not provide any insight into strategies for social change if these values are conditioned and constrained by our economic behaviour, rather than driving it. 
by post-development theory, this is not because it is motivated by fundamentally different political concerns, but because the effect of post-development logic is to make certain exclusions which unnecessarily close off potential allies and strategies. By addressing these limitations, this critique intends not to reject the concerns of post-development theorists, but precisely to re-affirm many of them, while re-tracing the common ground between alternatives to development and other social actors which has been theorized out of existence. If the potential for "thinking" and "acting" otherwise can be extended to include those both within and outside of modernity, it might be possible to start constructing a better world, in common. 


\section{Work Cited}

Almond, G. A. \& Powell, C. B. (1965). Comparative Politics: A Development Approach. Boston: Little Brown.

Alvares, C. (1992). Science. In W. Sachs (Ed.), The Development Dictionary: A Guide to Knowledge as Power (219-232). New Jersey: Zed Books.

Alvarez, S. E., Dagnino, E., \& Escobar, A. (1998). Introduction: The Cultural and the Political in Latin American Social Movements. In S. E. Alvarez, E. Dagnino, \& A. Escobar (Eds.), Cultures of Politics, Politics of Cultures: Re-visioning Latin American Social Movements (1-29). Boulder, CO: Westview Press.

Amin, S. (1977). Imperialism and Unequal Development. New York: Monthly Review Press.

Anderson, K. B. (2010). Marx at the Margins: On Nationalism, Ethnicity, and NonWestern Societies. Chicago: University of Chicago Press.

Arrighi, G. (2010). The Long Twentieth Century: Money, Power, and the Origins of Our Times. New York: Verso.

Arrighi, G., Aschoff, N., \& Scully, B. (2010). Accumulation by Dispossession and Its Limits: The Southern Africa Paradigm Revisited. Studies in Comparative International Development, 45, 410-438.

Baran, P. (1957). The Political Economy of Growth. New York: Monthly Review Press.

Barras, B. (2004). Life Projects: Development Our Way. In M. Blaser, H. A. Feit \& G. McRae (Eds.), In the Way of Development: Indigenous Peoples, Life Projects and Globalization (47-51). New York: Zed Books.

Barrett, M. (1991). The Politics of Truth: From Marx to Foucault. Stanford, California: Stanford University Press.

Bebbington, A. (1999). Capitals and Capabilities: A Framework for Analyzing Peasant Viability, Rural Livelihoods and Poverty. World Development, 27(12), 2021-2044.

Bebbington, A. (2008). Social Capital and Development Studies III: Social Capital and the State. Progress in Development Studies, 8(3), 271-279.

Bebbington, A. \& Bebbington, D. H. (2011). An Andean Avatar: Post-Neoliberal Strategies for Securing the Unobtainable. New Political Economy, 16(1), 131-145. 
Blaser, M. (2004a). Life Projects: Indigenous Peoples' Agency and Development. In M. Blaser, H. A. Feit \& G. McRae (Eds.), In the Way of Development: Indigenous Peoples, Life Projects and Globalization (26-44). New York: Zed Books.

Blaser, M. (2004b). 'Way of Life' or 'Who Decides': Development, Paraguayan Indigenism and the Yshiro People's Life Projects. In M. Blaser, H. A. Feit \& G. McRae (Eds.), In the Way of Development: Indigenous Peoples, Life Projects and Globalization (52-71). New York: Zed Books.

Blaser, M. (2010). Storytelling Globalization from the Chaco and Beyond. London: Duke University Press.

Blaser, M., Feit, H. A., \& McRae, G. (2004). Indigenous Peoples and Development Processes: New Terrains of Struggle. In M. Blaser, H. A. Feit \& G. McRae (Eds.), In the Way of Development: Indigenous Peoples, Life Projects and Globalization (1-25). New York: Zed Books.

Brenner, R. (1977). The Origins of Capitalist Development: A Critique of Neo-Smithian Marxism. New Left Review, I/104, 25-92.

Chibber, V. (2013). Postcolonial Theory and the Specter of Capital. New York: Verso.

Clement, W. (2001). Canadian Political Economy's Legacy for Sociology. The Canadian Journal of Sociology, 26(3), 405-420.

Colclough, C. (1991). Structuralism vs. Neo-Liberalism: An Introduction. In C. Colclough \& J. Manor (Eds.), States or Markets?: Neoliberalism and the Development Policy Debate $(1-25)$. New York: Oxford University Press.

Cornwall, A., Harrison, E. \& Whitehead, A. (2007). Gender Myths and Feminist Fables: The Struggle for Interpretive Power in Gender and Development. Development and Change, 38(1), 1-20.

Desmarais, A. A. (2007). La Via Campesina: Globalization and the Power of Peasants. Winnipeg, MB: Fernwood Publishing.

Dussel, E. (1996). The Underside of Modernity: Apel, Ricoeur, Rorty, Taylor, and the Philosophy of Liberation. (E. Mendieta, Trans.). New Jersey: Humanities Press.

Dussel, E. (2000). Europe, Modernity, and Eurocentrism. Nepantla: Views from South, 1(3), 465-478.

Dussel, E. (2002). World-System and Trans-Modernity. Nepantla: Views from South, $3(2), 221-$ 244. 
Escobar, A. (1995). Encountering Development: The Making and Unmaking of the Third World. Princeton, NJ: Princeton University Press.

Escobar, A. (2000). Beyond the Search for a Paradigm?: Post-Development and Beyond. Development, 43(4), 11-14.

Escobar, A. (2001). Culture Sits in Places: Reflections on Globalism and Subaltern Strategies of Localization. Political Geography, 20, 139-174.

Escobar, A. (2004). Beyond the Third World: Imperial Globality, Global Coloniality and Anti-Globalisation Social Movements. Third World Quarterly, 25(1), 207-230.

Escobar, A. (2007a). 'Post-Development' as Concept and Social Practice. In A. Ziai (Ed.), Exploring Post-Development: Theory and Practice, Problems and Perspectives (18-31). New York: Routledge.

Escobar, A. (2007b). Worlds and Knowledges Otherwise: The Latin American Modernity/Coloniality Research Program. Cultural Studies, 21(2-3), 179-210.

Escobar, A. (2008). Territories of Difference: Place, Movements, Life, Redes. Durham, NC: Duke University Press

Escobar, A. (2010). Latin America at a Crossroads: Alternative Modernizations, PostLiberalism, or Post-Development? Cultural Studies, 24(1), 1-65.

Escobar, A. (2012). Preface to the 2012 Edition. In Encountering Development: The Making and Unmaking of the Third World (pp. vii-xliii). Princeton, New Jersey: Princeton University Press.

Esteva, G. (1992). Development. In W. Sachs (Ed.), The Development Dictionary: A Guide to Knowledge as Power (6-25). New Jersey: Zed Books.

Esteva, G. \& Prakesh, M. S. (1998). Grassroots Post-Modernism: Remaking the Soil of Cultures. New York: Zed Books.

Evans, P. (1992). The State as Problem and Solution: Predation, Embedded Autonomy and Structural Change. In S. Haggard \& R. Kaufman (Eds.), The Politics of Economic Adjustment (139-181). Princeton: Princeton University Press.

Evans, P. (2010). Constructing the 21st Century Developmental State: Potentialities and Pitfalls. In O. Edigheje (Ed.), Constructing a Democratic Developmental State in South Africa, Potentials and Challenges (37-58). Cape Town, HRSRC Press.

Fine, B. (n.d.). Neither the Washington Nor the Post-Washington Consensus: An 
Introduction. International Economic Development Associates. Retrieved from http://www.networkideas.org/featart/sep2002/Washington.pdf

Ferguson, J. (1990). The Anti-Politics Machine: “Development,” Depoliticization, and Bureaucratic Power in Lesotho. Cambridge: Cambridge University Press.

Foucault, M. (1972). Archaeology of Knowledge. (A. M. Sheridan Smith, Trans.). London: Routledge.

Foucault, M. (1984). What is Enlightenment? In P. Rabinow (Ed.), The Foucault Reader (pp. 32-50). Markham, ON: Penguin Books Canada.

Frank, A. G. (1966). The Development of Underdevelopment. Monthly Review, 18(4), 1732.

Frank, A. G. (1991). The Underdevelopment of Development. Retrieved from http://www.druckversion.studien-von-zeitfragen.net/The\%20Underdevelopment $\% 20$ of\%20Development.htm

Freire, P. (2007). Pedagogy of the Oppressed (30th Anniversary Edition). (M. B. Ramos, Trans.). New York: Continuum. (Original work published 1970).

Gibson-Graham, J. K. (1996). The End of Capitalism (As We Knew It). Oxford: Blackwell Publishers.

Gibson-Graham, J.K. (2005). Surplus Possibilities: Postdevelopment and Community Economies. Singapore Journal of Tropical Geography, 26(1), 4-26.

Gibson-Graham, J. K. (2006). A Post-Capitalist Politics. Minneapolis: University of Minnesota Press.

Gibson-Graham, J. K., Resnick, S. A., \& Wolff, R. D. (2000). Introduction: Class in a Poststructuralist Frame. In J. K. Gibson-Graham, S. A. Resnick, \& R. D. Wolff (Eds.), Class and its Others (1-22). Minneapolis: University of Minnesota Press.

Glassman, J. (2003). Rethinking Overdetermination, Structural Power, and Social Change: A Critique of Gibson-Graham, Resnick, and Wolff. Antipode, 35(4), 678698.

Gramsci, A. (1971). Selections from the Prison Notebooks. (Q. Hoare \& G. N. Smith, Trans.). Q. Hoare \& G. N. Smith (Eds.). New York: International Publishers.

Gudeman, S. (1986). Economics as Culture: Models and Metaphors of Livelihood. Boston: Routledge \& Kegan Paul. 
Gudeman, S. (2001). The Anthropology of Economy: Community: Market, and Culture. Malden, MA: Blackwell Publishers.

Gudynas, E. (2010). The New Extractivism of the $21^{\text {st }}$ Century: Ten Urgent Theses about Extractivism in Relation to Current South American Progressivism. Americas Program Report. Washington, DC: Center for International Policy, 1-14.

Hall, S. (1986). The Problem of Ideology: Marxism without Guarantees. Journal of Communication Inquiry, 10, 28-44.

Hall, S. (1992). Cultural Studies and its Theoretical Legacies. In L. Grossberg, C. Nelson, \& P. A. Treichler (Eds.), Cultural Studies (277-294). New York: Routledge.

Hall, S. (2003). Marx's Notes on Method: A "Reading” of the "1857 Introduction". Cultural Studies, 17(2), 113-149.

Halperin, S. (2007). Re-Envisioning Global Development: Conceptual and Methodological Issues. Globalizations, 4(4), 543-558.

Hardt, M. \& Negri, A. (2000). Empire. Cambridge, MA: Harvard University Press.

Harvey, D. (2005). A Brief History of Neoliberalism. New York: Oxford University Press.

Harvey, D. (2006). The Limits to Capital. New York: Verso Books.

Harvey, D. (2008). Right to the City. New Left Review, 53, 23-40.

Harvey, D. (2010). A Companion to Marx's Capital. New York: Verso.

Hegel, G. W. F. (1975). The Philosophical History of the World [Second Draft 1830]. In Lectures on the Philosophy of World History (25-151). (H. B. Nisbet, Trans.). New York: Cambridge University Press.

Heinrich, M. (2012). An Introduction to the Three Volumes of Karl Marx's Capital. (A. Locascio, Trans.). New York: Monthly Review Press.

Heller, H. (2011). The Birth of Capitalism: A Twenty-First-Century Perspective. Winnipeg, MB: Fernwood Publishing.

Hennessy, R. (2000). Profit and Pleasure: Sexual Identities in Late Capitalism. New York: Routledge.

Hickey, S., \& Mohan, G. (2004). Towards Participation as Transformation: Critical Themes and Challenges. In S. Hickey \& G. Mohan (Eds.), Participation: From 
Tyranny to Transformation?: Exploring New Approaches to Participation in Development (3-24). New York: Zed Books.

Holloway, J. (2002). Change the World Without Taking Power. New York: Pluto Press.

Horkheimer, M. \& Adorno, T. W. (2002). Dialectic of Enlightenment: Philosophical Fragments. (E. Jephcott, Trans.). G. S. Noerr (Ed.). Standford: Stanford University Press. (Original work published 1944).

Huntington, S. (1971). The Change to Change: Modernization, Development and Politics. Comparative Politics, 3(3), 283-322.

Kant, I. (1949). What is Enlightenment? In C. J. Fridrich (Ed.), The Philosophy of Kant: Immanuel Kant's Moral and Political Writings (pp. 133-9). New York: Random House. (Original work published 1784).

Kay, C. (1989). The Structuralist School of Development. In C. Kay (Ed.), Latin American Theories of Development and Underdevelopment (25-57). London and New York: Routledge.

Kohl, B. \& Farthing, L. (2012). Material Constraints to Popular Imaginaries: The Extractive Economy and Resource Nationalism in Bolivia. Political Geography, $31,225-235$.

Laclau, E., \& Mouffe, C. (1985). Hegemony and Socialist Strategy: Towards a Radical Democratic Politics. (W. Moore \& P. Cammack, Trans.). London: Verso.

Laclau, E. \& Mouffe, C. (1987). Post-Marxism Without Apologies. New Left Review, $\mathrm{I} / 166,79-106$.

Latouche, S. (1992). Standard of Living. In W. Sachs (Ed.), The Development Dictionary: A Guide to Knowledge as Power (250-263). New Jersey: Zed Books.

Latouche, S. (1997). Paradoxical Growth. In M. Rahnema \& V. Bawtree (Eds.), The Post-Development Reader (135-142). New York: Zed Books.

Leftwich, A. (2008). Developmental States, Effective States and Poverty Reduction: The Primacy of Politics (Draft). Background paper for UNRISD Flagship Report: Combating Poverty and Inequality. United Nations Research Institute for Social Development. Retrieved from http://www.unrisd.org/80256B3C005BCCF9 (httpPublications)/ EE2D4DF653F6077BC1257A5D004C7E5E? OpenDocument\&panel=seriespapers

Leiva, F. I. (2008). Toward a Critique of Latin American Neostructuralism. Latin American Politics and Society, 50(4), 1-25. 
Leys, C. (1996). The Rise and Fall of Development Theory. London: James Currey.

Lukács, G. (1972). History and Class Consciousness. (R. Livingstone, Trans.). Cambridge, Mass: MIT Press. (Original work published 1923).

Luxemburg, R. (2003). The Accumulation of Capital. (A. Schwarzschild, Trans.). New York: Routledge Classics. (Original work published 1913).

Luxemburg, R. (2008). Reform or Revolution? In H. Scott (Ed.), The Essential Rosa Luxemburg: Reform or Revolution \& The Mass Strike (41-109). Chicago, IL: Haymarket Books. (Original work published 1898).

Mahon, R. (1977). Canadian Public Policy: the Unequal Structure of Representation. In L. Panitch (Ed.), The Canadian State: Political Economy and Political Power (165-198). Toronto: University of Toronto Press.

Marcuse, H. (1960). Reason and Revolution: Hegel and the Rise of Social Theory (2nd ed.). Boston: Beacon Press. (Original work published 1940).

Marcuse, H. (1964). One-Dimensional Man: Studies in the Ideology of Advanced Industrial Society. Boston: Beacon Press.

Marx, K. (1973). Grundrisse: Foundations of the Critique of Political Economy (Rough Draft). (M. Nicolaus, Trans.). Toronto, ON: Penguin Books Canada. (Original work published in 1939).

Marx, K. (1990). Capital: A Critique of Political Economy, Volume 1. (B. Fowkes, Trans.). Toronto: Penguin Books Canada Ltd. (Original work published 1867).

Marx, K. (1994a). On the Jewish Question. In L. H. Simon (Ed.), Selected Writings (126). Indianapolis, Indiana: Hackett Publishing. (Original work published in 1844).

Marx, K. (1994b). Preface to A Contribution to the Critique of Political Economy. In L. H. Simon (Ed.), Selected Writings (209-213). Indianapolis, Indiana: Hackett Publishing. (Original work published in 1859).

Marx, K. \& Engels, F. (1994). The German Ideology: Part I (selections). In L. H. Simon (Ed.), Selected Writings (102-156). Indianapolis, Indiana: Hackett Publishing. (Original work published in 1932).

McGregor, A. (2009). New Possibilities?: Shifts in Post-Development Theory and Practice. Geography Compass, 3(5), 1688-1702.

McNally, D. (1993). Against the Market: Political Economy, Market Socialism and the 
Marxist Critique. New York: Verso.

Mignolo, W. D. (1999). I Am Where I Think: Epistemology and the Colonial Difference. Journal of Latin American Cultural Studies, 8(2), 235-245.

Mignolo, W. D. (2000a). Local Histories/Global Designs: Coloniality, Subaltern Knowledges, and Border Thinking. Princeton University Press.

Mignolo, W. D. (2000b). Local Histories and Global Designs: An Interview with Walter Mignolo. Discourse, 22(3), 7-33.

Mignolo, W. D. (2002). The Geopolitics of Knowledge and the Colonial Difference. The South Atlantic Quarterly, 101(1), 56-96.

Mignolo, W. D., \& Nouzeilles, B. (2003). From Neplanta to Worlds and Knowledges Otherwise. Neplanta: Views from the South, 4(3), 421-422.

Mignolo, W. D. (2011). The Darker Side of Western Modernity: Global Futures, Decolonial Options. Durham \& London: Duke University Press.

Mignolo, W. D. (2012). Preface to the 2012 Edition. In Local Histories/Global Designs: Coloniality, Subaltern Knowledges, and Border Thinking. Princeton University Press.

North, D. C. (1995). The New Institutional Economics and Third World Development. In J. Harriss, J. Hunter \& C. W. Lewis (Eds), The New Institutional Economics and Third World Development (17-26). London and New York: Routledge.

Nustad, K. G. (2007). Development: The Devil We Know? In A. Ziai (Ed.), Exploring Post-Development: Theory and Practice, Problems and Perspectives (35-46). New York: Routledge.

Panitch, L. (2008). Renewing Socialism: Transforming Democracy, Strategy and Imagination. Pontypool, Wales: Merlin Press.

Panitch, L. (2012). American Empire, Capitalist Crisis and the Global South. Socialist Studies, 8(2), 1-11.

Panitch, L., \& Gindin, S. (2012). The Making of Global Capitalism: The Political Economy of American Empire. New York: Verso.

Parajuli, P. (2004). Revisiting Gandhi and Zapata: Motion of Global Capital, Geographies of Difference and the Formation of Ecological Ethnicities. In M. Blaser, H.A. Feit \& G. McRae (Eds.), In the Way of Development: Indigenous Peoples, Life Projects and Globalization (235-255). New York: Zed Books. 
Paulson, J. (2005). Uneven Reification. (Doctoral Dissertation). Retrieved from ProQuest. (AAT 3191900).

Paulson, J. (2010). The Uneven Development of Radical Imagination. Affinities: A Journal of Radical Theory, Culture, and Action, 4(2), 33-38.

Perrons, D. (1999). Reintegrating Production and Consumption, or Why Political Economy Still Matters. In R. Munck \& D. O'Hearn, (Eds.), Critical Development Theory: Contributions to a New Paradigm (91-112). New York: Zed Books.

Pieterse, J. N. (2001). Development Theory: Deconstructions/Reconstructions. London: SAGE Publications.

Quijano, A. (2000). Coloniality of Power, Eurocentrism, and Latin America. Nepantla: Views from the South, 1(3), 533-580.

Quijano, A. (2007). Coloniality and Modernity/Rationality. Cultural Studies, 21(2), 168178.

Radcliff, S. A., Laurie, N., \& Andolina, R. (2009). Indigenous Development in the Andes: Culture, Power, and Transnationalism. Durham: Duke University Press.

Rahnema, M. (1992). Poverty. In W. Sachs (Ed.), The Development Dictionary: A Guide to Knowledge as Power (158-176). New Jersey: Zed Books.

Rahnema, M. (1997a). Introduction. In M. Rahnema \& V. Bawtree (Eds.), The PostDevelopment Reader (ix-xix). New York: Zed Books.

Rahnema, M. (1997b). Development and the People's Immune System: The Story of Another Variety of Aids. In M. Rahnema \& V. Bawtree (Eds.), The PostDevelopment Reader (111-131). New York: Zed Books.

Rahnema, M. \& Bawtree, V. (Eds.). (1997). The Post-Development Reader. New York: Zed Books.

Rapley, J. (2002). Understanding Development: Theory and Practice in the Third World ( $2^{\text {nd }}$ ed.). Boulder, CO: Lynne Rienner Publishers.

Rees, J. (2000). Introduction. In G. Lukács, A Defence of History and Class Consciousness: Tailism and the Dialectic (pp. 1-38). New York: Verso.

Resnick, S. A., \& Wolff, R. D. (1985). Introduction: Solutions and Problems. In S. A. Resnick \& R. D. Wolff (Eds.), Rethinking Marxism: Essays for Harry Magdoff \& Paul Sweezy (ix-xxxiv). New York: Automedia. 
Rist, G. (1997). The History of Development: From Western Origins to Global Faith. (P. Camiller, Trans.). New York: Zed Books.

Rojas, C. (2001). "Development": What's in a Word? Views from the Paradigms. Canadian Journal of Development Studies, XXII(3), 571-596.

Rojas, C. (2007). International Political Economy/Development Otherwise. Globalizations, 4(4), 573-587.

Rostow, W. W. (1960). The Stages of Economic Growth: A Non-Communist Manifesto. New York: Cambridge University Press.

Sachs, W. (Ed.). (1992a). The Development Dictionary: A Guide to Knowledge as Power. New Jersey: Zed Books.

Sachs, W. (1992b). Introduction. In W. Sachs (Ed.), The Development Dictionary: A Guide to Knowledge as Power (1-5). New Jersey: Zed Books.

Sachs, W. (1997). The Need for the Home Perspective. In M. Rahnema \& V. Bawtree (Eds.), The Post-Development Reader (290-301). New York: Zed Books.

Santos, B. de Sousa. (1998). Participatory Budgeting in Porto Alegre: Toward a Redistributive Democracy. Politics \& Society, 26(4), 461-510.

Santos, B. de Sousa (2001a). In Search of the Negation of the Negation. European Journal of Social Theory, 4(3), 291-294.

Santos, B. de Sousa (2001b). Nuestra America: Reinventing a Subaltern Paradigm of Recognition and Redistribution. Theory, Culture \& Society, 18(2-3), 185-217.

Santos, B. de Sousa (2006). The Rise of the Global Left: The World Social Forum and Beyond. New York: Zed Books.

Santos, B. de Sousa (2010). From the Postmodern to the Postcolonial-And Beyond Both. In E. G. Rodriquez, M. Boatca \& S. Costa (Eds.), Decolonizing European Sociology: Transdisciplinary Approaches (pp. 225-242). Burlington, VA: Ashgate Publishing Company.

Santos, B. de Sousa, Nunes, J. A., \& Meneses, M. P. (2007). Introduction: Opening Up the Canon of Knowledge and Recognition of Difference. In B. de Sousa Santos (Ed.), Another Knowledge is Possible: Beyond Northern Epistemologies (pp.ix1xii). New York: Verso.

Santos, B. de Sousa, \& Rodriguez-Garavito, C.A. (2006). Introduction: Expanding the 
Economic Canon and Searching for Alternatives to Neoliberal Globalization. In B. de Sousa Santos (Ed.), Another Production is Possible: Beyond the Capitalist Canon (xvii-lxii). New York: Verso.

Sen, A. (1999). Development as Freedom. New York: Alfred A. Knopf.

Shiva, V. (1992). Resources. In W. Sachs (Ed.), The Development Dictionary: A Guide to Knowledge as Power (206-218). New Jersey: Zed Books.

Shiva, V. (1993). Monocultures of the Mind: Perspectives on Biodiversity and Biotechnology. New Jersey: Zed Books.

Shiva, V. (1997). Western Science and its Destruction of Local Knowledge. In M. Rahnema \& V. Bawtree (Eds.), The Post-Development Reader (161-167). New York: Zed Books.

Shiva, V. (2005). Earth Democracy: Justice, Sustainability, and Peace. Cambridge, MA: South End Press.

Simon, D. (2007). Beyond Antidevelopment: Discourses, Convergences, Practices. Singapore Journal of Tropical Geography, 28, 205-218.

Singer, P. (2006). The Recent Rebirth of the Solidary Economy in Brazil. In B. de Sousa Santos (Ed.), Another Production is Possible: Beyond the Capitalist Canon (142). New York: Verso.

Smith, A. (1999). The Wealth of Nations, Books I-III. Toronto: Penguin Books Canada Ltd. (Original work published 1776).

Spronk, S. (2013). Neoliberal Class Formation(s): The Informal Proletariat and "New" Workers' Organizations In Latin America. In J. R. Webber \& B. Carr (Eds.), The New Latin American Left: Cracks in the Empire (pp. 75-93). Toronto, ON: Rowman \& Littlefield Publishers, Inc.

Stiglitz, J. E. (n.d.). The Post Washington Consensus Consensus. The Initiative for Policy Dialogue. Retrieved from http://policydialogue.org/files/events/ Stiglitz_Post_Washington_Consensus_Paper.pdf

Sunkel, O. \& Zuleta, G. (1990). Neo-structuralism Versus Neo-liberalism in the 1990s. CEPAL Review, 42, 35-51.

Swyngedouw, E. (2000). The Marxian Alternative: Historical-Geographical Materialism and the Political Economy of Capitalism. In E. Sheppard \& T. J. Barnes (Eds.), A Companion to Economic Geography (41-59). Malden, Mass.: Blackwell Publishers. 
United Nations Development Program (2013). Human Development Report 2013: The Rise of the South: Human Progress in a Diverse World. New York: Author.

Veltmeyer, H. (2001). The Politics of Language: Deconstructing the Discourse of Postdevelopment. Canadian Journal of Development Studies, XXII(3), 597-620.

Wallerstein, I. (1979). The Capitalist World-Economy. New York: Cambridge University Press.

Wood, E. M. (2002). The Origin of Capitalism: A Longer View. New York: Verso.

World Bank (n.d.). The Complete World Development Report Online. Retrieved from http://wdronline.worldbank.org/

Ziai, A. (2007a). Development Discourse and its Critics: An Introduction to PostDevelopment. In A. Ziai (Ed.), Exploring Post-Development: Theory and Practice, Problems and Perspectives (3-17). New York: Routledge.

Ziai, A. (2007b). The Ambivalence of Post-Development: Between Reactionary Populism and Radical Democracy. In A. Ziai (Ed.), Exploring Post-Development: Theory and Practice, Problems and Perspectives (111-128). New York: Routledge.

Zibechi, R. (2010). Dispersing Power: Social Movements as Anti-Social Forces. Oakland, CA: AK Press.

Zibechi, R. (2012). Territories In Resistance: A Cartography of Latin American Social Movements. (R. Ryan, Trans.). Oakland, CA: AK Press. 